\title{
Creating new perspectives on work-home interface : a cross-cultural comparison of Malta, Serbia and the Netherlands
}

Citation for published version (APA):

Putnik, K. (2015). Creating new perspectives on work-home interface : a cross-cultural comparison of Malta, Serbia and the Netherlands. [Doctoral Thesis, Maastricht University]. Maastricht University. https://doi.org/10.26481/dis.20150924kp

Document status and date:

Published: 01/01/2015

DOI:

10.26481/dis.20150924kp

Document Version:

Publisher's PDF, also known as Version of record

Please check the document version of this publication:

- A submitted manuscript is the version of the article upon submission and before peer-review. There can be important differences between the submitted version and the official published version of record.

People interested in the research are advised to contact the author for the final version of the publication, or visit the DOI to the publisher's website.

- The final author version and the galley proof are versions of the publication after peer review.

- The final published version features the final layout of the paper including the volume, issue and page numbers.

Link to publication

\footnotetext{
General rights rights.

- You may freely distribute the URL identifying the publication in the public portal. please follow below link for the End User Agreement:

www.umlib.nl/taverne-license

Take down policy

If you believe that this document breaches copyright please contact us at:

repository@maastrichtuniversity.nl

providing details and we will investigate your claim.
}

Copyright and moral rights for the publications made accessible in the public portal are retained by the authors and/or other copyright owners and it is a condition of accessing publications that users recognise and abide by the legal requirements associated with these

- Users may download and print one copy of any publication from the public portal for the purpose of private study or research.

- You may not further distribute the material or use it for any profit-making activity or commercial gain

If the publication is distributed under the terms of Article 25fa of the Dutch Copyright Act, indicated by the "Taverne" license above, 
CREATING NEW PERSPECTIVES ON WORK-HOME INTERFACE

A cross-cultural comparison of Malta, Serbia and the Netherlands 
Creating new perspectives on work-home interface: A cross-cultural comparison of Malta, Serbia and the Netherlands

\section{Katarina Putnik}

ISBN 978-90-9029187-1

Layout/cover: Jos Bruystens, Maastricht

Printed by: Printservice Ede

(C) Katarina Putnik, Maastricht, 2015

All rights reserved. No part of this publication may be reproduced, stored in a retrieval system, or transmitted in any form or by any means, electronic, mechanical, photocopying, recording or otherwise, without the written permission from the author. 


\title{
CREATING NEW PERSPECTIVES ON WORK-HOME INTERFACE
}

A cross-cultural comparison of Malta, Serbia and the Netherlands

\author{
DISSERTATION
}

to obtain the degree of Doctor at Maastricht University, on the authority of the Rector Magnificus, Prof Dr. L.L. G Soete in accordance with the decision of the Board of Deans, to be defended in public

on Thursday, 24 September 2015, at 12.00 hours

by

Katarina Putnik 


\section{PROMOTORES}

Prof. Dr. IJ. Kant

Prof. Dr. F.J.N. Nijhuis

\section{CO-PROMOTOR}

Dr. I. Houkes

\section{READING COMMITTEE}

Prof. Dr. F.R.H. Zijlstra (chair)

Prof. Dr. H. Bosma

Dr. A.M. Meershoek

Prof. Dr. K.G. Tijdens (Erasmus University Rotterdam)

Prof. Dr. G. Widdershoven (VUmc Amsterdam) 
For Tamić

'We live as long as we are remembered' 



\section{Table of contents}

1 Introduction 9

2 A comparison between Maltese, Serbian and Dutch cultural contexts 25

in relation to negative work-home interface

3 Work-home interface in a cross-cultural context: 45

A framework for future research and practice

$4 \quad$ Cultural context and gender roles matter: $\quad 63$

Work-home interface among professionals in Malta, Serbia and the Netherlands

5 Work related characteristics, work-home and home-work interference and burnout $\quad 87$ among primary healthcare physicians: A gender perspective in a Serbian context

6 General discussion $\quad 105$

$\begin{array}{ll}\text { Appendix A } & 123\end{array}$

$\begin{array}{ll}\text { Summary } & 127\end{array}$

$\begin{array}{ll}\text { Samenvatting } & 135\end{array}$

$\begin{array}{ll}\text { Valorisation } & 143\end{array}$

$\begin{array}{ll}\text { Acknowledgments } & 153\end{array}$

$\begin{array}{ll}\text { About the author } & 158\end{array}$ 

Introduction 

Tom is a professor in his early forties at the University, who lives with his wife (a headmaster at a secondary school) and their two year-old child in Malta. The child is cared for by the grandparents while the parents work. Tom could work from home during the week, however given the extensive teaching and writing commitments as well as social engagements related to his lecturing position, he does not spend much time with his family. His wife, besides having a responsible, full-time job, takes care of the household and the childcare. Tom often comes home just before his son's bedtime, and enjoys time spent reading to him and putting him to sleep. He spends parts of the weekend working in the attic. Tom wishes for more time with his son and wife, and feels guilty when he cancels family dinners and weekend outings due to work demands. He feels committed to his work, and responsible for the financial stability of his family, so he does not attempt to make any changes to his work commitments.

Ana is in her early thirties, lives with her husband (a full-time teacher) and three year-old and five year-old daughters, and works as a full-time nurse in Serbia. She prepares children for the daycare, her husband drops them off, and she collects them. Ana cooks for the family and they put the children to bed together. The household chores, such as cooking, cleaning and ironing are her duties. She would like to, but cannot afford to pay for someone to help with the cleaning of the house. Food shopping is done together with her husband. She feels it is her role to do these chores as a good mother and wife, and is grateful for the help her husband provides, however sometimes she does feel tired and needs more rest than she can take.

Both Tom and Ana are full-time employees, yet the daily realities of combining work and home domains are quite different. They both place high value on their work and families, but the amount of time they spend on each domain differs between Tom and Ana. The question is: how much of the difference in their organisation of work and home is due to the fact that Tom is a man and Ana a woman? And how much is due to the fact that they work in different cultural contexts with different possibilities and facilities for combining work and family life as well as different expectations placed on them? Furthermore, what is the impact of such different work and home scenarios on their health? Work-home interface (WHI) is an umbrella term for the difficulties (in the form of strain, time issues and behavior incompatibilities), as well as positive spillovers from work to the home domain and vice versa (Grzywacz \& Marks, 2000). When the work domain is interfering with the home domain, it is called negative work-home interface (-WHI) and when the home domain is interfering with the work domain, it is called negative home-work interface (-HWI). Negative work-home interface is also called work-home conflict or work-home interference and negative home-work interface is also called homework conflict or home-work interference. These terms are used interchangeably in the literature. Both -WHI and -HWI may occur through time, energy or behavior conflicts (Grzywacz \& Marks, 2000). In this thesis the focus is on negative work-home interface, since it is associated with numerous unfavourable outcomes. By understanding negative work-home interface better we wish to create knowledge that can be used for prevention purposes that would be suitable for particular cultural contexts.

At an individual level, work-home interface is influenced by demographics, work, and home 
characteristics. What is known so far is that demands such as working hours, pressure at work and lack of resources, such as low social support, play an important role in making it more difficult to combine the work and home domains, while family stress, number of hours spent on household or childcare duties and number of children, are associated with difficulties in combining home with the work domain (Byron, 2005). In general, unfavourable work characteristics are more related to negative work-home interface and high demands at home with negative home-work interface (Byron, 2005; Eby, Casper, Lockwood, Bordeaux, \& Brinley, 2005).

Difficulties in combining work and home domains are undesirable and stressful in itself. However, they are also associated with unfavourable individual, organisational and societal outcomes. At an individual level, poor health and burnout are some of the consequences, while at an organizational level decreased productivity, increased sickness absence and high turnover rates are common (Allen, Herst, Bruck, \& Sutton, 2000; Amstad, Meier, Fasel, Elfering, \& Semmer, 2011). Thus, negative work-home interface is also associated with increased costs for the organisation. Furthermore, understanding the impact of the work-home interface is relevant for societies. A European Union (EU) report states that appropriate work-home interface is central to achieving the EU's goals of 'more and better jobs, improved well-being and greater dynamics and productivity performance at the workplace' (p. 2, Eurofound, 2014b). If people are unable to combine work and care duties, they are likely to exit the labour market, either partially or fully, thus affecting the rate of participation. Sustainable employment is given a lot of importance in the EU and globally. One way to achieve it is to create working conditions that facilitate combining work and home duties for both men and women.

Cultural context plays a role in relation to work-home interface through societal beliefs, values and institutional frameworks (Camilleri-Cassar, 2005; van der Lippe, Jager, \& Kops, 2006). Gender roles and values differ across cultural contexts and also impact the experience of work-home interface (Greenhaus \& Beutell, 1985; Strandh \& Nordenmark, 2006). Thus, in different cultural contexts, different variables may be relevant for work-home interface and the experience with work-home interface may vary between these contexts. Studies that examine two or more cultural contexts simultaneously are very scarce though (Cohen \& Kirchmeyer, 2005). There is also a lack of an adequate theoretical framework that links individual and cultural levels of analysis (Parasuraman \& Greenhaus, 2002). There is a societal and scientific need to understand the role of the cultural context in work-home interface. Such understanding would allow us to draw culturally sensitive guidelines and develop culturally sensitive intervention programs concerning WHI. In this way, the resources invested in research and policy/interventions would be used more efficiently and produce greater impact. Currently, we do not know whether, and to what extent, the findings concerning work-home interface originating from one cultural context can be applied in another type of cultural context. Thus, not enough is known about similarities and differences between European cultural contexts in relation to work-home interface and health. This thesis will contribute by making insights about the role of the cultural context in relation to work-home interface and by developing a new framework of work-home interface. The insights gained can be used to help policy makers and researchers to improve work-home interface in Europe. 


\section{Current situation concerning work-home interface}

Negative work-home interface is an issue for a substantial number of people in Europe. The prevalence varies between the European cultural contexts and is affected by the measuring instrument, family constellation, profession as well as the cultural context. According to the European Quality of Life Survey, conducted in 2012, overall in the EU 59\% for women and 54\% men experienced difficulties in balancing work and home demands (Eurofound, 2013). Negative work-home and home-work interface was measured by persons experiencing at least one of the following three difficulties in the past month: being tired at home after work, time spent at work interfering with home demands and difficulties concentrating at work. According to this source, in Serbia there was the highest proportion of persons having difficulties with balancing the two domains: overall $80 \%$ of participants experienced difficulties, of which there were $85 \%$ women and $77 \%$ men. The lowest level of negative work-home interface was reported in Italy, by $44 \%$ of women and $39 \%$ of men. Explanations for differences between countries were sought in (in)flexible working time arrangements and organisation of work. In sum, there are variations in work -home interface across European cultural contexts. These differences can be due to work and home characteristics, but also due to sex and gender roles or differences in organisations of work per country (van der Lippe et al., 2006).

\section{Cultural context, sex and gender in relation to work-home interface}

The cultural context encompasses various elements, including institutions and legislation, values and norms, historic context, implying that different approaches can be taken to examine it. Assessing its role is a challenging task. Often scholars studying it, used country of residence as a proxy for cultural context. Some went a step further, and based the cultural differences on for instance Hofstede's values dimensions. These values concern 'broad tendencies to prefer certain states of affairs over others' (p.263, Hofstede, 1991). Hofstede defined these preferences through the following values: power distance (valuing inequality vs equality in positions between superiors and subordinates for example), uncertainty avoidance (preference for rigid planning of the future vs flexibility), individualism/collectivism (valuing the group vs valuing and placing an individual first) and masculinity/femininity (valuing toughness and competitiveness vs valuing tenderness). Differences in Hofstede's values dimensions have been associated with differences in predictors of work-home interface as well as occupational and health outcomes (Lu, Gilmour, Kao, \& Huang, 2006; Lu et al., 2009; Masuda et al., 2012; Spector et al., 2007; Spector et al., 2004).

There are also differences between men and women concerning the work and home interface: antecedents vary between men and women as well as the importance of each domain, expectations and interpretation of experiences (Eby et al., 2005). For example, the amount of hours spent on work and home domains varies. In general, men spend more hours in paid work, while women spend more hours in domestic work. In total, women's amount of hours engaged in work and home duties 
surpasses men's in all European countries (Eurofound, 2014a). However, this does not imply that women necessarily experience more negative work-home interface or more negative home-work interface. The effect of the amount of working hours is believed to be influenced by gender roles, which are linked with the cultural context (Greenhaus \& Beutell, 1985; Strandh \& Nordenmark, 2006). Gender role attitudes (egalitarian versus traditional) shape the expectations concerning the division of care and household chores as well as the perception of fairness of these divisions. Agreement on division of household chores was found to be associated with lower -WHI (van der Lippe et al., 2006). Concerning the overall effect of gender role attitudes on WHI, the findings are still inconclusive. Some studies found that, when working and home conditions were corrected for, women with traditional gender role attitudes experienced lower -WHI than women with egalitarian gender role attitudes (Strandh \& Nordenmark, 2006; van der Lippe et al., 2006). On the other hand, lack of associations between the gender role attitudes and work-home interface has also been reported, as well as findings that traditional gender role attitudes were associated with higher -WHI and higher - HWI (Korabik, McElwain, \& Chappell, 2008). Furthermore, in cultural contexts where both men and women work out of necessity and where dual labour participation is not always linked with progressive gender attitudes are also expected to experience better work-home interface since they are busy with survival rather than work-home strategies (Pfau-Effinger, 1998; van der Lippe et al., 2006). It appears that there are differences between men and women across different cultural contexts in terms of expectations regarding the work and home domain. Here we illustrated it through the example of working hours, but gender role attitudes also shape the perception and experience of other work and home related variables that are relevant for work-home interface. Thus, it is relevant to explore how sex and gender, and cultural context interact with each other in relation to work-home interface.

\section{Recent shifts over time that impact work-home interface}

The pace of work has increased in recent decades in Europe and globally and there are more dual earner households and single parent families than before who need to manage the complexities of work and home domains simultaneously (Parasuraman \& Greenhaus, 2002). The pressure on work-home interface has increased for families with children in the last decade (Eurofound, 2014c). Increase in female labour participation has been (partially) linked with changes in values and norms concerning women's role in the society. Changes in institutions also affect work-home interface. For example, until recently, welfare states in Western Europe have been characterised by a strong form of formal social protection. People in these countries could use (largely) state-funded facilities like nursing homes and childcare centers. At the same time, welfare states models in South Europe relied more on informal care for both children and elderly. However, currently there is an increased emphasis on the participation society, a shift taking place in countries such as the Netherlands: there is a shift towards less institutionalised care for the elderly and more reliance on informal caretakers, such as family, friends and neighbours. The effect of trends and shifts mentioned above on work-home interface and health should be examined. 


\section{Policy perspective}

It is important for policy makers to gain insight into the extent of similarity and differences between cultural contexts concerning work-home interface, since specific policies aimed at improving workhome interface may be well-suited for particular cultural contexts, yet very unsuitable for others. For example, policies that promote provision and accessibility of daycare centers may be very important to Ana and her work-home interface. However these policies may not be relevant for Tom, since he would not want to send his son to a daycare center. Daycare centers are not in line with his and his wife's cultural values and norms about appropriate childcare. Thus it is important to ensure that the policies fit the societal values and norms and are also supported by institutional frameworks. Different work-related cultures and traditionally established gender-role models make the policy making in this field challenging. However, current EU preference is towards convergence, i.e., making more universal policy models to be used across the EU (Eurofound, 2014b).

For the sake of efficiency and usefulness of policies, it would be important that policy makers know whether there are factors of work or home domain that are emic (culture-specific) and whether there are also some that are etic (universal across cultures). For example, do Tom and Ana experience the same pressure on work-home interface? Which aspects are common for these countries and which are culture specific? We would also need to know what role perception and expectations play and whether that is culture and/or gender specific or represents an interplay of these factors. If we would know this, it would allow policy makers to make appropriate inferences about which findings from studies from other countries could be applied to their cultural context and which not. By ignoring the role of the cultural context and its specificity, there is a risk of implementing inefficient, ineffective or suboptimal work-life policies that would not have the desired effects for individuals, organisations and society as a whole.

\section{Scientific perspective}

An extensive body of research exists about personal characteristics, demands and resources that affect work-home interface (Allen et al., 2000; Allen et al., 2012; Byron, 2005). Despite extensive research on antecedents of $-\mathrm{WHI}$, we do not know much about whether the same factors are equally important across different contexts, given that most research on this topic originates from the western, Anglo speaking world (Parasuraman \& Greenhaus, 2002; Poelmans, O’Driscoll, \& Beham, 2005; Shaffer, Joplin, \& Hsu, 2011). Considerably less research exists about work-home interface in non-western, non-English speaking contexts, and comparative cross-cultural research including two or more such contexts is even scarcer. There is a need for more theoretical and empirical research on this topic, since many questions are still unanswered (Poelmans, 2005; Shaffer et al., 2011). Some of them concern the meaning of work and home domains across cultural contexts and universality of relations of different factors to work-home interface. One of the reasons for this lack of deeper 
understanding of the work-home interface may lie in the fact that most of the studies are largely quantitative (Poelmans, 2005). Qualitative or mixed-method studies are needed in order to explore the meaning given to various aspects of work-home interface. Therefore this thesis will be based on both qualitative and quantitative methods employed in three different cultural contexts, one Mediterranean country, one South East European and one Northern European country.

\section{Research context}

We focus our research on three European countries that differ in values, norms and institutional frameworks. The three countries represent three different welfare state regimes with different expectations of men and women's labour participation and with different gender roles. Malta is a Mediterranean/conservative corporatist welfare state, Serbia a socialist welfare state with elements of a social democratic regime when it comes to expected labour participation of men and women and the Netherlands a hybrid between the social democratic and corporistic welfare state. The three countries also differ concerning the convergence to the EU's norms and policies. Malta is a relatively new EU member state that joined the EU in 2004, Serbia is a non-EU member state and the Netherlands is an old EU member state, being one of EU's founding members.

In this study, we use both the country of residence (Malta, Serbia, the Netherlands) and Hofstede's cultural dimensions of power distance and masculinity/femininity (Hofstede, 2008) as proxies of cultural context. Hofstede's model has been recognized as one of the core models for explaining cultural differences related to work-home interference. However, some have criticised Hofstede's research as being outdated, given that the majority of data was collected in 1980, and that thus findings might not hold to this present day (Vaiman \& Brewster, 2014). To overcome this critique, we pre-tested the cultural differences of our sample on the dimensions of power distance and masculinity/femininity (see Appendix A of the thesis). Our findings indicate that the three countries represent three different cultural contexts. Thus, using country as a proxy of cultural context seems reasonable. To depict more closely these differences we provide a brief description of the Maltese, Serbian and Dutch cultural setting.

\section{Malta}

Malta is a Mediterranean country, where a traditional breadwinner model is still the norm (CamilleriCassar, 2005) and female labour participation is the lowest of the $25 \mathrm{EU}$-member states with lowest provision of childcare facilities for below 3 years of age (Borg, 2009). In Pfau-Effinger's terms, Malta could be classified as male breadwinner/female part-time carer model (Pfau-Effinger, 1998), meaning that men are main breadwinners, while women are working part-time or hours that are compatible with the childcare, and are responsible for childcare. Only $5 \%$ of families are dual earner (NSOM, 2008) and even in such cases, men are perceived as the main financial providers of the family, fulfilling the breadwinner role (Rizzo, 2009). In the recent years, dual earner families are on the 
increase, mostly out of financial necessities (Abela, Casha, Borg Xuereb, Clark, Inguanez, \& Sammut Scerri, 2012). Discrepancy in employment rates between men and women occurs when women get married or have children. An overwhelming majority of Maltese mothers are economically inactive. One of the reasons for this is related to the lack of support systems for paid work (Camilleri-Cassar, 2005). Children are often cared for by mothers or maternal grandmothers (Camilleri-Cassar, 2005). Married working women are often criticized for their labour participation, especially when they have children and when the work was not out of financial necessity (Abela, 2000). Women's main responsibility is to take care of children and other relatives (Naudi, 2004). Once the children arrive, men's participation in childcare and household activities is low (Abela, 2009). However, the Maltese society is undergoing change, with more young women joining the labour force than before, and these young women are also more likely to return to the labour force after having children than previous generations of women (Abela et al., 2012). For example, from 2003 to 2008, there has been a $16 \%$ increase in the group of married mothers who worked (Abela, 2009).

\section{Serbia}

Serbia is an ex-socialist country where men and women have been working alongside each other since the Second World War (Denich, 1976). Family is prioritised and work has primarily an instrumental value (Blagojevic Hughson, 2012). Dual earner families and full time employment are the norm (Krstić \& Corbanese, 2008). Many families function according to the dual breadwinner/state carer model, meaning that both parents are responsible for securing the income, while childcare is in the hands of the state (Pfau-Effinger, 1998). Overall formal employment rate is low (47\%), especially among women where it is around $40 \%$ (SORS, 2014).

However, this figure may be misleading, since there is substantial part of population that is in informal employment (Vuković \& Perišić, 2011). In 2010, of all employed persons, 98.1\% of working men and $97.5 \%$ of working women were in full time employment. Part-time employment is not common, and the percentage has been shrinking even further in the recent years. Despite women's long tradition of labour participation, fulfillment of household and family related tasks is still mostly in the women's hands (Gavrilović, 2008; Massey, Hahn, \& Sekulić, 1995). In one study, over twothirds of men stated they never or rarely cooked or helped in maintenance of the household such as cleaning (Blagojević Hughson, 2013). Serbia allows for three months of paid maternity leave and up to 365 days of paid parental leave (that includes maternity leave).

\section{The Netherlands}

The Netherlands is a Northern European country that has one of the highest labour participation rates in the EU: labour participation among men is $80 \%$ and women $70 \%$ (OECD, 2013). However, in terms of total amount of working hours of women, the Netherlands fares rather low compared to other EU countries, as $70 \%$ of all working women (in contrast to $15 \%$ of men) work part-time (Beckers \& Langenberg, 2006). This creates a large difference in the amount of working hours between men and women: average amount of working hours per week is 25 hours for women, and 37 hours for 
men (Merens, Hartgers, \& van den Brakel, 2012). The proportion of female part-time employees is especially high when they have children (Teichgraber, 2013), creating a one and a half earner model as the standard (Kosters, Moonen, \& Cloin, 2012). In 2012, 54\% of couples with children younger than 12 living at home were part of a one-and-half income model, where one person worked fulltime and one part-time (CBS, 2013). In the same year, nearly a quarter of couples consisted of one person working full-time and the other not participating in the paid labour (CBS, 2013). Roughly half of men and women believe household chores and childcare should be shared equally, yet around $70 \%$ of these tasks are still done by women (Portegijs \& Cloin, 2012). The Netherlands allows three months of paid maternity leave and another three months parental leave. Private organisations do not remunerate the employees during parental leave absence.

\section{Aim of the study}

Work and home characteristics, as well as the prevalence of negative work-home interface vary across cultural contexts (Eurofound, 2014d). Understanding the differences in work-home interface across cultural contexts would be important for researchers and policy makers who work on intervention and prevention strategies concerning employees' well-being and sustainable employment. The main aim of this thesis is to gain insight in the role of the cultural context on work-home interface in order to serve future research and policy makers at various levels. The focus in this thesis is given to WHI. More specifically, this study explores the role of the cultural context in relation to work-home interface in three European countries: Malta, Serbia and the Netherlands. To achieve the main aim of this thesis, several research questions are addressed:

1) What are the similarities and differences in work and home characteristics and what is their relationship to negative work-home interface in Malta, Serbia and the Netherlands?

2) How can we better conceptualise work-home interface so that the role of the cultural context is taken into account?

3) What is the role of cultural context and gender in relation to work-home interface?

4) What is the role of gender in relation to the prevalence of work characteristics, work-home and home-work interference and burnout and how do health outcomes of Serbian physicians compare to the findings in other international results?

\section{Methodological framework}

In this thesis, both quantitative and qualitative methods are applied in order to examine workhome interface and its relation with the cultural context broadly and thoroughly. Surveys and semi-structured interviews are conducted, which are used in quantitative and qualitative analyses respectively. The mix of the two approaches is one of the strongpoints of this study. We also wished 
to contribute to the methodology of studying work-home interface in different cultural contexts by examining whether the two approaches yield congruent, additive or disparate results. Another strongpoint is that the quantitative data is largely based on the same instruments in the three cultural contexts and the qualitative data is based on the same topic list. Thus, the data collection instruments in the three countries are highly comparable.

Research questions 1-3 are answered by the data that were collected during the period 2010-2013 in Malta, Serbia and the Netherlands on a sample of human service professionals, i.e. employees working in the healthcare and education sectors. Research question 4 is answered by the data collected in 2008 in Serbia on a sample of primary healthcare physicians. Data in Malta and the Netherlands are collected throughout the country, while in Serbia it originates mostly from the capital of Belgrade. In all three countries, surveys are distributed to people working in a mix of small and large healthcare and educational institutions.

To answer the research question 1 and 4, quantitative analyses are carried out. For chapter 4, qualitative techniques are applied. For chapter 3 , the findings from different theories and existing literature are combined.

\section{Outline of the thesis}

Chapter 2 explores via quantitative means the similarities and differences in work and home characteristics, and negative work-home interface between Malta, Serbia and the Netherlands. Prevalence, direction and strength of associations as well as interactions of individual factors such as age, sex, gender with culture in relation to $-\mathrm{WHI}$ are examined. The findings are based on surveys collected in Malta and Serbia in 2010 and in the Netherlands in 2012 and 2013. In chapter 3 we examine the conceptualisation of work-home interface that takes the cultural context into account. In this chapter, a new framework of work-home interface is proposed. In chapter 4 we explore the way work and home domains are combined in the three countries. The findings are based on interviews conducted in Malta and Serbia in 2010 and in the Netherlands in 2012 and 2013. In the final empirical chapter of this thesis, chapter 5, the differences in work and home characteristics, work-home interface and health (burnout) between men and women in Serbia alongside the differences in levels of burnout between countries (Hungary, Italy and the Netherlands) are explored. The primary data is based on surveys collected in 2008 in Serbia. Finally in, chapter 6, the findings of the previous chapters are reflected on, and discussed. Implications for policy makers working in the area of organisational health are discussed along with the suggestions for future empirical research into the area of work-home interface in relation to cultural context. 


\section{References}

Abela, A. (2009). The changing landscape of Maltese families. In J. A. Cutajar \& G. Cassar (Eds.), Social transitions in Maltese society (pp. 23-50). Hal Luqa: Agenda.

Abela, A., Casha, C., Borg Xuereb, R., Clark, M., Inguanez, J., \& Sammut Scerri, C. (2012). The needs of Maltese families with dependent children: A focus group study among professionals. Bank of Valletta Review(45), 55-86.

Abela, A. M. (2000). Values of women and men in the Maltese islands: A comparative European perspective. Malta: Commission for the advancement of women, Ministry for Social Policy.

Allen, T. D., Herst, D. E. L., Bruck, C. S., \& Sutton, M. (2000). Consequences associated with work-to-family conflict: A review and agenda for future research. Journal of occupational health psychology, 5(2), 278-308.

Allen, T. D., Johnson, R., Saboe, K., Cho, E., Dumani, S., \& Evans, S. (2012). Dispositional variables and work-family conflict: A meta-analysis. Journal of Vocational Behavior, 80, 17-26.

Amstad, F. T., Meier, L. L., Fasel, U., Elfering, A., \& Semmer, N. K. (2011). A meta-analysis of work-family conflict and various outcomes with a special emphasis on cross-domain versus matching-domain relations. Journal of occupational health psychology, 16(2), 121-169.

Beckers, I., \& Langenberg, H. (2006). Hoge arbeidsdeelname, maar lage arbedisduur [High employment, but low working hours]. Sociaal-economische trends, 4, 9-18.

Blagojevic Hughson, M. (2012). Muskarci i zene u Srbiji: Sta nam govore brojevi? (Men and women in Serbia: What are the numbers telling us?). Beograd: The United Nations Development Programme.

Blagojević Hughson, M. (2013). Rodni barometar u Sribiji: Razvoj i svakodnevni život [Gender barometer in Serbia: Development and everydaylife]. Belgrade: UN Women, Norwegian Ministry of Foreign Affairs.

Borg, A. (2009). Reflections on Women's day. Retrieved from http://www.timesofmalta.com/articles/ view/20090306/opinion/reflections-on-womens-day-2009. Times of Malta, March $6^{\text {th }} 2009$.

Byron, K. (2005). A meta-analytic review of work-family conflict and its antecedents. Journal of Vocational Behavior, 67(2), 169-198.

Camilleri-Cassar, F. (2005). Gender equality in Maltese social policy? Graduate women and the male breadwinner model. Luqa, Malta: Agenda.

CBS. (2013). More than half of couples with young children one-and-a-half income earners. Web magazine. Retrieved $10^{\text {th }}$ January, 2015, from http://www.cbs.nl/en-GB/menu/themas/arbeid-sociale-zekerheid/ publicaties/artikelen/archief/2013/2013-3925-wm.htm

Cohen, A., \& Kirchmeyer, C. (2005). A cross cultural study of the work/nonwork interface among Israeli nurses. Applied Psychology, 54(4), 537-567.

Denich, B. S. (1976). Urbanization and women's roles in Yugoslavia. Anthropological Quarterly, 11-19.

Eby, L., Casper, W., Lockwood, A., Bordeaux, C., \& Brinley, A. (2005). Work and family research in IO/OB: Content analysis and review of the literature (1980-2002). Journal of Vocational Behavior, 66, 124-197.

Eurofound. (2013). Quality of life in enlargement countries: Third European Quality of Life Survey-Serbia. Luxembourg: Publications Office of the European Union.

Eurofound. (2014a). Eurofound yearbook 2013: Living and working in Europe. Luxembourg: Publications Office of the European Union. 
Eurofound. (2014b). Policy lessons from the fifth EWCS: The pursuit of more and better jobs. Luxembourg: Publications Office of the European Union.

Eurofound. (2014c). Third European Quality of Life Survey-Families in the economic crisis. Luxembourg: Publications Office of the European Union.

Eurofound. (2014d). Third European Quality of Life Survey-Quality of life in Europe: Trends 2003-2012. Luxembourg: Publications Office of the European Union.

Gavrilović, D. (2008). Obrazovanje i edukacija kao preduslov za prevazilaženje teškoća u implementaciji etičkih i pravnih normi rodne ravnopravnosti u društvenoj sredini [Education and training as prerequisites for overcoming the difficulties in the implementation of ethical and legal norms concerning gender equality in a social environment]. TEMIDA, 11(3), 27-40.

Greenhaus, J., \& Beutell, N. (1985). Sources of conflict between work and family roles. Academy of Management Review, 10(1), 76-88.

Grzywacz, J. G., \& Marks, N. F. (2000). Reconceptualizing the work-family interface: An ecological perspective on the correlates of positive and negative spillover between work and family. Journal of occupational health psychology, 5(1), 111-126.

Hofstede, G. (1991). Cultures and organisations: Software of the mind. London: McGraw-Hill.

Hofstede, G. (2008). Values Survey Module 2008 questionnaire. Retrieved 1909 2009, from http://www. geerthofstede.eu/vsm-08

Korabik, K., McElwain, A., \& Chappell, D. B. (2008). Integrating gender-related issues into research on work and family. In K. Korabik, D. S. Lero \& D. L. Whitehead (Eds.), Handbook of work-family integration: Research, theory and best practices. Amsterdam: Academic Press.

Kosters, L., Moonen, L., \& Cloin, M. (2012). Flexibel werken [Flexible working]. In A. Merens, M. Hartgers \& M. van den Brakel (Eds.), Emancipatiemonitor 2012. Den Haag: Sociaal en Cultureel Planbureau, Centraal Bureau voor de Statistiek.

Krstić, G., \& Corbanese, V. (2008). Situation analysis of youth employment in the Republic of Serbia. ILO Employment Papers. Budapest: International Labour Office.

Lu, L., Gilmour, R., Kao, S. F., \& Huang, M. T. (2006). A cross-cultural study of work/family demands, work/family conflict and wellbeing: the Taiwanese vs British. Career Development International, 11(1), 9-27.

Lu, L., Kao, S. F., Cooper, C. L., Allen, T. D., Lapierre, L. M., O’Driscoll, M., . . Spector, P. E. (2009). Work resources, work-to-family conflict, and its consequences: A Taiwanese-British cross-cultural comparison. International Journal of Stress Management, 16(1), 25-44.

Massey, G., Hahn, K., \& Sekulić, D. (1995). Women, men, and the 'second shift' in socialist Yugoslavia. Gender \& Society, 9(3), 359-379.

Masuda, A. D., Poelmans, S. A. Y., Allen, T. D., Spector, P. E., Lapierre, L. M., Cooper, C. L., . . Woo, J. M. (2012). Flexible work arrangements availability and their relationship with work-to-family conflict, job satisfaction, and turnover intentions: A comparison of three country clusters. Applied Psychology: An International Review, 61(1), 1-29.

Merens, A., Hartgers, M., \& van den Brakel, M. (2012). Emancipatiemonitor 2012. Den Haag: Sociaal en Cultureel Planbureau, Centraal Bureau voor de Statistiek. 
Naudi, M. (2004). Gender mainstreaming in the public employment service Final report on gender mainstreaming in the public employment service (pp. 80-89). Copenhagen: European Commission-DG Employment and Social Affairs, peer review programme of the European Employment Strategy.

National Statistical Office of Malta (NSOM). (2008). Labour fource survey 2007. Retrieved 0503 2014, from http://www.nso.gov.mt/statdoc/document_file.aspx?id=2375

OECD. (2013). Better Life Index: Netherlands. Retrieved 1201 2015, from http://www.oecdbetterlifeindex.org/ countries/netherlands/

Parasuraman, S., \& Greenhaus, J. H. (2002). Toward reducing some critical gaps in work-family research. Human Resource Management Review, 12(3), 299-312. doi: 10.1016/s1053-4822(02)00062-1

Pfau-Effinger, B. (1998). Gender cultures and the gender arrangement-a theoretical framework for crossnational gender research. Innovation: The European Journal of Social Science Research, 11(2), 147-166.

Poelmans, S. (2005). Organisational research on work and family: Recommendations for future research. In S. A. Y. Poelmans (Ed.), Work and family: An international research perspective (pp. 439-462). London: Lawrence Erlbaum Associates.

Poelmans, S., O'Driscoll, M., \& Beham, B. (2005). An overview of international research on the work-family interface. In S. Poelmans (Ed.), Work and family: An international research perspective (pp. 3-46). London: Lawrence Erlbaum Associates.

Portegijs, W., \& Cloin, M. (2012). Verdeling van onbetaalde arbeid tussen partners (Division of unpaid work between partners). In A. Merens, M. Hartgers \& M. van den Brakel (Eds.), Emancipatiemonitor 2012 (pp. 115-125). Den Haag: Sociaal en cultureel Planbureau, Centraal Bureau voor Statistiek.

Rizzo, S. (2009). The dual-worker family: Combining working life with social life. Bank of Valletta Review(39), 1-19.

Statistical Office of the Republic of Serbia (SORS). (2014). Statistical yearbook of the Republic of Serbia 2014. Belgrade: Statistical Office of the Republic of Serbia.

Shaffer, M. A., Joplin, J. R. W., \& Hsu, Y. S. (2011). Special review article: Expanding the boundaries of work-family research: A review and agenda for future research. International Journal of Cross Cultural Management, 11(2), 221-268.

Spector, P. E., Allen, T. D., Poelmans, S. A. Y., Lapierre, L. M., Cooper, C. L., O’Driscoll, M., . . Beham, B. (2007). Cross national differences in relationships of work demands, job satisfaction, and turnover intentions with work-family conflict. Personnel Psychology, 60(4), 805-835.

Spector, P. E., Cooper, C. L., Poelmans, S. A. Y., Allen, T. D., O’Driscoll, M., Sanchez, J. I., . . Lu, L. (2004). A crossnational comparative study of work-family stressors, working hours, and well-being: China and Latin America versus the Anglo world. Personnel Psychology, 57(1), 119-142.

Strandh, M., \& Nordenmark, M. (2006). The interference of paid work with household demands in different social policy contexts: perceived work-household conflict in Sweden, the UK, the Netherlands, Hungary, and the Czech Republic. The British Journal of Sociology, 57(4), 597-617.

Teichgraber, M. (2013). EUROSTAT European Union Labour force survey-Annual results 2012. Retrieved 16 072014 from http://www.google.nl/url?sa=t\&rct=j\&q=\&esrc=s\&frm=1\&source=web\&cd=2\&ved=0C DgQFjAB\&url=http\%3A\%2F\%2Fbookshop.europa.eu\%2Fen\%2Feuropean-union-labour-force-survey- 
pbKSSF13014\%2Fdownloads\%2FKS-SF-13-014-EN-N\%2FKSSF13014ENN_002.pdf\%3FFileName\%3DKSSF13 014ENN_002.pdf\%26SKU\%3DKSSF13014ENN_PDF\%26CatalogueNumber\%3DKS-SF-13-014-EN-N\&ei=NMZ sU537CoG9OcSdgKgL\&usg=AFQjCNGRTHhkAWUFFC-wMNgmQdiAKGMQQg\&sig2=u2m9KijaGqFs4YPISuss EA

Vaiman, V., \& Brewster, C. (2014). How far do cultural differences explain the differences between nations? Implications for HRM. The International Journal of Human Resource Management, 26(2), 151-164.

van der Lippe, T., Jager, A., \& Kops, Y. (2006). Combination pressure: The paid work-family balance of men and women in European countries. Acta Sociologica, 49(3), 303-319. doi: 10.1177/0001699306067711

Vuković, D., \& Perišić, N. (2011). Social security in Serbia: Twenty years later. In M. Stambolieva \& S. Dehnert (Eds.), Welfare states in transition: 20 years after the Yugoslav welfare model (pp. 228-261). Sofia, Bulgaria: Friedrich Ebert Foundation. 


\section{A comparison between Maltese, Serbian and Dutch cultural contexts in relation to negative work-home interface}




\section{Abstract}

Background: Insufficient knowledge exists on the role of the cultural context regarding work-home interface. In this study, the role of the cultural context was examined in relation to negative work-home interface (-WHI) on a sample of professionals living in Malta, Serbia and the Netherlands. Methods: A cross-sectional survey was distributed in Malta in English, in Serbia in Serbian and in the Netherlands in Dutch. The total sample size was 864 ( 288 from each country). Data were analysed using analysis of variance, chi-square tests and linear regression. Results: In our sample, there were statistically significant differences between Malta, Serbia and the Netherlands concerning prevalence of -WHI. When individual factors such as age, sex and gender, work and home characteristics were controlled for, differences between the cultural contexts (operationalized as country of residence) concerning negative work-home interface still remained. No interaction effects of the cultural context, age, sex and gender were detected in relation to -WHI. Conclusions: Cultural context appears to play a role in relation to $-\mathrm{WHI}$ and its impact on the perception of the meaning of work-home interface needs to be explored in the future more thoroughly.

Keywords: work-home interface, cross-cultural, gender, quantitative research, professionals 


\section{Background}

Female labour participation and dual income families are on the increase in many countries (Oomens, Geurts, \& Scheepers, 2007). As a result, more people have to combine work and family duties. A vast body of knowledge exists on the work-home interface (WHI), its predictors and outcomes (Allen, Herst, Bruck, \& Sutton, 2000; Allen, Johnson, Saboe, Cho, Dumani, \& Evans, 2012; Byron, 2005). An unfavourable influence of the work domain on home is called negative work-home interface (-WHI). Experiencing $-\mathrm{WHI}$ is an unpleasant and stressful situation in itself. Furthermore, it is also associated with adverse health outcomes such as depression, burnout and health problems and unfavourable organisational outcomes such as job dissatisfaction, high turnover rate and reduced performance and productivity (Allen et al., 2000; Amstad, Meier, Fasel, Elfering, \& Semmer, 2011).

Negative work-home interface can be due to time conflict, low energy or behaviour difficulties that originate from the work domain and translate into the home domain (Greenhaus \& Beutell, 1985). Job demands resources theory (Demerouti, Bakker, Nachreiner, \& Schaufeli, 2001) for instance postulates, and research confirms, that high demands at work (long working hours, high mental and psychological demands) and low resources at work (low job control, low supervisor support) are associated with high -WHI (Amstad et al., 2011; Byron, 2005; Geurts, Taris, Kompier, Dikkers, van Hooff, \& Kinnunen, 2005).

Also cultural context appears to play a role in relation to $-\mathrm{WHI}$ (Poelmans, 2005). There are many facets of the cultural context; ranging from the differences in values and norms, differences in institutional frameworks, such as childcare and labour market, to differences in work and home characteristics, that play a role in the onset of WHI. In this paper we operationalise cultural context as country of residence as we believe it captures the different aspects of the cultural context. So far, insufficiently is known about the role of the cultural context and the interplay with individual factors such as age and sex in relation to the way work and home domains are experienced. Moreover, gender, which is the expression of one's biological sex, usually examined as degree of masculinity and femininity, is also relevant for understanding work-home interface. One may wonder whether employees from a certain cultural background experience the same difficulties with combining the two domains as employees from a different cultural context? Are men and women of different ages in different countries struggling in different ways? Or is it a mix of age, sex, gender and cultural context that interact to determine the way $-\mathrm{WHI}$ is experienced? Considering that the majority of research on the topic of work-home interface is conducted in the affluent western, and generally English speaking, countries (Shaffer, Joplin, \& Hsu, 2011), examining this issue in underexplored Maltese and Serbian contexts is relevant for learning whether or not findings from the western contexts can be applied to other settings as well. Understanding these issues would be beneficial for national policy makers and organisational health experts, as they could use these findings to tailor prevention and intervention policies to suit the particular needs of the diverse working population.

The aim of this paper is to explore differences between diverse European cultural contexts of Malta, Serbia and the Netherlands concerning work and home characteristics and -WHI, exploring 
also interactions of the cultural context and the individual factors of age, sex and gender in relation to -WHI. These three cultural contexts differ in values and norms as well as institutional frameworks concerning work and home spheres. For example, the power distance dimension of culture, defined by Hofstede as preference for inequality between superiors and subordinates, and the masculinity/ femininity dimension, defined as preference for competition and assertiveness and distinction of social gender roles between men and women differ between the three cultural contexts (Hofstede, 1997). The Netherlands is a country with low power distance and low masculinity/femininity, implying that there is a small power distance between superiors and subordinates and that there are preferences for tenderness, modesty and an overlap between male and female social gender roles. On the other hand, Serbia and Malta are both found to be high power distance countries, favouring large power distance between superiors and subordinates. Serbia is a low masculinity/ femininity country, while Malta scores high on this dimension, indicating preference for competition and distinct gender roles between men and women (Hofstede, 1997). These different preferences affect the expectations and the way work is organised. An example of differences in institutional frameworks between Malta, Serbia and the Netherlands concerns the use of childcare facilities. In Malta, less than $10 \%$ of children attend childcare facilities (Eurofound, 2014), in the Netherlands around $30 \%$ of children aged below two years and slightly below $60 \%$ of children aged three to five years attend childcare facilities (Eurofound, 2009) and in Serbia, 23\% of households with children aged below 12 years use childcare services (Eurofound, 2013). These institutional frameworks also affect the organisation of the work domain and the labour participation rate.

To achieve the aim of this study, the following research questions (RQs) will be addressed: (RQ1) What are the differences in work and home characteristics, individual factors and -WHI between Malta, Serbia and the Netherlands?; (RQ2) Do the associations between individual factors and work and home characteristics with $-\mathrm{WHI}$ differ between the three cultural contexts?; and (RQ3) Does the cultural context, and its interaction with individual factors, play a role in relation to -WHI when individual factors and work and home characteristics are controlled for?

\section{Methods}

\section{Sample and procedure}

This paper is based on cross-sectional data collected via questionnaires distributed to professionals in Malta, Serbia and the Netherlands. Data from Malta and Serbia were collected in 2010 and data from the Netherlands originate from the Maastricht Cohort Study (MCS) a large, prospective cohort study conducted on a heterogeneous working population (Kant, Bültmann, Schröer, Beurskens, van Amelsvoort, \& Swaen, 2003). The Dutch data are based on a subsample of the MCS, consisting of professionals selected from the 2012 wave and additional data that were collected from this subsample in 2013, in order to make the dataset more comparable to the Maltese and Serbian sample. 
The sample consists of professionals working in teaching, nursing and the medical field (i.e. human service professionals). When studying the role of the cultural context in relation to -WHI it is recommended to investigate the relations between work and home characteristics and $-\mathrm{WHI}$ in a relatively homogenous sample, since in that way disparities due to different occupational groups are diminished and more focused inquiry is possible (Polit \& Beck, 2012). Human service professionals represent a relatively homogenous occupational group since they are all involved in a caring profession, doing people work with patients or students, and they all experience high job demands (Drago, 2001; Lewis, 2003). The Maltese sample consisted of 720 participants (70\% response rate), the Serbian of 595 participants (52\% response rate), and the Dutch of 288 participants ( $87 \%$ response rate). Considering that the sample size can influence the chance of finding statistically significant results (Field, 2005), we decided to randomly select 288 participants from Maltese and Serbian samples to match the Dutch sample size. Table 1 shows the characteristics of the samples.

\section{Ethics}

Ethical approval was obtained from the Maastricht University for the Maastricht Cohort Study (METC 08-4-032), the University of Malta for Maltese data collection and from individual organisations for Serbian data collection.

\section{Measures}

\section{Independent predictors}

Independent predictors were the cultural context, work and home characteristics and self-reported health.

i. Cultural context was operationalised via country of residence, that is, Malta, Serbia or the Netherlands. Country was dummy coded, so that the Netherlands was the reference group.

ii. Full-time work was measured by one item question: "Do you work full-time?" Answering options were no (0) and yes (1).

iii. Supervisory duties were measured by one item question inquiring whether the participant supervises other staff members. Answering options were no (0) yes (1).

iv. Mental demands in the Maltese and Serbian sample were measured by an eight item scale ( $\alpha=.86 ; \alpha=.88$ respectively) developed to measure autonomy at work (De Jonge, Landeweerd, \& Nijhuis, 1993). Answering categories ranged from never (1) to very often (4). An example was: "The work is too complicated". In the Dutch sample, the scale was measured by a five-item scale ( $\alpha=.73$ ) of the psychological job demands subscale of the Job Content Questionnaire (JCQ) (Houtman, 1995; Karasek, 1985). Response options varied from strongly disagree (1) to strongly agree (4). An example item was: "I have to work very hard in my job". A mean scale score was computed for the Maltese, Serbian and Dutch subsample.

$v$. Job control in the Maltese and Serbian samples was measured by a four item scale $(\alpha=.80$; $\alpha=.78$ respectively) (Dierendonck, Groenenweg, \& Sixma, 1992). Answering categories ranged from none (1) to high (4). An example item was "To what extent do you have control over planning of your 
work?". In the Dutch sample it was measured by a three item scale $(\alpha=.64)$ of the decision authority subscale of the JCQ (Houtman, 1995; Karasek, 1985). Answering options ranged from strongly disagree (1) to strongly agree (4). An example item was: "My job offers me the space to take many decisions myself". Mean scale score was computed for the Maltese, Serbian and Dutch subsamples. vi. Emotional demands in the Serbian and Maltese samples were measured by one item: "How often in your work are you confronted with unfriendly clients?", taken from a larger scale on emotional demands (De Jonge et al., 1993). Answering categories ranged from never (1) to always (5). In order to be compatible with the Dutch data, the item was recoded into no emotional demands if the score was between 1 and 2.5 (scale middle) and presence of emotional demands, if above 2.5. In the Dutch sample it was measured by the item: "In your work, do you have contact with difficult clients or patients?" The answering categories were no (0) and yes (1).

vii. Social support was measured by means of two subscales: supervisor and colleague support. In Serbian and Maltese data, each subscale consisted of 5 items (Bergers, Marcelissen, \& Wolff, 1986). An example item for supervisor support was: "How would you describe your relationship with your supervisor?" and for colleague support: "How would you describe your relationship with your colleagues?" Answering categories ranged from bad (1) to very good (4). In the Dutch data, each subscale of supervisor and co-worker support of the JCQ questionnaire (Houtman, 1995; Karasek, 1985) consisted of a four-item scale, ranging from strongly disagree (1) to strongly agree (4). An example item was: "My supervisor helps me get the work done".

viii. Having children below the age of 12 living at home was a self-formulated one item variable (0=no, 1=yes).

ix. Partner/spouse having a job was also a self-formulated item with three options: no (0), yes part-time (1) and yes full-time (2).

$x$. Being in charge of planning and organising the household (in the tables below called planner household) inquired whether the participant was in charge of planning the household duties. Answering categories were coded as no (0) and yes (1).

$x i$. Self-reported health was measured by a one-item question concerning respondent's general health based on the Short Form 36 health survey (Aaronson et al., 1998; Ware Jr \& Sherbourne, 1992). Answering options included very bad (1) to very good (5).

\section{Control variables: Individual factors}

Individual factors examined included age, sex, gender and household composition.

i. Age was measured as a categorical variable with 8 answering options: $20-24,25-30,31-35,36-$ 40, 41-45, 46-50, 51-55, above 55 years.

ii. Sex was measured as a dichotomous variable (1=male, $2=$ female).

iii. Gender was measured using masculinity and femininity scales (van Vianen, 1987). Since the femininity scale had a low reliability $(\alpha=.47)$, it was not included in the analyses. Masculinity was measured by an 8 item scale ( $\alpha=.71$ in the Maltese sample; $\alpha=.76$ in the Serbian sample; $\alpha=.76$ in the Dutch sample). Respondents were asked to rate how much they identified with certain attributes, 
such as being dominant, or rational. Answering categories ranged from hardly (1) to very strongly (4). Mean scale score was computed for the Maltese, Serbian and Dutch subsamples.

iv. Household composition was classified into five categories: living alone, living with a partner or spouse, living with a partner or spouse and a child, living alone with a child or other (for example living with extended family or family of origin).

\section{Outcome variable}

Negative work-home interface in the Maltese and Serbian sample was measured by the mean scale ( $\alpha=.84 ; \alpha=.88$ respectively) of a subscale of the Survey Work-home Interference Nijmegen (SWING) (Geurts et al., 2005) consisting of eight items with answering categories ranging from never (1) to always (4). An example of the item was: "How often does it happen that you are irritable at home because your work is demanding?". In the Dutch dataset, a shortened version of the SWING questionnaire ( 6 of the original 8 items) mean scale ( $\alpha=.79$ ) was used (Jansen, Kant, van Amelsvoort, Kristensen, Swaen, \& Nijhuis, 2006; Wagena \& Geurts, 2000). Answering options ranged from rarely or never (1) to very often (4).

We examined whether the mean scores on -WHI in the Serbian and Maltese sample differed depending on whether the original 8 items, or the shortened version of the survey based on the 6 items from the Dutch sample, was used. No differences in the mean scores neither for men and women, nor for the total Serbian and Maltese samples were detected between the mean scores based on 8 versus 6 items. Thus, we used the 8 items of - WHI for the Serbian and Maltese samples in the analyses because that was the original version of the SWING.

\section{Statistical analyses}

\section{Primary analyses}

No standardised cut-off points are available for determining when work and home characteristics are unfavourable, so the rules of thumb (Janssen et al., 1996) were used instead: for scales from 1-4, cut-off point for unfavourable score was 2.5 and for scales from 1-5, the cut-off point was 3.5. If prevalence of unfavourable scores is above $20 \%$, it is considered as being a clinically relevant problem in need of attention (Janssen et al., 1996). The differences between cultural contexts regarding work and home characteristics, individual factors and -WHI were calculated using analysis of variance for continuous variables and a chi square test of independence for categorical variables (RQ 1). Some variables had missing data, which ranged from $0.6 \%$ (age) or $0.7 \%$ (child below age 12 ) to $5.3 \%$ (partner work) or $8 \% \max$ (masculinity). Although per variable the number of missing values was not very high, the distribution of the missing values over the different variables resulted in a considerable number of total missing values. This created a large number of lost participants in the listwise approach of the multiple regression analyses. To increase the power of the regression analysis, missing data were replaced through the technique of the multiple imputation procedure, using the fully conditioned specification method available in SPSS 22. The advantage of the multiple imputation method is that it allows for uncertainty in the missing values by creating multiple copies 
of datasets with estimated missing values based on all of the other variables in the imputation model (Lee \& Carlin, 2010). The missing values were calculated and imputed for twenty sets for all variables under study using the following predictors: cultural context, sex and child below the age of 12. Linear regression analyses (method=enter) were used to examine the associations of work and home characteristics and individual factors in relation to $-\mathrm{WHI}$ per cultural context (RQ 2), and to examine the relationship between work and home characteristics, individual factors, cultural context and its interactions with sex, gender and age on -WHI (RQ 3).

\section{Results}

\section{Descriptives}

In the Maltese and Serbian sample there were more women than men (66\%, $86 \%$ respectively) and in the Dutch sample there were more men than women (68\%). Due to the fact that the Dutch sample is part of a large longitudinal study of the Dutch working population that started in 1998 (Kant et al., 2003), all participants were older than 36 years. Most of the participants lived with a partner/spouse and/or children (Table 1). Correlation matrices (available upon request) for all study variables in the three countries indicated there was no multicollinearity between the variables.

\section{$R Q$ 1: Differences in work and home characteristics, individual factors and -WHI between cultural contexts}

Work and home characteristics and -WHI differed between cultural contexts (Table 2). Unfavorable mental and emotional demands were highly prevalent in all three countries, being experienced by $60-80 \%$ of the study sample. Low job control was reported by a third of Maltese and Serbian sample. On the other hand for the Dutch sample, low job control and poor colleague support relatively rarely reported compared to the Maltese and Serbian sample. The prevalence of $-\mathrm{WHI}$ differed between countries. In the Maltese and Serbian samples, negative work-home interface was experienced by more than a fifth of the sample, while in the Dutch sample it was reported by only $5 \%$ of respondents. Concerning the gender characteristic of masculinity, the Serbian sample scored highest, while the Netherlands scored lowest. Subanalyses (not shown) indicated that in the Netherlands, women scored higher on masculinity than men, while in Malta and Serbia men scored higher than women. 
Table 1 Demographic variables among countries

\begin{tabular}{|c|c|c|c|c|c|}
\hline Variables & Malta $n(\%)$ & Serbia $n(\%)$ & $\mathrm{NL} n(\%)$ & Total $n(\%)$ & $\chi^{2}(\mathrm{df}, \mathrm{n}) p$ \\
\hline \multicolumn{6}{|l|}{ Sex } \\
\hline Male & $99(34.4)$ & $41(14.2)$ & $190(68.1)$ & $330(38.6)$ & \multirow[t]{2}{*}{$\chi^{2}(2, n=855)=176.75^{* * *}$} \\
\hline Female & $189(65.6)$ & $247(85.8)$ & 89 (31.9) & $525(61.4)$ & \\
\hline \multicolumn{6}{|l|}{ Age, y } \\
\hline $20-24$ & $31(10.8)$ & $9(3.1)$ & 0 & $40(4.7)$ & \multirow[t]{8}{*}{$\chi^{2}(14, n=859)=402.20^{* * *}$} \\
\hline $25-30$ & $80(27.9)$ & $26(9.1)$ & 0 & $106(12.3)$ & \\
\hline $31-35$ & $45(15.7)$ & $39(13.6)$ & 0 & $84(9.8)$ & \\
\hline $36-40$ & $22(7.7)$ & $59(20.6)$ & $11(3.9)$ & $92(10.7)$ & \\
\hline $41-45$ & $40(13.9)$ & $46(16.0)$ & $19(6.7)$ & $105(12.2)$ & \\
\hline $46-50$ & $34(11.8)$ & $52(18.1)$ & $54(18.9)$ & $140(16.3)$ & \\
\hline $51-55$ & $16(5.6)$ & $23(8.0)$ & $75(26.3)$ & $114(13.3)$ & \\
\hline $55+$ & $19(6.6)$ & $33(11.5)$ & $126(44.2)$ & $178(20.7)$ & \\
\hline \multicolumn{6}{|l|}{ Profession } \\
\hline Nurse & $183(63.5)$ & $126(43.8)$ & $183(65.8)$ & $492(57.0)$ & \multirow[t]{4}{*}{$\chi^{2}(4, n=854)=44.72^{* * *}$} \\
\hline Doctor & 44 (15.3) & $54(18.8)$ & $18(6.5)$ & $116(13.4)$ & \\
\hline Teacher & $61(21.2)$ & $108(37.5)$ & $77(27.7)$ & $246(28.5)$ & \\
\hline Missing & 0 & 0 & $10(3.5)$ & $10(1.1)$ & \\
\hline \multicolumn{6}{|l|}{ Household composition } \\
\hline Living alone & $26(9.1)$ & $25(8.7)$ & $22(8.0)$ & $73(8.6)$ & \multirow[t]{5}{*}{$\chi^{2}(8, n=849)=107.47^{* * *}$} \\
\hline With partner/spouse & $47(6.4)$ & $52(18.1)$ & $128(46.7)$ & $227(26.7)$ & \\
\hline With partner/spouse+child & $150(52.3)$ & $144(50.0)$ & $112(40.9)$ & $406(47.8)$ & \\
\hline Alone+child & $11(3.9)$ & $9(3.1)$ & $7(2.6)$ & $27(3.2)$ & \\
\hline Other & $53(18.5)$ & $58(20.1)$ & $5(1.8)$ & $116(13.7)$ & \\
\hline
\end{tabular}

Note: ${ }^{* * *} p<.001$

RQ 2: Associations between individual factors, work and home characteristics in relation to -WHI in Serbia, Malta and the Netherlands

Individual factors, work and home characteristics explain 36\% of variance in -WHI in Serbian and Dutch samples, while in the Maltese sample they explain $28 \%$ of variance. When correcting for age, sex and gender, mental demands were significantly associated with -WHI in Malta, Serbia and the Netherlands (Table 3). Full-time work was positively associated with -WHI in Malta and the Netherlands. Colleague social support was negatively associated with negative work-home interface in the Netherlands. Sex (being a woman), being in charge of planning the household duties and having poor health were all positively associated with -WHI in Malta only. In the Netherlands, the presence of a young child was positively associated with $-\mathrm{WHI}$. 







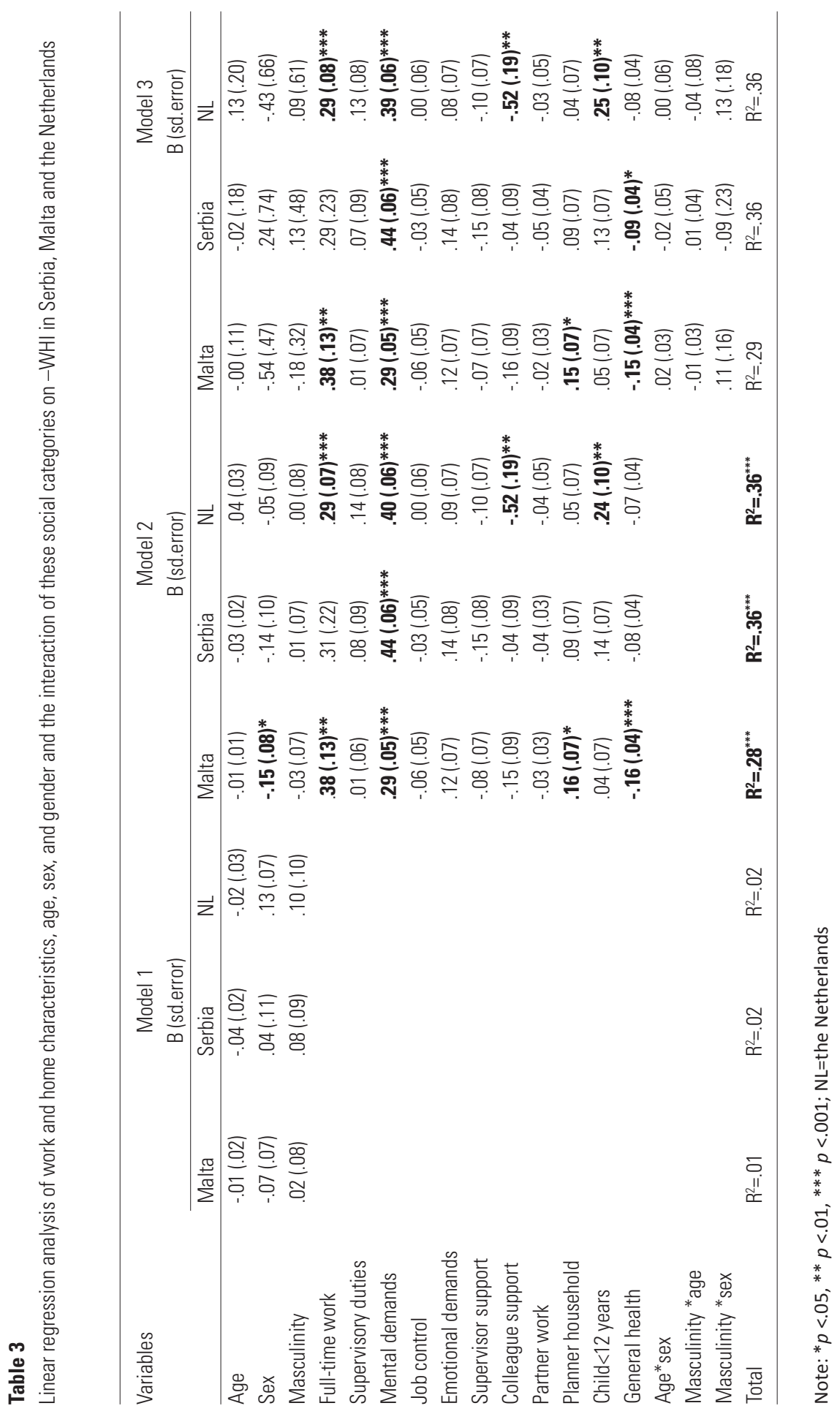




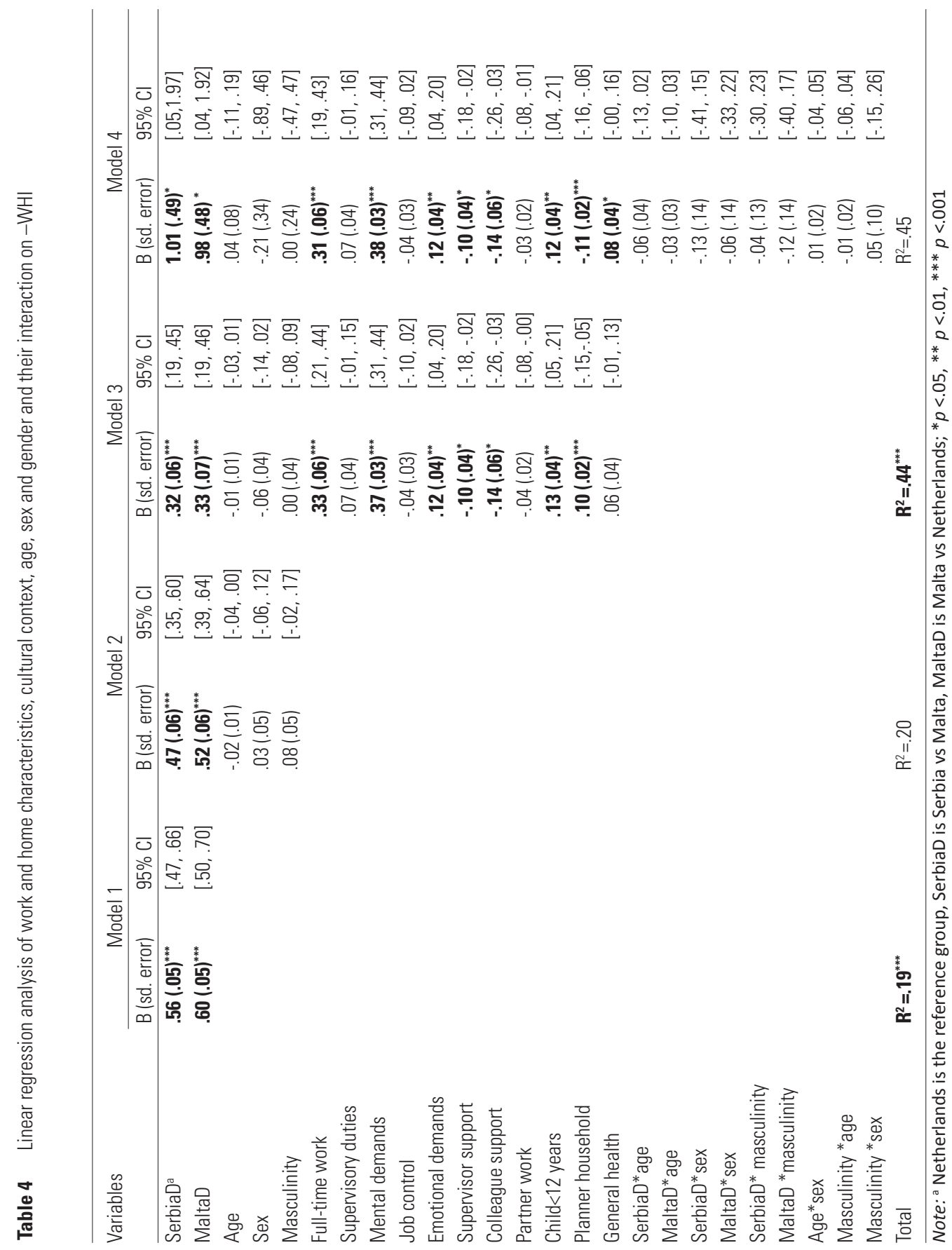


$R Q$ 3: The role of the cultural context and interactions of the cultural context with individual factors in relation to $-W H I$

When individual factors, such as age, sex and gender, and work and home characteristics were controlled for, cultural context was still significantly associated with -WHI (Table 4). No interaction effects of the cultural context and individual factors were detected.

\section{Discussion}

This study investigated via quantitative means the role of the cultural context and its interactions with individual factors in relation to the negative work-home interface among professionals in Malta, Serbia and the Netherlands. Its main contribution is that it shows that the cultural context appears to play a role in regard to negative work-home interface: problem areas differ between countries and different variables are important in different cultural contexts concerning $-\mathrm{WHI}$ among employees in similar professions. When work and home characteristics are controlled for, differences between cultural contexts regarding -WHI remain, indicating that cultural context plays a role. However, given that cultural context is in this study a broad construct operationalised as a country of residence, further research is needed to get more insight into what aspects of cultural context play a role in relation to negative work-home interface.

Differences in unfavourable work and home characteristics and negative work-home interface between the three countries

It appears that the teaching and medical occupations are highly mentally demanding regardless of the cultural context. This confirms previous findings, which showed high mental strain among doctors (Putnik \& Houkes, 2011). On many other aspects that were examined, Dutch participants in our sample had a lower percentage of unfavourable prevalence on variables compared to Maltese and Serbian participants. From the cultural perspective, the higher prevalence of low job control in high power distance countries, such as Serbia and Malta is not surprising. In high power distance countries there is more hierarchy and greater control by the supervisor than in low power distance countries. It may also be that the meaning of work and negative work-home interface differs between three countries. The economic necessity for both partners to work may also be relevant (ten Brummelhuis \& Bakker, 2012). Linked to this argument is the aspect of the freedom to choose a particular combination of work and home duties. In the Netherlands, for example, part-time work is widely used (since it is both available and financially affordable), and is associated with lower -WHI compared to full-time employment (Jansen, Kant, Nijhuis, Swaen, \& Kristensen, 2004). Moreover, studies have shown that $-\mathrm{WHI}$ is related to a higher probability of reducing working hours overtime. As such, for people struggling to combine work and home domains, switching from full-time to part-time work may be a resolution to better reconcile work and family life again (Jansen, Mohren, van Amelsvoort, Janssen, \& Kant, 2010). Thus, it may also be that the Dutch sample experiences 
less $-\mathrm{WHI}$ because participants have already adapted their working life so that it fits better with their preferred amount of working hours and private life. Those who did work full-time in our Dutch sample, experienced higher -WHI than those who did not, thus supporting previous findings concerning association of full-time work and -WHI in the Dutch setting (Jansen et al., 2004).

Due to the study design and approach, we could not control for potential differences in sample composition such as age and sex prior to the study. For example, one may wonder whether differences in age and sex composition between samples could have resulted in differences concerning prevalence of - WHI. For this particular outcome, our further analyses (RQ 2) have shown that sex and age do not impact -WHI. For other variables indeed, the differences in prevalence may have been influenced by differences in sample composition.

\section{Differences in relations between work and home characteristics and -WHI between the three countries}

Some of the existing differences in associations between variables and $-\mathrm{WHI}$ between countries could be explained by the cultural aspect of power distance. In high power distance countries, supervisor support is particularly relevant in relation to negative work-home interface, while in lower power distance countries, the support of colleagues may be more important (Lu et al., 2010). This finding was partially confirmed in this study. In the Netherlands colleague support was negatively associated with -WHI, while contrary to expectations, in Serbia and Malta, the role of the supervisor support was not statistically significant.

Full-time work is a relevant variable to consider in Malta and the Netherlands, countries that offer options for part-time and reduced hours. Given that in Serbia there is very little opportunity for working part-time, associations may be lacking due to limited variance in this variable. Being in charge of planning the household duties was positively associated with -WHI only in Malta. In Malta there is a strong pressure for clean and well-kept houses. One of the ways in which social pressure is exerted is gossip (O'Reilly Mizzi, 1994).

\section{Importance of the cultural context and interactions between the cultural context, individual factors and $-W H I$}

The cultural context appears to play an important role in -WHI. It explains nearly as much variance as individual factors and work and home characteristics, variables traditionally included in workhome interface research. No evidence was found for the interaction effect of the cultural context with individual factors, such as age, sex and gender. This is contradictory to some of the previous findings that detected interaction of sex and age (i.e. presence and age of children) with -WHI (Martinengo, Jacob, \& Hill, 2010). It may be that the quantification of certain factors, such as gender is too general. It may have been better to use gender role ideology, or gender role expectations, to acknowledge the contextual dependency of gender in relation to work-home interface (Özbilgin, Beauregard, Tatli, \& Bell, 2010). Perhaps there is a need to tap into gender norms and roles, rather than only gender, and also include wider economic context to capture the interactions of cultural 
context, age, sex and gender. Another study, examining work-family arrangements has shown that the quantitative data collection failed to capture important aspects of the work-family arrangements, which were detected via qualitative data (Estes, 2005). Perhaps, a combination of both quantitative and qualitative techniques may be the most adequate way for examining the topic in the future.

\section{Methodological reflections}

This study was based on extensive cross-sectional surveys among professionals. Besides including the Netherlands, a well-researched country in terms of work and home characteristics, it also included Malta and Serbia, two underexplored European cultural contexts. The data in the Dutch sample partly contained variables from an already existing dataset. Thus, some questions and scales were not always the same as in the Maltese and Serbian samples. However, the meaning of the items was compatible and scales were highly comparable with each other. This makes the study unique, given that in many other cross-cultural studies so far, there was no possibility to use comparable instruments and compare different samples simultaneously.

In this study, country was used as a proxy for the cultural context. Since the three countries differ in terms of cultural aspects of power distance and masculinity/femininity and institutional frameworks, one may wonder whether we are certain to have grasped the cultural aspect, rather than for example only one specific part, reflected in economic or institutional differences or simply variance unaccounted for. Earlier research has indicated that differences in negative work-home interface between cultural contexts go beyond differences in institutional frameworks and social policies (Stier, Lewin-Epstein, \& Braun, 2012). Furthermore, we included a large number of work and home characteristics variables, which are known for explaining a large variance in -WHI. Given that even after controlling for these variables (such as working full-time, having a young child at home, mental demands and so on), cultural context remained significant, gives a good basis for conclusion that its role is important and needs to be further explored in relation to $-\mathrm{WHI}$.

Although a number of relevant confounders were accounted for, we are unable to exclude potential effects of residual confounders such as performing shift work or overtime work, which were not included.

As shown in table 1, our samples differed concerning sex, age, and family constellation. This may have influenced the findings concerning prevalence of work and home characteristics health and -WHI, and we reflect on it in the findings above under the section 'Differences in unfavourable work and home characteristics and negative work-home interface between the three countries'. However in other analyses we have controlled for these aspects, thus the differences should not have impacted our conclusions concerning research questions 2 and 3 regarding associations of variables with -WHI.

In order to assure our participants of their anonymity, we opted for recording age as a categorical variable. Similarly, the number and ages of children were not asked, and we opted for a more general variable that examined the presence of a young child (younger than the age of 12). We believe this has helped us achieve greater response rates, since participants were assured that they could not be individually identified. 
Samples from all three countries consisted of teaching and medical professionals, forming part of human service professionals. The selection into jobs may be a result of their personality traits and affinities for certain work characteristics, which may starkly differ for other professionals. So caution should be exercised in applying the findings to other occupational groups of professionals.

\section{Recommendations for future research}

Future research should explore in more detail the roles of different aspects of the cultural context (values, norms, and institutional frameworks) in relation to -WHI. For this, more in-depth mixedmethod studies are needed.

Furthermore, although teachers, nurses and doctors all belong to the group of human service professionals, their level of education and status may differ. With greater level of education, financial resources and status increase, meaning that higher educated people have more resources to balance off the negative demands. Thus, future research should make more precise differentiation based on level of education/financial resources and also include other occupational groups.

It may also be that we saw only a sample of people who managed to combine work and home duties reasonably well, since those who struggled too much may have exited the labour market or adapted their working situation to solve the problem of -WHI. Longitudinal studies would be particularly useful to examine this aspect of $-\mathrm{WHI}$ overtime.

\section{Recommendations for policy and practice}

This study shows that besides work and home characteristics, it is also important to include the cultural context in understanding negative work-home interface. Understanding the role of the cultural context for -WHI has consequences for policy makers and researchers since it may reveal opportunities for effective prevention and intervention. Therefore the role of the cultural context needs to be explored more closely in the future.

This study has also shown how some aspects of work and home characteristics appear to play a role across the contexts, while some other aspects appear to be context-specific. A common area of concern relates to the high prevalence of mental and emotional demands at work, which should be prioritised in organizational interventions for our sample of people working as human service professionals in Malta, Serbia and the Netherlands. Our findings indicate that other aspects of the intervention may need to be context dependent: for our sample targeting $-\mathrm{WHI}$ should be a priority in the Maltese and Serbian samples. In the Dutch sample, -WHI was not highly prevalent, but should be monitored nonetheless to examine whether it is due to adaptive coping mechanisms and decreased working hours of participants that it is lower than in other countries. Thus, different variables need to be prioritised as targets in different cultural contexts when it comes to policy and practice concerning work-home interface.

However, health policies that aim to decrease $-\mathrm{WHI}$, should also largely be context specific, since different variables appear to be associated with it in different contexts. For example, our sample in all three countries, would benefit from the policies that would focus on decreasing high mental 
demands. On the other hand, colleague support in relation to -WHI appears to be important for the Dutch sample only and implementation of organisational policies focusing on fostering such support could be beneficial.

Overall, we conclude that health policies targeting improvement of working conditions and promotion of work and life balance should largely be context specific. Ideally, policies would be developed based on context-specific findings that would pinpoint areas of concern, and variables relevant for each specific cultural context.

\section{Conclusion}

The findings of this study imply that the experience of negative work-home interface is influenced by the cultural context and that the individual characteristics, as well as work and home characteristics are not able to fully account for these differences. The cultural context, tapped by the country of residence can represent values, norms and beliefs, as well as institutional and structural differences (Vaiman \& Brewster, 2014). Current quantitative studies, such as this one, are not able to tap more deeply into which aspect of the cultural context is responsible for this difference in experience of - WHI.

\section{Acknowledgments}

We would like to thank Dr. Frans Tan (Maastricht University) for his expertise advice on issues related to statistical analyses in this paper and Dr. Gonnie Klabbers for her expertise on the topic of missing data imputations. 


\section{References}

Aaronson, N. K., Muller, M., Cohen, P. D., Essink-Bot, M.-L., Fekkes, M., Sanderman, R., . . Verrips, E. (1998). Translation, validation, and norming of the Dutch language version of the SF-36 Health Survey in community and chronic disease populations. Journal of clinical epidemiology, 51(11), 1055-1068.

Allen, T. D., Herst, D. E. L., Bruck, C. S., \& Sutton, M. (2000). Consequences associated with work-to-family conflict: A review and agenda for future research. Journal of occupational health psychology, 5(2), 278-308.

Allen, T. D., Johnson, R., Saboe, K., Cho, E., Dumani, S., \& Evans, S. (2012). Dispositional variables and work-family conflict: A meta-analysis. Journal of Vocational Behavior, 80, 17-26.

Amstad, F. T., Meier, L. L., Fasel, U., Elfering, A., \& Semmer, N. K. (2011). A meta-analysis of work-family conflict and various outcomes with a special emphasis on cross-domain versus matching-domain relations. Journal of occupational health psychology, 16(2), 121-169.

Bergers, G. P. A., Marcelissen, F. H. G., \& Wolff, C. J. d. (1986). VOS-D. Vragenlijst Organisatie stress-Doetinchem: Handleiding [VOS-D. Work Stress Questionnaire Doetinchem: Manual]. Nijmegen: University of Nijmegen.

Byron, K. (2005). A meta-analytic review of work-family conflict and its antecedents. Journal of Vocational Behavior, 67(2), 169-198.

De Jonge, J., Landeweerd, J., \& Nijhuis, F. (1993). Constructie en validering van de vragenlijst ten behoeve van het project 'autonomie in het werk' [Construction and validation of the questionnaire for the 'job autonomy project'] Studies bedrijfsgezondheidszorg nummer (Vol. 9). Maastricht: Rijksuniversiteit Limburg.

Demerouti, E., Bakker, A. B., Nachreiner, F., \& Schaufeli, W. B. (2001). The job demands-resources model of burnout. Journal of Applied Psychology, 86(3), 499-512.

Dierendonck, D. v., Groenenweg, P. P., \& Sixma, H. (1992). Opgebrand. Een inventariserend onderzoek naar gevoelens van motivatie en demotivatie bij huisartsen [Burnout. A study into feelings of motivation and demotivation among General Practitioners]. Utrecht: NIVEL.

Drago, R. (2001). Time on the job and time with their kids: Cultures of teaching and parenthood in the US. Feminist Economics, 7(3), 1-31.

Estes, S. B. (2005). Work-family arrangements and parenting: Are "family-friendly" arrangements related to mothers' involvement in children's lives? Sociological Perspectives, 48(3), 293-317.

Eurofound. (2013). Quality of life in enlargement countries: Third European Quality of Life Survey-Serbia. Luxembourg: Publications Office of the European Union.

Eurofound. (2014). Eurofound yearbook 2013: Living and working in Europe. Luxembourg: Publications Office of the European Union.

Eurofound (Ed.). (2009). Childcare services in Europe. Luxembourg: Publications Office of the European Union. Field, A. (2005). Discovering statistics using SPSS (2nd ed.). London: Sage Publications.

Geurts, S. A. E., Taris, T. W., Kompier, M., Dikkers, J. S. E., Van Hooff, M. L. M., \& Kinnunen, U. M.(2005). Work-home interaction from a work psychological perspective: Development and validation of a new questionnaire, the SWING. Work \& Stress, 19(4), 319-339.

Greenhaus, J., \& Beutell, N. (1985). Sources of conflict between work and family roles. Academy of Management Review, 10(1), 76-88. 
Hofstede, G. (1997). Cultures and organizations: Software of the mind. New York: McGraw-Hill.

Houtman, I. (1995). Reliability and validity of the Dutch version of the Karasek Job Content Questionnaire. Paper presented at the APA/NIOSH conference on Work, Stress \& Health, Washington, DC.

Jansen, N. W., Kant, I., van Amelsvoort, L. G., Kristensen, T. S., Swaen, G. M., \& Nijhuis, F. J. (2006). Workfamily conflict as a risk factor for sickness absence. Occupational and Environmental Medicine, 63(7), 488-494.

Jansen, N. W., Mohren, D. C., van Amelsvoort, L. G., Janssen, N., \& Kant, I. (2010). Changes in working time arrangements over time as a consequence of work-family conflict. Chronobiology international, 27(5), 1045-1061.

Jansen, N. W., Kant, I., Nijhuis, F. J. N., Swaen, G. M. H., \& Kristensen, T. S. (2004). Impact of worktime arrangements on work-home interference among Dutch employees. Scandinavian Journal of Work, Environment \& Health, 30(2), 139.

Janssen, P. P. M., Nijhuis, F. J. N., Lourijsen, E. C. M. P., \& Schaufeli, W. B. (1996). Gezonder werken: minder verzuim! Handleiding voor integrale gezondheidsbevordering op het werk [Healthier work: lower levels of scikness absence! Manual for integral health promotion at the work place]. Amsterdam, The Netherlands: Nederalnds Instituut voor Arbeidsomstandigheden.

Kant, I., Bültmann, U., Schröer, K., Beurskens, A., Van Amelsvoort, L., \& Swaen, G. (2003). An epidemiological approach to study fatigue in the working population: the Maastricht Cohort Study. Occupational and Environmental Medicine, 60(suppl 1), i32-i39.

Karasek, R. A. (1985). Job content questionnaire and user's guide (version 1.1). Los Angeles: Department of Industrial and Systems Engineering, University of South California.

Lee, K. J., \& Carlin, J. B. (2010). Multiple imputation for missing data: Fully conditional specification versus multivariate normal imputation. American journal of epidemiology, 171(5), 624-632.

Lewis, S. (2003). The integration of paid work and the rest of life. Is post-industrial work the new leisure? Leisure studies, 22(4), 343-345.

Lu, L., Cooper, C. L., Kao, S. F., Chang, T. T., Allen, T. D., Lapierre, L. M., . . Spector, P. E. (2010). Cross-cultural differences on work-to-family conflict and role satisfaction: A Taiwanese-British comparison. Human Resource Management, 49(1), 67-85.

Martinengo, G., Jacob, J. I., \& Hill, E. J. (2010). Gender and the work-family interface: Exploring differences across the family life course. Journal of Family Issues, 31(10), 1363-1390.

O’Reilly Mizzi, S. (1994). Gossip: A means of social control. In R. G. Sultana \& G. Baldacchino (Eds.), Maltese society: A sociological inquiry (pp. 369-382). Msida: Mireva Publications.

Oomens, S., Geurts, S. A. E., \& Scheepers, P. (2007). Combining work and family in the Netherlands: Blessing or burden for one's mental health? International Journal of Law and Psychiatry, 30(4), 369-384.

Özbilgin, M. F., Beauregard, T. A., Tatli, A., \& Bell, M. P. (2010). Work-life, diversity and intersectionality: A critical review and research agenda. International Journal of Management Reviews, 177-198. doi: 10.1111/j.14682370.2010.00291.x

Poelmans, S. (2005). Organisational research on work and family: Recommendations for future research. In S. A. Y. Poelmans (Ed.), Work and family: An international research perspective (pp. 439-462). London: Lawrence Erlbaum Associates. 
Polit, D. F., \& Beck, C. T. (2012). Nursing research: Principles and methods (9th ed.). Philadelphia: Lippincott Williams \& Wilkins.

Putnik, K., \& Houkes, I. (2011). Work related characteristics, work-home and home-work interference and burnout among primary healthcare physicians: A gender perspective in a Serbian context. BMC Public Health, 11(1), 716.

Shaffer, M. A., Joplin, J. R. W., \& Hsu, Y. S. (2011). Special review article: Expanding the boundaries of work-family research: A review and agenda for future research. International Journal of Cross Cultural Management, 11(2), 221-268.

Stier, H., Lewin-Epstein, N., \& Braun, M. (2012). Work-family conflict in comparative perspective: The role of social policies. Research in Social Stratification and Mobility, 30(3), 265-279. ten Brummelhuis, L. L., \& Bakker, A. B. (2012). A resource perspective on the work-home interface: The work-home resources model. American Psychologist, 67(7), 545-556.

Vaiman, V., \& Brewster, C. (2014). How far do cultural differences explain the differences between nations? Implications for HRM. The International Journal of Human Resource Management, 26(2), 151-164.

van Vianen, A. E. M. (1987). Het selektie-interview. Over de rol van sekse-stereotypen [The selection interview. The role of gender stereotyping]. . (PhD thesis), Leiden University, Leiden, the Netherlands.

Wagena, E., \& Geurts, S. A. E. (2000). SWING. Ontwikkeling en validering van de" Survey Werk-thuis InterferentieNijmegen.". Gedrag \& Gezondheid: Tijdschrift voor Psychologie en Gezondheid, 28(3), 138-157.

Ware Jr, J. E., \& Sherbourne, C. D. (1992). The MOS 36-item short-form health survey (SF-36): I. Conceptual framework and item selection. Medical care, 473-483. 


\section{Work-home interface in a cross-cultural context \\ A framework for future research and practice}




\section{Abstract}

With dual-income families on the increase, combining work and family obligations is a daily reality for many individuals. Unsatisfactory combinations of work and home duties can result in various unfavourable individual and organisational outcomes, therefore its proper understanding is essential in order to create adequate recommendations for interventions and prevention. There is a need to develop theoretical frameworks that would include cultural context and other domains into account in relation to work-home interface (Gelfand and Knight 2005). In this paper a new framework is proposed: 'the pyramid of intersecting domains of work-home interface' that incorporates cultural context and other important work-life interface aspects. It builds on empirical findings of the intersectionality (Crenshaw, 1989) and work/family border theories (Clark, 2000). The pyramid consists of four domains: the domain of work and home characteristics, the roles domain and the cultural domain. These three domains intersect to determine the fourth, observed workhome interface domain. Recommendations for implementation and usage of the framework for researchers and policy makers are provided.

Keywords: work-home research framework; work-home interface; cross-cultural; intersectionality; work/family border theory 


\section{Work-home interface: The importance of cultural context}

Over the last few decades, the number of dual earner families has increased globally, and this has been accompanied by a greater speed of life. Consequently, combining work and home duties has become an important issue and has been extensively studied (Gelfand \& Knight, 2005). However, theoretical frameworks that would incorporate individual, organisational and socio-cultural findings relevant for cross- cultural research are lacking (Poelmans, 2005). Work-home interface (WHI) refers to the effect of work on home sphere of life and vice versa. According to Grzywacz and Marks (2000), when work duties are conflicting with the duties at home, work-home conflict (WHC) occurs, while when home environment is interfering with fulfilment of work related duties, home-work conflict (HWC) is experienced. Positive impact from work on home sphere of life is referred to as workfamily enhancement and from home to work sphere of life as home-work enhancement. Workhome interface (WHI) is an umbrella term for all these different interactions between work and home spheres of life (Grzywacz \& Marks, 2000). When conflicts between work and home arise, they can adversely affect health and manifest as depression, cardiovascular complaints or burnout, for instance (Allen, Herst, Bruck, \& Sutton, 2000). Poor work-home interface is also related to undesirable organizational outcomes such as higher turnover rates and poor job satisfaction (Eby, Casper, Lockwood, Bordeaux, \& Brinley, 2005).

This paper strives to advance the field of cross-cultural research by building on existing theories and knowledge to propose a framework of work-home interface that takes into account work and home characteristics, roles and cultural context when examining work-home interface.

In trying to explain work-home interface, research has mostly focused on factors in the environment of the person, such as work and home characteristics and only rarely were they joined with other factors, such as roles and cultural context. Work-home interface is affected by social roles and perception of roles. For instance, the way men and women combine work and home roles may differ depending on their gender role ideologies and their beliefs and norms of appropriate division of work and home tasks (Galovan, Fackrell, Buswell, Jones, Hill, \& Carroll, 2010). Research has supported this statement, showing that men and women's gender identities can differently impact the combination of work and home duties (Emslie \& Hunt, 2009) and it can also be differentially associated with health outcomes (Houkes, Winants, \& Twellaar, 2008). Gender and cultural context are associated with each other (Gelfand \& Knight, 2005; Mortazavi, Pedhiwala, Shafiro, \& Hammer, 2009). In this study we define gender as the social meaning and behaviour associated with the biological sex rather than as a synonym for biological sex (Basow, 2010). An example of the close link between gender and cultural context is that collectivistic countries generally have more traditional gender role ideologies, while more individualistic countries have more egalitarian gender role ideologies (Westman, 2005). To understand and measure the role of cultural context in work-home interface a plea has been made for new theoretical models that take the role of cultural context and other domains into account (Gelfand \& Knight, 2005). Some models have been developed that take cultural aspects into account. For example Powell and colleagues take some specific aspects of 
cultural context into account (individualism/collectivism and humane orientation), while Shaffer and colleagues include culture as a general concept that shapes the experience of work-home interface (Powell, Francesco, \& Ling, 2009; Shaffer, Joplin, \& Hsu, 2011). The strongpoint of these models is the incorporation of aspects of cultural context when measuring work-home interface and in explaining how other variables relate to cultural context to shape work-home interface. However, Shaffer and colleagues, although taking into account personal attributes, do not explicitly position gender in the model, and Powell and colleagues do not examine positive aspects of work-home interface, such as work-home enrichment, and do not give explanations how other cultural aspects besides the two they mention could be accounted for.

The impact of cultural context is not limited to the perception of the work-home interface but may also affect it indirectly through the domains of work and home and roles. The newly proposed framework in this paper includes these issues and allows for a greater number of variables to be accounted for, showing how the model can keep expanding to take into account other variables than the ones we mention. Furthermore, it gives another perspective concerning the interrelationships between the concepts.

In today's globalizing world where multicultural organisations and ex-patriot communities are common, inter-cultural comparability of findings is important. In order to create adequate work and home policies that fit employees in different countries and to set appropriate intervention priorities depending on the specific needs of individuals it is necessary to better understand what exact role cultural context plays.

\section{Theoretical basis of the new framework of work-home interface}

Guided by the research findings that show the relevance of work and home characteristics, individual's roles and cultural context, we propose a new framework of work-home interface. The framework builds on two existing theoretical frameworks, namely the intersectionality framework (Crenshaw, 1989) and the work/family border theory (Clark, 2000) to show how these different aspects of work-home interface combine. We chose these two theories as the building foundations for our framework, since they go beyond simple relationships and expose the complexity of domains and their interactions, while taking into account the wider context and acknowledging interpersonal aspects related to WHI.

Intersectionality posits that (i) different social categories, such as gender, culture or ethnicity are not independent and additive, but intersecting, (ii) there is no primacy of one category over another; the primacy of the categories is context and case dependent, (iii) temporal and historic aspects shape the lived experience and (iv) the social categories intersect with structural forces to shape or determine the health outcomes (Bowleg, 2012; Hankivsky, 2012). By emphasising the intersecting aspects of social categories, intersectionality allows us to identify particularly vulnerable groups concerning work-home interface. For example, previous research has shown that higher socioeconomic status (SES) is associated with better health outcomes, including lower rates of 
homicide. However, this is true for white people and not for black men (Bowleg, 2012), i.e. race and SES intersect. Similar situations may occur for intersections of social categories in relation to work-home interface. Furthermore, positing that primacy of social categories is context and case dependent, makes intersectionality a very good theoretical framework for cross-cultural research. Within the work-home interface particular social categories may play different roles and be of different importance in different cultural contexts. As has been stated by Özbilgin and colleagues

'... patterns of social life are temporally and spatially specific, [thus] the context dependence of the organisation of 'life' needs to be captured by work-life studies (Özbilgin, Beauregard, Tatli, \& Bell, 2010)'. The inclusion of the time aspects and the emphasis on the context are important contributions of intersectionality for work-home interface research as they allow us to acknowledge that processes change over time and that they are shaped by outside forces such as institutions.

For our framework we also draw on aspects of the work/family border theory (Clark, 2000) which describes work and home as two separate domains with varying border strengths for different people. It states that people are border crossers: they daily cross the borders from work to home and vice versa. Their experience of work-home interface is influenced by the degree of internalisation of the domain's culture, competence and identification with responsibilities and degree of connectedness with others, who internalise the culture, are competent and identify with responsibilities of the domain. Experiences are further influenced by border keepers and other domain members, whose attitudes and beliefs impact the way people feel about each domain and the way they combine work and home. Border keepers are domain members who are influential in defining the domain and its borders, such as spouses for the home domain and supervisors for the work domain. Other domain members have no power over the border crosser, although they may be influential in defining the domain and its borders, such as colleagues in the work domain. When preferences for permeability and flexibility of borders differ between border keepers (spouse, supervisor) and the individual, friction in the work-home interface can be experienced. For example, if an individual prefers flexible working time arrangements and teleworking, but has a supervisor who prefers more strict borders and thus does not allow it, this may create work-home conflict.

\section{New framework: The pyramid of intersecting domains of work-home inter- face}

Based on the existing literature and theory, we developed the new framework of work-home interface called the 'pyramid ${ }^{1}$ of intersecting domains of work-home interface'. This is a triangular based pyramid consisting of four triangles: three sides and the base (Figure 1). The base of the pyramid

1 Note that the figure is in fact a Tetrahedron also known as 'triangular pyramid' of which any of the four faces can be considered the base 
represents the observed work-home interface (4), which is influenced and defined by the three other sides, three intersecting triangles of the pyramid, called domains: the domain of individual work and home characteristics (1), the roles domain (2) and the cultural domain (3). We first provide a short overview of all domains of the pyramid, before describing them more elaborately in the following sections.

The Pyramid

(3-dimensional)

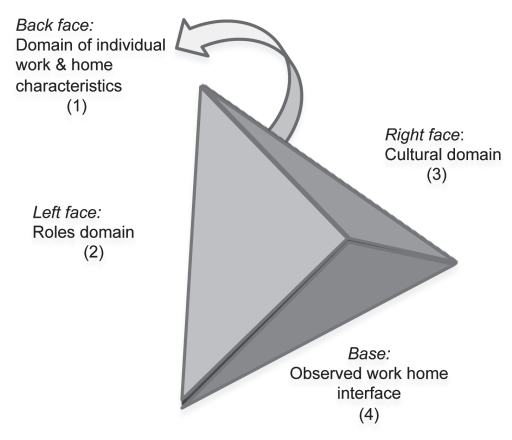

The Pyramid expanded

(2-Dimensional)

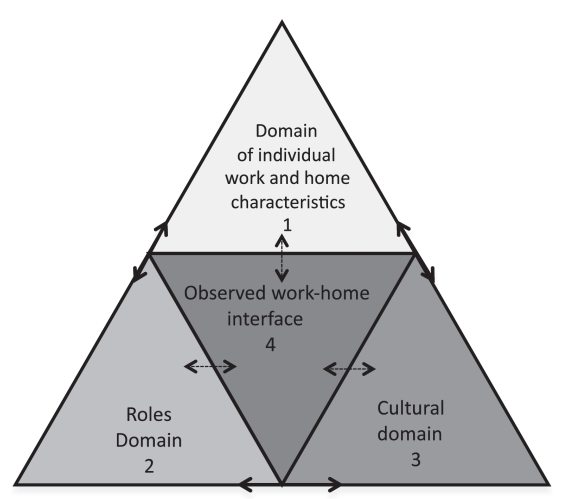

Figure 1 The pyramid of intersecting domains of WHI

The base of the pyramid, observed work-home interface domain refers to the prevalence or incidence of work-home interface. This domain is traditionally explained by work and home characteristics. The domain of individual work and home characteristics includes issues related to the work and home demands and resources and generally represents variables measured at the micro level. This individual level domain is the most commonly studied aspect of work-home interface (Casper, Eby, Bordeaux, Lockwood, \& Lambert, 2007; Eby et al., 2005). Work and home characteristics are important, but not sufficient to explain work-home interface. The roles domain refers to different roles that an individual takes in life and is associated with values, norms and expectations for each of these roles. It also includes interactions with others and their values, norms and expectations concerning individual's roles. Thus, this represents factors related to the interpersonal level. The roles affect the perception of work and home characteristics and also shape expectations of others about the domain of work and home characteristics. The roles domain is also influenced by the cultural domain. The cultural domain refers to wider socio-cultural and organisational factors, including values, norms and expectations concerning the work and home spheres of life. It denotes meso and macro level characteristics. We posit that besides the domain of work and home characteristics, also 
the roles and cultural domains need to be accounted for in order to better understand and explain the observed work-home interface.

Drawing on intersectionality theory, we postulate that the three domains of work and home characteristics, roles and cultural domains intersect with each other. There is no primacy of one domain over another. No one characteristic of the domain or social category is per se more favourable than the other, it is in interaction with other domains that its effect (favourable or unfavourable) is determined. Furthermore, each domain consists of intersecting subdomains and each subdomain could be further divided into other subdomains. Findings based on the pyramid are time-dependent: wider sociocultural context, as well as values and norms can change over time and thus need to be re-evaluated after a period of time. Social categories intersect with social structures and policies in their relation to work-home interface. An illustration of how such an intersection could take place is the finding that policies that provide availability of childcare centers have a different relationship with the level of work-home conflict for male and female parents: for women such availability of childcare is related to lower work-home conflict, while for men no such association is found (Stier, Lewin-Epstein, \& Braun, 2012). Thus, policies intersect with social categories to shape the outcome, work-home conflict, in this case.

Given that the meaning and centrality of work and home spheres of life are influenced by individual's roles and culture, we expand on the work/family border theory to account for this. The proposal is that borders (their strength, permeability and flexibility), and domains (extent of segmentation, integration), are influenced by individual's roles and cultural expectations. Preferences for certain border and domain characteristics are distinctly influenced by culture. For example, some cultural contexts, such as the Netherlands and Sweden favour border flexibility and integration in the form of teleworking, while Southern and Eastern European countries do not (Peters \& den Dulk, 2003). The study by Peters and den Dulk (2003) found that teleworking preferences are correlated with national cultures of power distance and uncertainty avoidance: countries that score low on power distance and uncertainty avoidance tend to implement teleworking, while those high on power distance and uncertainty avoidance do not.

Another proposed extension of the work/family border theory is that expectations of border crossers, border keepers and domain members are influenced by gender and culture to distinctly affect the outcome. For example, in countries with more traditional gender role ideologies, working women are expected to carry on more home demands than in more egalitarian countries (Korabik, Lero, \& Ayman, 2003). These expectations are in turn distinctly related to outcomes. For traditional couples such unequal sharing of home demands is not related to marital disruption, since it is consistent with their expectations, while unequal division of household labour is related to marriage dissatisfaction by egalitarian couples (Greenstein, 1995).

We provide below an example of the pyramid, its subdomains and how they intersect with each other (Figure 2). Since this framework is envisaged as a meta-theory (Walker and Avant 1995), variables in the pyramid do not represent an exclusive list, but rather a pointer for what variables could be included. We call for further research to build on and expand the framework. 


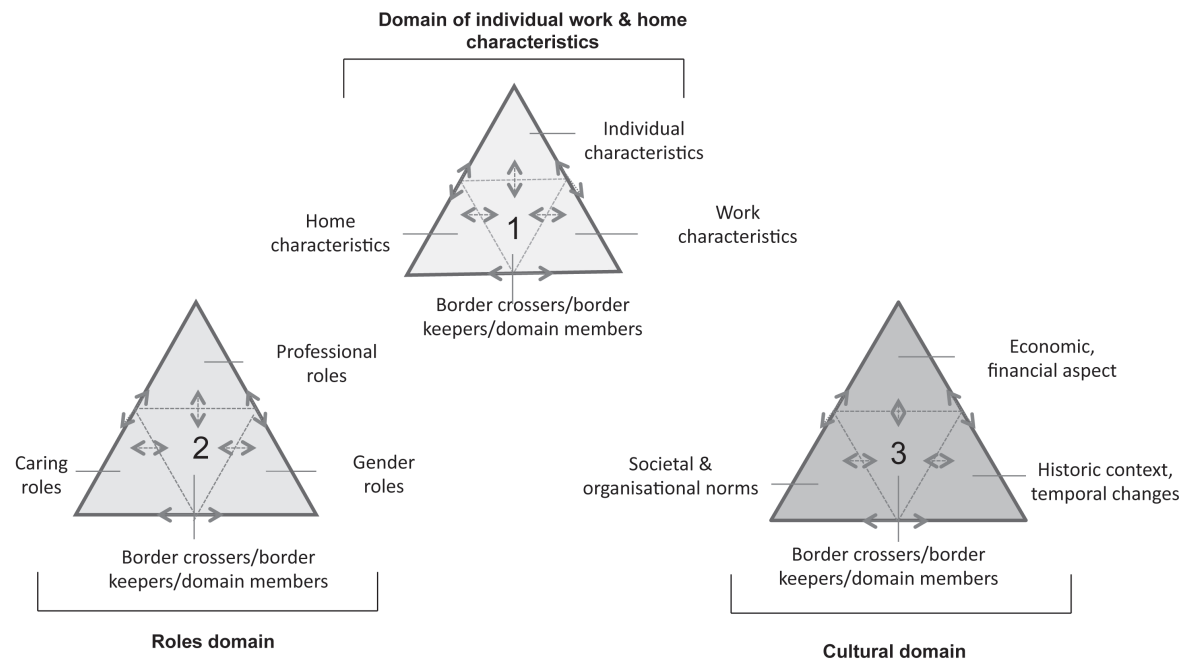

Figure 2 Domains of the pyramid explained

\section{The pyramid of intersecting domains of work-home interface explained}

\section{Domain of individual work and home characteristics (Domain 1)}

This domain is characterised by the work characteristics subdomain which includes demands at work (working hours, psychological and physical demands) and work resources (supervisor support, job control); the family characteristics subdomain which includes family demands (number and age of children) and family resources (partner and family support and such); individual characteristics subdomain (age, sex, personality, coping style); and characteristics of border crossers/border keepers/domain members subdomain. These factors are deemed relevant based on border theory as well as the empirical literature reviews concerning the relationship between determinants and work-home interface (Byron, 2005; Eby et al., 2005). Characteristics of border crossers, border keepers and domain members play a role in shaping the experience with work-home interface.

When comparing the domain of individual work and home characteristics across cultural contexts in relation to work-home interface, it is important to control for differences in other predictors in order to draw correct conclusions. If predictors are not accounted for, the differences in findings may be misleading. For example, a study conducted in Europe found the highest level of work-home conflict among the Swedish sample, however when working hours and job qualifications were controlled for, it turned out they had the same level of WHC as participants from UK and the Netherlands (Strandh \& Nordenmark, 2006). 


\section{Roles domain (Domain 2)}

This domain refers to the roles a person occupies, as well as person's interaction with the people in their surroundings. This interaction is shaped by expectations that are formed on the basis of the roles they occupy. We define this domain as consisting of the following subdomains: gender, professional roles, caring roles and interaction between border crossers/border keepers/domain members based on these roles. These subdomains are included in the roles domain because it is believed that they shape the expectations and preferences of domain members and border keepers, as well as of individuals themselves. In line with the work-family border theory, when preferences of border keepers are in line with those individuals, i.e. their view and expectations concerning what is appropriate for given gender, professional and caring roles, there will be no work-home conflict.

Gender and gender roles have been identified as shaping the way in which the 'objective' and more tangible circumstances are perceived and experienced (Galovan et al., 2010; Greenstein, 1995; Strandh \& Nordenmark, 2006). A study conducted in Europe has found that differences in work-home conflict between Sweden and Hungary or Czech Republic, could not be explained by differences in working conditions (Strandh \& Nordenmark, 2006). Authors indicate that this may be due to differences in gender ideology between these countries: Sweden had the most gender liberal attitudes, while Hungary and the Czech Republic had more traditional gender role attitudes. Considering that in all countries women do more housework than men, Swedish women may perceive this division more unfairly than Hungarian and Czech women, which expresses itself in higher work-home conflict. This finding is further supported by a study that found higher work-home conflict among the progressive gender cultures of Sweden, United Kingdom and the Netherlands than the more traditional gender cultures of the Czech republic, Hungary, Romania and Bulgaria (van der Lippe, Jager, \& Kops, 2006).

Professional roles are also linked to the perception and experience of the work-home interface. Certain professions, such as those whose main aim is to help and support others (e.g. medical and teaching staff) may be particularly under pressure to show strength and deny any expression of distress, which may in the long run impact their family life and health (Miller \& McGowen, 2000).

Caring roles, for example being a partner or a parent and carer in this sense, brings about different work-home interface than when one is single and has no caring obligations towards parents or other family members. Having children is related to work-home interface and the effect of parenting differs for men and women. When there are more parents in a sample, work-home conflict is high particularly for women, whereas when there are less parents in the sample, work-home conflict is particularly high for men (Byron, 2005). Cohabitating women have more household tasks than men across Europe, and this difference is much larger than when men and women are single. Thus, cohabitation decreases household tasks for men, yet increases them for women (Strandh \& Nordenmark, 2006). Work-home interface in relation to childcare is also closely related to gender: women are more likely to adjust their working time arrangements than men in order to take care of the children (Verdonk, 2006; Visser, 2002).

Drawing on the work/family border theory, we postulate that the border crossers/border 
keepers/domain members subdomain represents the interaction between the border crossers and border keepers/domain members based on each other's' expectations of appropriate work and home characteristics. These expectations are influenced by their own gender, professional and caring roles and interact with the other person's roles.

\section{Cultural domain (Domain 3)}

The cultural domain represents the influence of the cultural context: societal and organisational values and norms; economic and financial aspect; historic context and border keepers/domain members' expectations on individuals' experiences of work-home interface. The cultural domain is about differences between cultural contexts, that is, countries, but also about subcultures within a country. We include the societal and organisational values and norms, as well as economic and financial aspects based on the intersectionality framework which states that the social categories (included in domain two of the pyramid) intersect with structural forces, emphasised in this, third domain. Similarly, the historic context is included, based on the intersectionality framework which highlights the importance of temporal and historic aspects.

Societal and organisational values and norms can for instance be captured via different dimensions of Hofstede's cultural work values (Hofstede, 2009). He postulates that countries' (work) cultures can be different on certain dimensions, such as masculinity-femininity, power distance, individualismcollectivism or uncertainty avoidance and that they shape the importance of certain work and home characteristics, as well as influencing overall levels of work-home interface. For example, persons living in individualistic cultures where independence and intimacy in close relationships are valued, may be particularly sensitive to time pressure, in contrast to persons living in more collectivist cultures, where work dedication is perceived as an expression of care for the family members, thus overtime and long working hours may not be evaluated as negatively (Wong \& Goodwin, 2009). A study on Taiwanese and UK samples has shown that predictors and their associations with workhome conflict differ between these two cultural contexts: in Taiwan, a country with large power distance, supervisor support is more important in relation to WHC than in UK, a country with small power distance (Lu et al., 2009).

Economic and financial aspects impact the degree of choice one has over work-home interface. For example, financial situation impacts the amount of working hours. According to Pfau-Effinger, a certain level of affluence is a pre-condition for having the male breadwinner model as a norm (Pfau-Effinger, 1998). There are countries where it is a preference of both partners to work. However, there are also countries where dual earner families exist out of financial necessity, and in these cases labour participation is not a matter of choice, but a need. If unemployment is high, chances for accepting any paid work, regardless of its' conditions are more likely than when unemployment is low.

The historical background and the time in which work and home spheres of life are combined affect the preferred way of work-home interface as well. The societal expectations of work-home interface can change over time, when the wider societal and economic circumstances change. For 
example, increased costs of childcare may lead to decreased labour participation (of women), and thus create different preferences for the optimal work-home interface than during the times when childcare is more affordable. When macro level changes are in the opposite direction of the cultural values, they may lead to work-home conflict (Joplin, Shaffer, Francesco, \& Lau, 2003).

The relation between border crossers and border keepers/domain members is influenced by the societal expectations concerning work and home spheres of life. The degree to which work and home spheres of life are expected to be integrated or separated is influenced by cultural context (Ashforth, Kreiner, \& Fugate, 2000), both organisational and societal. Ashforth and colleagues make a link between Hofstede's work values and degree of integration and segmentation: persons living in collectivist, feminine, low uncertainty avoidance and low power distance countries are expected to favour integration between work and home spheres of life, while those living in individualistic, masculine, high uncertainty avoidance and large power distance countries are expected to favour segmentation between work and home spheres of life. Furthermore, the point at which a particular work-home interface is experienced negatively may vary between cultural contexts. There is some indication that in different cultural contexts, thresholds for reporting problems are higher than in other cultural contexts (Madan, Reading, Palmer, \& Coggon, 2008). It may also be that participants with the same level of WHI respond to items differently, due to their cultural background differences (differential item functioning).

\section{Observed work-home interface (Domain 4)}

The observed work-home interface represents the findings regarding the prevalence or incidence of different aspects of work-home interface (work-home conflict, home-work conflict, work-home enhancement and/or home-work enhancement) that is measured by current instruments, such as those developed by Netemeyer and colleagues, Carlson and colleagues and Geurts and colleagues (Carlson, Kacmar, \& Williams, 2000; Geurts, Taris, Kompier, Dikkers, van Hooff, \& Kinnunen, 2005; Netemeyer, Boles, \& McMurrian, 1996). As mentioned, the observed work-home interface is influenced by the domain of work and home characteristics, roles and culture. Drawing on intersectionality, it is posited that these three domains intersect to determine this fourth domain: observed work-home interface. However in most current research the factors influencing this observed work-home interface are generally narrowly defined, focusing mainly on work and home characteristics, leaving the impact of roles and cultural aspects unaccounted for (Poelmans, 2005). Since all three domains impact on work-home interface, they should be empirically incorporated in the studies. It is in this way that the Observed work-home interface is captured more adequately, allowing for better comparison of findings across cultural contexts. Furthermore, to understand the meaning of work-home interface in different cultural contexts, we need to supplement it with findings originating from qualitative research. 


\section{Added value of the pyramid as a framework for research and practice}

\section{Research guidelines}

The pyramid expands the definition of work-home interface beyond work and home characteristics. It shows that individual work and home characteristics, roles and cultural domains intersect, influencing each other in specific ways. These intersections imply that these individual (domain of work and home characteristics), interpersonal (roles domain) and meso and macro levels (cultural domain) need to be considered simultaneously. Failing to account for aspects of these three domains leads to difficulties in interpretation or even misinterpretation of the observed work-home interface and cross-cultural comparisons with respect to work-home interface.

In the newly developed framework, each side of the pyramid is influenced/ determined by three other sides. In future research, any of the four faces of this 'triangular pyramid' can be considered the base. Therefore, the model can also be used for a better understanding of the other domains. For instance, the observed work- home interface may contribute to a better insight of the cultural domain.

In line with the intersectionality framework, there is no hierarchy in the pyramid, and no hypotheses regarding which aspects of domains are good or bad. This is a strength of the framework, since it allows for seeing the complex relationships without giving predetermined preference or 'weight' to some issues more than others. It is in interactions that the relevance of the variable and its effect are determined.

Some basic and practical pointers for future researchers using the pyramid in their empirical research are:

1 Be culturally sensitive-Researchers should be alert to various factors that are relevant for work-home interface given the cultural context. Some factors may be the same across cultures (etic), while some others may only be relevant for certain cultures (emic). It appears that work and home resources are negatively associated with work-home conflict and that high job demands are positively associated with it across cultural contexts (Lu et al., 2009; Shaffer et al., 2011). In line with the intersectionality framework, we call on researchers to be sensitive to the fact that some variables may be more important or relevant in some countries and less in others and may intersect with each other, thus changing the outcome. For example, research conducted in Taiwan and Britain has shown that supervisor support was negatively associated with work-home conflict in both countries, but that the relationship was stronger in Taiwan than Britain (Lu et al., 2009). Furthermore, besides the impact that these variables have, their meaning, may differ as well. What may be a facilitating variable, or a resource, in one country may be a constraining, demanding factor in another (Shaffer et al., 2011). The same is true for the roles domain: every individual faces some constraints based on his/her gender, professional roles, caring roles and interaction with border keepers/domain members, that is shaped and influenced by the cultural context. Thus, to summarise, factors in the aetiology of work-home conflict in one cultural context may not be readily transferred to another. This has important implications for generalisation of findings across cultural contexts. To grasp 
the most important determinants, their relevance and meaning across different cultural contexts, a combination of quantitative and qualitative methods may yield the most insightful results. At the moment we are cautious in naming precise variables, other than the general resources and demands, along with the incorporation of the roles domain as well as the cultural domain in general for understanding of work-home interface across different (sub)cultural contexts.

2 Methodological aspects- In order to interpret correctly the associations and strength of relationships between variables in relation to work-home interface across countries, sample sizes of datasets should be similar. In some current cross-cultural research, sample sizes vary (such as in studies by (Galovan et al., 2010; Janssen, Peeters, de Jonge, Houkes, \& Tummers, 2004; Lu, Gilmour, Kao, \& Huang, 2006). For example, psychological demands were found to be less strongly related to work-home conflict in the United States than in the Dutch sample (Janssen et al., 2004) and workplace flexibility was found to be less strongly related to home-work conflict in the US than Singapore (Galovan et al., 2010). Since in these studies larger samples showed stronger associations, it is hard to interpret the findings: larger sample sizes have a greater chance of having significant results in associations between study variables. It is recommended to use similar sample sizes (such as in studies by (Spector et al., 2007; Wang, Lawler, Walumbwa, \& Shi, 2004) to prevent potentially spurious differences in WHI between cultural contexts.

The pyramid also points to the relevance and necessity of conducting both quantitative and qualitative studies. Mixed method studies would be the optimal way to fully grasp and understand the observed work-home interface. Qualitative studies give us insight into the meaning that workhome interface has for people living in different cultural contexts, how they negotiate work and home spheres and also the degree of choice they have in determining both home and work areas of life. On the other hand, quantitative studies allow us to quantify the problem areas by calculating the prevalence of various aspects of work-home interface. Together, they create the fuller understanding of the work-home interface across cultural contexts.

We also reflect on some guidelines with examples for testing the different domains of the pyramid. In order to be able to compare the level of work-home interface properly, predictors of work-home interface situated in the domain 1 of the pyramid need to be controlled for (see the results of Strandh and Nordenmark 2006). To understand the meaning of different levels of workhome interface, and different demands and resources across cultural contexts, qualitative studies are called for. Some of the aspects that could be tested quantitatively in the roles domain include gender role orientation (masculinity and femininity) and gender role attitudes (traditional vs egalitarian), professional roles and norms (caring, empathy) as well as caring duties (being a parent, carer of an extended family member or a neighbour). Existing scales, such as for example a masculinity and femininity scales by van Vianen (van Vianen, 1987) could be used to test role orientation and other roles aspects. Qualitative studies would help catch the breadth of each of these roles and help in its culture-specific definition, as sometimes the quantitative approach falls short to fully capture the richness of the aspects examined.

Sample's culture (domain 3 of the pyramid) should be explicitly measured. In empirical research, 
when culture is included as a variable, it is often equated with nation, or cultural differences between the samples are taken for granted based on country's cultural differences as found in in Hofstede's studies (Hofstede, 2009). We propose that in the future research, cultural differences be tested to check that indeed the samples are culturally different. This could be done by checking the sample's cultural work values via the values survey module of Hofstede (Hofstede, 2008). An example of testing cultural values can be found in a study of Mortazavi and colleagues, who examined cultural values of horizontal individualism and collectivism in an Iranian, American and Ukrainian sample when assessing work-family conflict (Mortazavi et al., 2009).

3 Time aspects -Many variables that are found in different domains affecting work-family interface may change over time. Work-home interface is highly dependent on wider societal and economic changes, as well as values and norms, that often differ between generations. In longitudinal observational studies these changes over time can be used to disentangle cause and effect relations. However, one should be aware of the fact that relations within and between different domains may follow a different time course of cause and effect. For instance, norms and values may take years to change, while certain work characteristics e.g. job demands may change within months. To avoid window and selection effects the time window should therefore be chosen very carefully.

Moreover, variables that are found in the different domains may be interrelated. In longitudinal studies this problem of multicollinearity can, at least partially, be avoided by conducting stratified analyses.

4 Prevention and intervention- The surveys created by organisations to monitor employee's health and well-being should include not only aspects of work and home characteristics, but also gender roles and wider cultural beliefs about appropriate division of work and home duties. Regular check-ups by a company physician could be offered for people who are suffering from, or are identified as being at a higher risk for work-home conflict. These check-ups should include all aspects of the domains of the pyramid and keep in mind the facilitating or constraining role of supervisors themselves as border keepers in this process. Occupational health practitioners could use the pyramid to signal and identify culture and organisation-specific determinants relevant for work-home interface of their employees. The (potentially) unfavourable aspects of these determinants could then be tackled in the organisation's prevention and intervention guidelines. The pyramid can also be applied to study, interpret and evaluate the effect of intervention studies. In designing intervention studies it can help us to consider and select the proper variables and outcomes. In the analysis of intervention studies it can help us understand which aspects of intervention are useful for different groups of people and why. Furthermore, the pyramid can also be used as a communication tool. Multidisciplinary teams can use the pyramid to guide discussions between members from different disciplines, concerning the design of prevention policies or intervention studies. With the help of the pyramid different disciplines can see the added value of each discipline for understanding work-home interface. 


\section{Policy recommendations}

Recommendations for policy members would be to create policies that are taking into consideration various intersections of the work and home, roles and cultural domain concerning work-home interface. This implies that policies covering broad groups of persons (based solely on their work subdomain, gender or culture) are likely to be ineffective, since it is in the intersections of these categories that different experiences are created, that requiring different approaches. Furthermore, policies should be evaluated after a number of years to ensure that they are still relevant, given the temporal aspect.

\section{Concluding remarks}

Work-home interface is a multifaceted concept. Thus, conducting research and creating policies that account for all aspects of work-home interface specified in the pyramid is complex. It requires an intersectional approach in order to understand how different aspects influence each other. Research requires extensive data sources from different cultural contexts based on both quantitative and qualitative approaches and complex tailor-making when it comes to policies. However, by envisaging work-home interface through the pyramid, even when researchers do not include all aspects of it in their research, they are aware which aspects were included and which not and could thus not be account for. Thus, the pyramid can be used to answer subquestions concerning work-home interface. For example, only the roles domain may be examined, or even a smaller part, such as an intersection of caring roles and gender roles subdomains in relation to work-home interface may be examined. In this way the 'blind' spots of the study are made explicit and help with interpretation of the findings. Similarly, the policy makers may not take all aspects of the pyramid into account when writing the policy documents, but the pyramid would help them become aware of which groups of people may be excluded from benefitting fully from the policies. The pyramid can be used to understand workhome interface across cultures, but also to understand differences between subcultures of one country, such as different minority groups based on nationality, ethnicity, race or sexual orientation. Probably the pyramid can also be used as an inspiration for studying other constructs that include culture, such as the health outcomes. In this way the pyramid and its emphasis on intersectionality may have a potential in other fields of social science. 


\section{References}

Allen, T. D., Herst, D. E. L., Bruck, C. S., \& Sutton, M. (2000). Consequences associated with work-to-family conflict: A review and agenda for future research. Journal of occupational health psychology, 5(2), 278308.

Ashforth, B. E., Kreiner, G. E., \& Fugate, M. (2000). All in a Day's Work: Boundaries and Micro Role Transitions. The Academy of Management Review, 25(3), 472-491.

Basow, S. A. (2010). Changes in psychology of women and psychology of gender textbooks (1975-2010). Sex Roles, 62(3), 151-152.

Bowleg, L. (2012). The problem with the phrase women and minorities: Intersectionality-an important theoretical framework for public health. American journal of public health, 102(7), 1267-1273.

Byron, K. (2005). A meta-analytic review of work-family conflict and its antecedents. Journal of Vocational Behavior, 67(2), 169-198.

Carlson, D. S., Kacmar, K. M., \& Williams, L. J. (2000). Construction and initial validation of a multidimensional measure of work-family conflict. Journal of Vocational Behavior, 56(2), 249-276.

Casper, W. J., Eby, L. T., Bordeaux, C., Lockwood, A., \& Lambert, D. (2007). A review of research methods in IO/OB work-family research. Journal of Applied Psychology, 92(1), 28-43. doi: 10.1037/0021-9010.92.1.28

Clark, S. C. (2000). Work/family border theory: A new theory of work/family balance. Human Relations, 53(6), 747-770.

Crenshaw, K. (1989). Demarginalizing the intersection of race and sex: A Black feminist critique of antidiscrimination doctrine, feminist theory and antiracist politics. University of Chicago Legal Forum, 139, 139-167.

Eby, L., Casper, W., Lockwood, A., Bordeaux, C., \& Brinley, A. (2005). Work and family research in IO/OB: Content analysis and review of the literature (1980-2002). Journal of Vocational Behavior, 66, 124-197.

Emslie, C., \& Hunt, K. (2009). 'Live to work' or 'Work to live'? A qualitative study of gender and work-life balance among men and women in mid-life. Gender, Work \& Organization, 16(1), 151-172.

Galovan, A. M., Fackrell, T., Buswell, L., Jones, B. L., Hill, E. J., \& Carroll, S. J. (2010). The work-family interface in the United States and Singapore: Conflict across cultures. Journal of family psychology, 24(5), 646-656.

Gelfand, M., \& Knight, A. (2005). Cross-cultural perspectives on work-family conflict. In S. A. Y. Poelmans (Ed.), Work and family: An international research perspective (pp. 401-414). London: Lawrence Erlbaum Associates.

Geurts, S. A. E., Taris, T. W., Kompier, M., Dikkers, J. S. E., Van Hooff, M. L. M., \& Kinnunen, U. M. (2005). Work-home interaction from a work psychological perspective: Development and validation of a new questionnaire, the SWING. Work \& Stress, 19(4), 319-339.

Greenstein, T. N. (1995). Gender ideology, marital disruption and the employment of married women. Journal of Marriage and Family, 57(1), 31-42.

Grzywacz, J. G., \& Marks, N. F. (2000). Reconceptualizing the work-family interface: An ecological perspective on the correlates of positive and negative spillover between work and family. Journal of occupational health psychology, 5(1), 111-126.

Hankivsky, O. (2012). Women's health, men's health, and gender and health: implications of intersectionality. Social Science \& Medicine, 74(11), 1712-1720. 
Hofstede, G. (2008). Values Survey Module 2008 questionnaire. Retrieved 1909 2009, from http://www. geerthofstede.eu/vsm-08

Hofstede, G. (2009). Country comparison. Retrieved 0704 2011, from http://geert-hofstede.com/countries.html

Houkes, I., Winants, Y., \& Twellaar, M. (2008). Specific determinants of burnout among male and female general practitioners. A cross-lagged panel analysis. Journal of Occupational and Organisational Psychology, 81, 249276.

Janssen, P. P. M., Peeters, M. C. W., de Jonge, J., Houkes, I., \& Tummers, G. E. R. (2004). Specific relationships between job demands, job resources and psychological outcomes and the mediating role of negative workhome interference. Journal of Vocational Behavior, 65(3), 411-429.

Joplin, J. R. W., Shaffer, M. A., Francesco, A. M., \& Lau, T. (2003). The macro-environment and work-family conflict: Development of a cross cultural comparative framework. International Journal of Cross Cultural Management, 3(3), 305-328.

Korabik, K., Lero, D. S., \& Ayman, R. (2003). A multi-level approach to cross cultural work-family research: A micro and macro perspective. International Journal of Cross Cultural Management, 3(3), 289-303.

Lu, L., Gilmour, R., Kao, S. F., \& Huang, M. T. (2006). A cross-cultural study of work/family demands, work/family conflict and wellbeing: the Taiwanese vs British. Career Development International, 11(1), 9-27.

Lu, L., Kao, S. F., Cooper, C. L., Allen, T. D., Lapierre, L. M., O’Driscoll, M., ... Spector, P. E. (2009). Work resources, work-to-family conflict, and its consequences: A Taiwanese-British cross-cultural comparison. International Journal of Stress Management, 16(1), 25-44.

Madan, I., Reading, I., Palmer, K. T., \& Coggon, D. (2008). Cultural differences in musculoskeletal symptoms and disability. International journal of epidemiology, 37(5), 1181-1189.

Miller, M. N., \& McGowen, K. R. (2000). The painful truth: Physicians are not invincible. Southern Medical Journal, 93(10), 966-973.

Mortazavi, S., Pedhiwala, N., Shafiro, M., \& Hammer, L. (2009). Work-family conflict related to culture and gender. Community, Work \& Family, 12(2), 251-273.

Netemeyer, R., Boles, J., \& McMurrian, R. (1996). Development and validation of Work-Family Conflict and Family-Work Conflict Scales* 1. Journal of Applied Psychology, 81(4), 400-410.

Özbilgin, M. F., Beauregard, T. A., Tatli, A., \& Bell, M. P. (2010). Work-life, diversity and intersectionality: A critical review and research agenda. International Journal of Management Reviews, 177-198. doi: 10.1111/j.14682370.2010.00291.x

Peters, P., \& den Dulk, L. (2003). Cross cultural differences in managers' support for home-based telework: A theoretical elaboration. International Journal of Cross Cultural Management, 3(3), 329-346.

Pfau-Effinger, B. (1998). Gender cultures and the gender arrangement-a theoretical framework for crossnational gender research. Innovation: The European Journal of Social Science Research, 11(2), 147-166.

Poelmans, S. (2005). Organisational research on work and family: Recommendations for future research. In S. A. Y. Poelmans (Ed.), Work and family: An international research perspective (pp. 439-462). London: Lawrence Erlbaum Associates.

Powell, G. N., Francesco, A. M., \& Ling, Y. (2009). Toward culture-sensitive theories of the work-family interface. Journal of Organizational Behavior, 30(5), 597-616. 
Shaffer, M. A., Joplin, J. R. W., \& Hsu, Y. S. (2011). Special review article: Expanding the boundaries of work-family research: A review and agenda for future research. International Journal of Cross Cultural Management, 11(2), 221-268.

Spector, P. E., Allen, T. D., Poelmans, S. A. Y., Lapierre, L. M., Cooper, C. L., O’Driscoll, M., . . Beham, B. (2007). Cross national differences in relationships of work demands, job satisfaction, and turnover intentions with work-family conflict. Personnel Psychology, 60(4), 805-835.

Stier, H., Lewin-Epstein, N., \& Braun, M. (2012). Work-family conflict in comparative perspective: The role of social policies. Research in Social Stratification and Mobility, 30(3), 265-279.

Strandh, M., \& Nordenmark, M. (2006). The interference of paid work with household demands in different social policy contexts: perceived work-household conflict in Sweden, the UK, the Netherlands, Hungary, and the Czech Republic. The British Journal of Sociology, 57(4), 597-617.

van der Lippe, T., Jager, A., \& Kops, Y. (2006). Combination pressure: The paid work-family balance of men and women in European countries. Acta Sociologica, 49(3), 303-319. doi: 10.1177/0001699306067711

van Vianen, A. E. M. (1987). Het selektie-interview. Over de rol van sekse-stereotypen [The selection interview. The role of gender stereotyping]. (PhD thesis), Leiden University, Leiden, the Netherlands.

Verdonk, P. (2006). 'Ik wil er gewoon voor ze zijn' ['I just want to be there for them']. Lover, 1, 4-6.

Visser, J. (2002). The first part-time economy in the world: A model to be followed? Journal of European Social Policy, 12(1), 23-42.

Wang, P., Lawler, J. J., Walumbwa, F. O., \& Shi, K. (2004). Work-family conflict and job withdrawal intentions: The moderating effect of cultural differences. International Journal of Stress Management, 11(4), 392-412.

Westman, M. (2005). Cross-cultural differences in crossover research. In S. A. Y. Poelmans (Ed.), Work and family: An international research perspective (pp. 241-260). London: Lawrence Erlbaum Associates.

Wong, S., \& Goodwin, R. (2009). The impact of work on marriage in three cultures: A qualitative study. Community, Work \& Family, 12(2), 213-232. 


\section{4}

\section{Cultural context and gender roles matter}

Work-home interface among professionals in Malta, Serbia and the Netherlands 


\section{Abstract}

This article explores how professionals in Malta, Serbia and the Netherlands combine work and home domains. The findings are based on 25 interviews with men and 33 interviews with women that were analysed using an interpretative phenomenological approach. Results show that cultural context and gender roles, as well as age and socioeconomic position intersect to make an impact on the negotiation of work and home domains. Four groups of people were identified that differed from each other with regards to work centrality and family values: (1) Striving for gender equality group; (2) Work domain equality with financial constraints group; (3) Transitional roles with family values constraints group and (4) Traditional roles with work values constraints group. The findings demonstrate the complexity of relationships between the cultural context and gender roles concerning work-home interface. They also highlight the need of exploring the roles of generational differences and socioeconomic position. The broad approach of 'one size fits all' of the European policies do not appear to be appropriate for work-home interface issues. Policies should be developed to take into account the cultural context and gender roles and be evaluated periodically to ensure their effectiveness.

Keywords: cultural context, gender, professionals, work-home interface 


\section{Introduction}

Work-home interface (WHI) refers to the process of combining work and home domains, which includes both positive and negative aspects of work on home domains and vice versa (Grzywacz \& Marks, 2000). The work-home interface is affected by work and home characteristics (Byron, 2005; Michel, Kotrba, Mitchelson, Clark, \& Baltes, 2011) as well as by the meanings and expectations that people associate with the combining of work and home domains (Galovan, Fackrell, Buswell, Jones, Hill, \& Carroll, 2010). Work-home interface is also affected by societal beliefs, values and norms and institutional frameworks of the country where people live (Camilleri-Cassar, 2005; van der Lippe, Jager, \& Kops, 2006), as well as by gender values and norms (Strandh \& Nordenmark, 2006). Gender prescribes roles, tasks, and characteristics for men and women, influencing the expectations concerning work and home domains. This implies that the meaning, as well as the preferred way of organizing work and home spheres of life, may differ substantially between cultural contexts and between men and women. It also means that findings from particular cultural contexts may not be applicable to different settings and may have a different impact on men and women. Some authors already indicate that local adaptations of policies and guidelines are needed in order to reach desired (health) outcomes (Engel, Van Hoyweghen, \& Krumeich, 2014). To date, a lot of research and theory on work-home interface originates from the western world (Shaffer, Joplin, \& Hsu, 2011) and we do not know to what extent these findings are generalisable to other cultural and gendered contexts. Given that in the European Union (EU) there is a tendency towards convergence of policies (Eurofound, 2014a), it is relevant to explore whether such uniformity in approaches and policies should actually be strived for. If uniform policies are applied, when in fact there is a need for a more locally-tailor made approach, it would mean that they would not be effective or perhaps be even counter effective. Thus, the interplay of culture and gender needs to be further explored in order to understand the work-home interface better and to design better policies.

Gender defines culture and culture defines gender - these identities shape each other reciprocally and occur as situated accomplishments (Acker, 2005). The societal and structural level on the one hand and the social and psychological level on the other hand are interrelated systems. In this study we strive to link the social to the structural by acknowledging that culture, gender, as well as work-home interface are socially constructed, contextualized, and involve material, ideological and psychological elements. By analyzing these aspects together we wish to understand the lived experiences of women and men, the processes that set the conditions for their lives, and to avoid an essentialist view of men and women, and of cultures (Acker, 2005). Ultimately, we strive to contribute to policies which facilitate working populations' diversity in needs and approaches to work-home interface. If policies for work-home interface do not facilitate the working population's needs, unfavourable effects may be experienced. For example, if work and home duties cannot be combined appropriately, the person may exit the labour market, decrease his or her number of working hours or experience stress and unfavourable health outcomes as well as decreased productivity (Eurofound, 2014a). 
In this study, we include the still underexplored European cultural contexts of Malta and Serbia, which are examined alongside the Dutch context. The three countries differ in many respects; gender differences in labour market participation are reported, and men and women juggle work and home within different value and normative systems. These countries also differ on Hofstede's values dimensions, which have often been used to describe differences in cultures and were found to be related to differences in work-home interface, occupational and health outcomes (Lu, Gilmour, Kao, \& Huang, 2006; Lu et al., 2009; Masuda et al., 2012; Spector et al., 2007; Spector et al., 2004). A high power distance culture implies that people prefer inequality and large distance between supervisors and employees while a low power distance means that people value more equality between supervisors and employees (Hofstede, 1991). People in high masculinity countries value competitiveness more often while people in countries scoring low on masculinity prefer tenderness more often. Table 1 summarises the differences between the three cultural contexts in this study. Persons working in healthcare and teaching professions are known for facing high emotional and work demands (Drago, 2001; Lewis, 2003) and were chosen as the target group.

It is known that cultural aspects such as affordability of childcare and gender equality are related to work-home interface (Eurofound, 2014b). What is not understood is how particular intersections of culture and gender may produce unique outcomes concerning work-home interface. The aim of this study was to explore how cultural context and gender are related to combining paid labour participation (work domain) and childcare (home domain) in Malta, Serbia and the Netherlands, and provide recommendations for future research and policy. The following research question was formulated: How are cultural context and gender roles related to combining work and home domains among male and female professionals in Malta, Serbia and the Netherlands? 
Table 1 Differences between the three cultural contexts of Malta, Serbia and the Netherlands

\begin{tabular}{|c|c|c|c|}
\hline Topic & Malta & Serbia & The Netherlands \\
\hline Geographical region & Mediterranean & South-East European & Northern European \\
\hline Membership to the EU & Member since 2004 & $\begin{array}{l}\text { Status of the candidate } \\
\text { country since } 2012\end{array}$ & Founding member \\
\hline Dominant religion & Catholic $(>90 \%)^{a}$ & Orthodox $(84 \%)^{b}$ & $\begin{array}{l}\text { Catholic }(24.6)^{\mathrm{c}} \\
\text { Protestant }(14.8)^{\mathrm{c}}\end{array}$ \\
\hline $\begin{array}{l}\text { Purchasing power index } \\
\text { (New York=100) }\end{array}$ & $92.33^{d}$ & $31.92^{d}$ & $100.29^{d}$ \\
\hline \multicolumn{4}{|l|}{ Employment rate } \\
\hline men & $74 \%{ }^{e}$ & $52 \%^{\dagger}$ & $80 \%^{9}$ \\
\hline women & $41 \%{ }^{\mathrm{e}}$ & $38 \%^{\dagger}$ & $70 \%^{9}$ \\
\hline \multicolumn{4}{|l|}{ Flexible working time schedules } \\
\hline men & $16.9 \%^{\mathrm{h}}$ & No data & $35.2 \%^{\mathrm{h}}$ \\
\hline women & $17.0 \%^{\mathrm{h}}$ & No data & $16.9 \%^{h}$ \\
\hline \multicolumn{4}{|l|}{ Part-time employment } \\
\hline men & $5.7 \%^{9}$ & No data & $24.9 \%^{9}$ \\
\hline women & $26.0 \%^{9}$ & No data & $76.9 \%^{9}$ \\
\hline Use of childcare centers & $<19 \%$ & $48 \%$ & $60 \%{ }^{k}$ \\
\hline $\begin{array}{l}\text { Birth-rate (births per year per } \\
1000 \text { people) }\end{array}$ & $10.27^{1}$ & $9.15^{\prime}$ & $10.85^{\prime}$ \\
\hline Power distance values & Highm $^{m}$ & High $^{n}$ & Low $^{m, n}$ \\
\hline Masculinity/femininity values & $\mathrm{High}^{\mathrm{m}}$ & Low $^{n}$ & LoW $^{m, n}$ \\
\hline
\end{tabular}

Note: ${ }^{\mathrm{a}=}(\mathrm{CIA}, 2011) ;{ }^{\mathrm{b}=}($ USDP, 2011); $\mathrm{c}=($ Knippenberg, 2005) $; \mathrm{d}=($ Numbeo, 2011); $\mathrm{e}=(\mathrm{NSOM}, 2012) ; \mathrm{f}=($ SORS, 2012); $\mathrm{g}=($ Teichgraber,

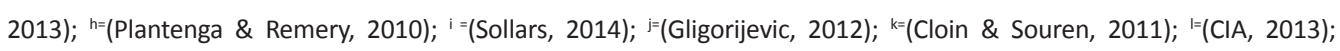
$\mathrm{m}=\left(\right.$ Hoppe, 1990); ${ }^{\mathrm{n}=}$ (Hofstede, 1980)

\section{Theoretical background}

In this article, work-home interface is positioned in the framework of the pyramid of intersecting domains of work-home interface (Putnik, Houkes, Jansen, Nijhuis \& Kant, submitted). The pyramid (Fig. 1) builds on the intersectionality framework (Crenshaw, 1989) and work/family border theory (Clark, 2000). Persons have multiple group memberships such as race, ethnicity, or socioeconomic position, to name a few. Intersectionality posits that there is no social category that is (dis) advantageous per se, but that each category needs to be examined in the context of other variables to understand their impact on a certain outcome. The framework of intersectionality discourages from giving primacy to certain social dimensions over others, and advocates for examination of various dimensions simultaneously (Hankivsky, 2012). Furthermore, intersectionality emphasizes that dimensions examined are fluid and interactive, and acknowledges the time and place at which the examination takes place (Hankivsky, 2012). 
The Pyramid

(3-dimensional)

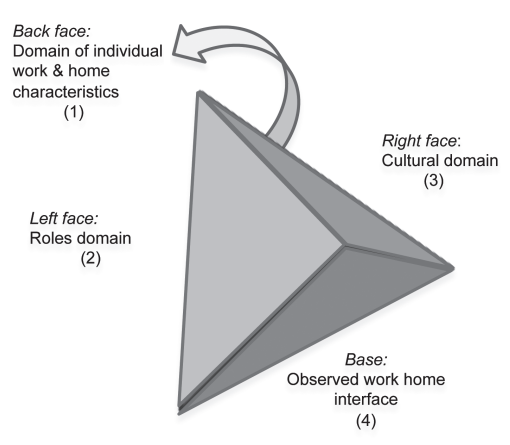

The Pyramid expanded

(2-Dimensional)

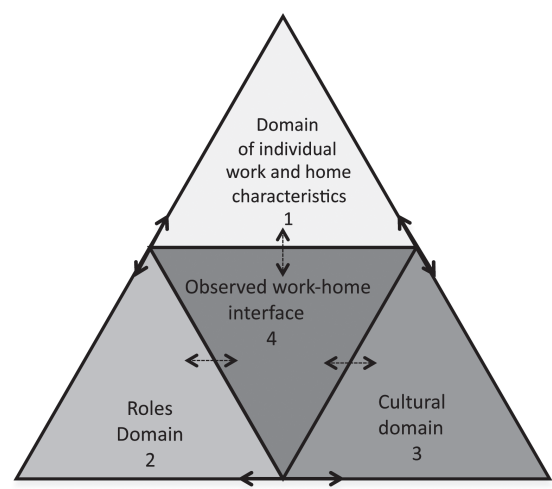

Figure 1 The pyramid of intersecting domains of work-home interface

Work/family border theory (Clark, 2000) centers on four main elements: work and home domain, borders between work and home domains, border crossers and border keepers. It proposes that work and home domains are separate and that their border strengths vary. Borders have different permeability, flexibility, degree of blending and strength. It also posits that people are border crossers. They cross between work and home domains. The degree to which people are central or peripheral in each domain differs. Their influence and identification with the domain is also different. In this process, border crossers also interact with border keepers, that is, with influential members of each domain such as supervisors or partner. Work-home interface of the border crosser is affected by the border keeper's awareness of the other domain commitment and the care for the border crosser.

The pyramid of intersecting domains of work-home interface builds on these theoretical foundations by incorporating their approaches in its structure. The pyramid consists of the domain of work and home characteristics, the various roles that the person occupies (roles domain) and the cultural domain, which intersect to determine the domain of observed/experienced work-home interface. The work and home characteristics domain concerns the individual level domain, which denotes aspects such as work pressure or social support. Since it is the most frequently studied aspect of work-home interface (Casper, Eby, Bordeaux, Lockwood, \& Lambert, 2007; Eby, Casper, Lockwood, Bordeaux, \& Brinley, 2005), it will not be explored further in this study. The roles domain denotes the interpersonal level, and refers to various roles of a person, including gender roles, professional roles, or caring roles to name a few. Gender roles affect the perception of, and the actual, work and home characteristics domain and are also influenced by the cultural domain. The cultural domain represents the meso/macro level, to include aspects such as societal and organizational norms, but 
also incorporates economic and financial aspects and historical context and temporal changes. In this study the focus lies on the gender roles and their intersection with the cultural domain. The pyramid also postulates that the different domains are not independent, but interactive and intersecting; each domain influences the other and it is in the intersections of the different domains that the observed work-home interface appears. Furthermore, in interaction with other domain members, border crosser's work-home interface is shaped and determined.

\section{Method}

This study builds on the interpretative phenomenological approach (IPA), since it is an approach which allows the researcher to explore the meaning given to the negotiation of work and home domains by the participants (Smith \& Osborn, 2003). Participants ascribe meaning to work and home domains and researchers attempt to understand and make sense of these meanings. In IPA research questions are framed broadly. While using the IPA approach, the role of different social categories and their intersections in relation to $\mathrm{WHI}$, were simultaneously examined, as is in line with the theoretical framework of this study.

\section{Sampling method and participants}

In all three countries, participants were recruited via purposive and snowball sampling (Polit \& Beck, 2012). Potential participants were generally contacted through personal networks of the researchers or the interviewees. The sample was homogeneous in the sense that only teaching and healthcare professionals were included, and this was done in order to diminish differences that were due to differences in occupation (Polit \& Beck, 2012). To understand the experiences of this particular group more extensively, participants of different ages and family constellations were included. A total of 26 participants from Malta, 23 from Serbia and 9 from the Netherlands were interviewed (Table 2). Although the focus was on exploring how paid work and childcare were negotiated, participants who were single or had no children were also included as they reflected on societal expectations on them that related to childcare and paid work. All participants were white. Sexual orientation was not explicitly explored. No participants reported having a partner of the same sex.

\section{Data collection}

This qualitative article is based on semi-structured interviews with 25 men and 33 women. Before the start of the interview, researchers introduced themselves and the purpose of the study. The interview guide consisted of 5 topics with roughly 20 main questions relating to work and home domains and how they were combined. The topics were about: culture (societal gender norms and expectations, how much one fits this role, parental gender roles); general work (description of work, typical working day/week); work home balance (typical day after work, weekend, division of household chores, childcare, involvement in elderly care, leisure time, type of obstacles in managing 
Table 2 Descriptive characteristics of participants from Malta, Serbia and the Netherlands

\begin{tabular}{|c|c|c|c|c|c|c|c|}
\hline & & \multicolumn{3}{|c|}{ Male $(n=25)$} & \multicolumn{3}{|c|}{ Female $(n=33)$} \\
\hline & & $\begin{array}{l}\text { Malta } \\
(\mathrm{n}=12)\end{array}$ & $\begin{array}{l}\text { Serbia } \\
(\mathrm{n}=10)\end{array}$ & $\begin{array}{l}\mathrm{NL} \\
(\mathrm{n}=3)\end{array}$ & $\begin{array}{l}\text { Malta } \\
(\mathrm{n}=14)\end{array}$ & $\begin{array}{l}\text { Serbia } \\
(n=13)\end{array}$ & $\begin{array}{l}\mathrm{NL} \\
(\mathrm{n}=6)\end{array}$ \\
\hline \multirow[t]{5}{*}{ Age } & $<25$ & 0 & 0 & 0 & 1 & 0 & 1 \\
\hline & $25-35$ & 3 & 6 & 0 & 5 & 2 & 1 \\
\hline & $36-45$ & 5 & 1 & 2 & 4 & 3 & 1 \\
\hline & $46-55$ & 3 & 2 & 1 & 4 & 6 & 3 \\
\hline & $55+$ & 1 & 1 & 0 & 0 & 2 & 0 \\
\hline \multirow[t]{3}{*}{ Occupation } & Doctor & 2 & 4 & $1^{*}$ & 2 & 1 & 0 \\
\hline & Nurse & 3 & 0 & 0 & 4 & 2 & 3 \\
\hline & Teacher & 7 & 6 & 3 & 8 & 10 & 3 \\
\hline \multirow[t]{5}{*}{ Living with } & Parents & 0 & 2 & 0 & 3 & 2 & 0 \\
\hline & Partner $^{\triangle}$ & 5 & 2 & 0 & 1 & 1 & 0 \\
\hline & Partner+child(ren) & 6 & 3 & 3 & 8 & 8 & 5 \\
\hline & Alone & 1 & 3 & 0 & 1 & 1 & 1 \\
\hline & Child(ren) & 0 & 0 & 0 & 1 & 1 & 0 \\
\hline \multirow[t]{2}{*}{ Work (contract hours) } & Full-time & 12 & 10 & 2 & 13 & 13 & 1 \\
\hline & Part-time & 0 & 0 & 1 & 1 & 0 & 5 \\
\hline \multirow[t]{4}{*}{ Partner work } & Not applicable & 0 & 0 & 0 & 3 & 3 & 1 \\
\hline & No & 1 & 3 & 0 & 0 & 2 & 0 \\
\hline & Yes, part-time & 3 & 1 & 2 & 0 & 0 & 1 \\
\hline & Full-time & 8 & 6 & 1 & 11 & 8 & 4 \\
\hline
\end{tabular}

Note: *one participant was both a doctor and a teacher ${ }^{\Delta}=$ partner is defined as husband/wife or boyfriend/girlfriend

work and home domains); work and family roles (facilitating or conflicting effect of parenthood on work roles and vice versa) and wider socio-economic circumstance (economic crisis, religion, politics).

Interviews were conducted at the participants' workplaces, the interviewer's or interviewee's home or a public space (cafeteria) suggested by the participant. Interviews in Malta were conducted in English (average duration one hour), in Serbia in Serbian (average duration 45 minutes) and in the Netherlands in Dutch (average duration one hour). Most of the Dutch interviews (7 out of 9) were conducted during March and April 2012 by a female Dutch interviewer (TdB) who was a master student in public health at the time. The rest of the data were collected by the first author, a PhD candidate at the time with a background in psychology and public health, in Malta during May 2010, in Serbia during November and December 2010 and in the Netherlands during December 2013. 


\section{Data analysis}

Audio recorded data were transcribed verbatim and all identifiers (names of people, schools, and cities) were removed. For each interview, a one page summary was written in English. Direct quotes from participants used in the results section were translated from Serbian or Dutch into English. In line with IPA, researchers began analysis by closely reading each individual transcript several times and noting emerging codes, before moving to the next transcript (Smith \& Osborn, 2003). Associations between codes were sought to create clusters. Associations between clusters were combined into superordinate themes and connected to the theory. They were subsequently discussed and agreed upon between KP and PV. Some themes were occasionally re-grouped and renamed. Themes were discussed among all the authors of the article until the final list of themes emerged (Table 3). All co-authors read a sample of Dutch and Maltese interviews and Serbian summaries to check the consistency of findings. Thus, researcher triangulation was used to increase the validity of the findings (Green \& Thorogood, 2014). Data were analysed with N-Vivo 9.

Great care was taken to ensure trustworthiness of the findings. Topic list for the semi-structured interviews was based on existing literature. Data analysis was done by first two authors KP and PV and was cross-checked with other co-authors. The first author (KP) has lived and worked in all three countries and speaks all three languages. Three authors are men, and four authors are women, of different ages and family constellations. All authors originate from one of the three countries studied in this article. This helped in interpreting the findings, since the authors understood the local culture of the participants. Diverging views of the participants were included in the findings to do justice to the multifaceted experiences and situations they experienced and prevent creation of oversimplified picture of reality.

\section{Ethical issues}

According to Dutch legislation, this type of study does not require ethical committee approval (CCMO, 2014). Written informed consent was obtained from all the participants (APA, 2009). Confidentiality was again brought up verbally at the start of the interview.

\section{Results}

Detailed results of the findings are reported in Table 3. It shows that work centrality and family values were important superordinate themes that impacted the way work and home domains were negotiated in Malta, Serbia and the Netherlands. It also shows that gender and cultural context played an important role in shaping work and home negotiations. Based on intersections of culture, gender and age, we identified four major groups that differed concerning the expectations and possibilities for combining the work and home domains: (1) Striving for gender equality group; (2) Work domain equality with financial constraints group (further referred to as work domain equality group); (3) Transitional roles with family values constraints group (further referred to as transitional 


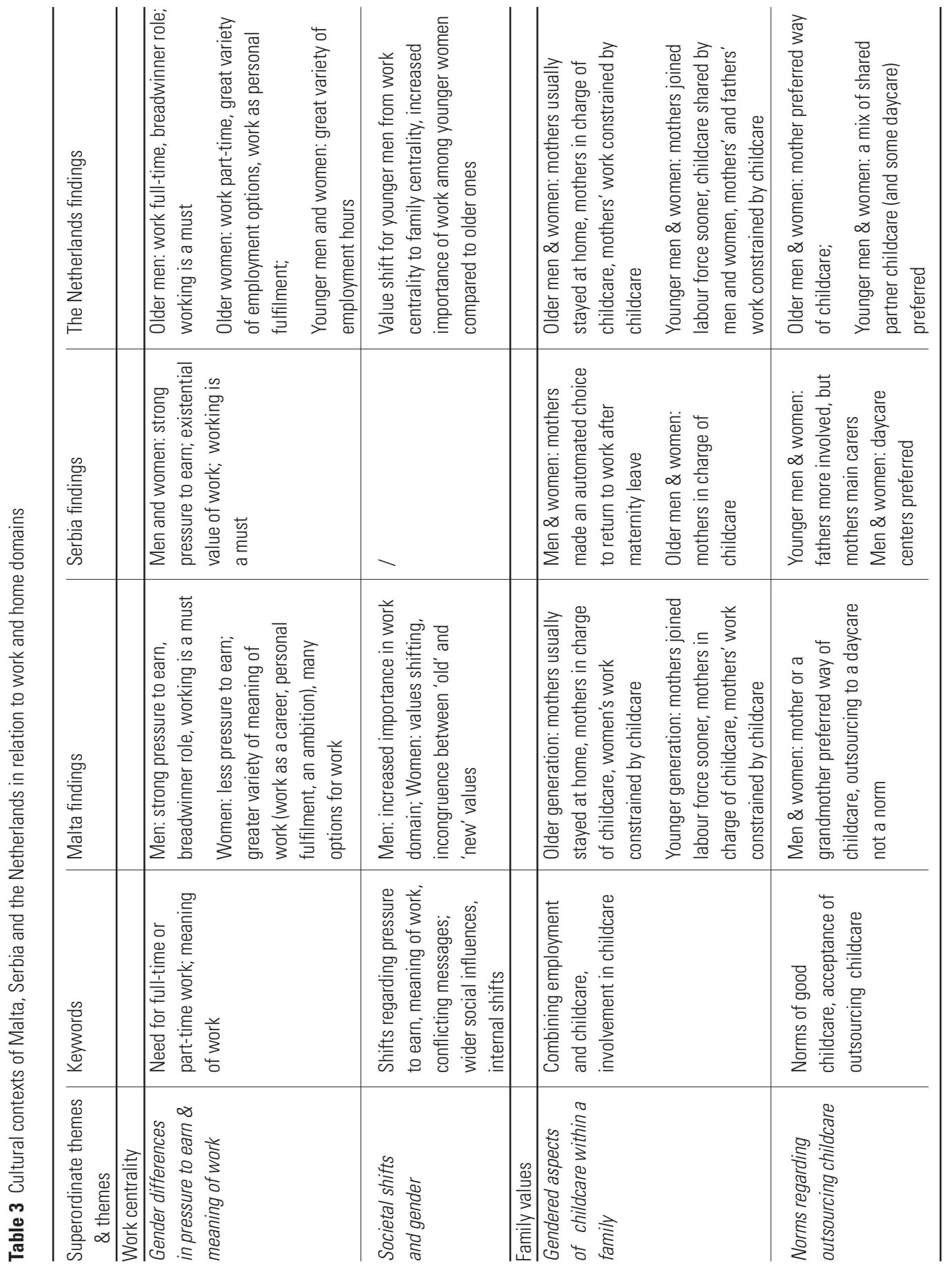


roles group) and (4) Traditional roles with work values constraints group (further referred to as traditional roles group).

\section{Striving for gender equality (Group 1)}

Members of this group had broad options concerning employment and childcare, which matched their values and norms. This concerned mostly young, male and female Dutch participants ( $<45$ years). Gender equality regarding negotiating and dividing work and childcare domain between partners was highly valued, and both work and family values were strong. Participants considered financial aspects of paid labour necessary to provide for their families, but personal fulfillment in work was also emphasized. The centrality of childcare and life outside the work sphere was evident.

'I see my work as very important, but I find my family even more important'. (Dutch participant 8, man, doctor and teacher, aged 36-45)

Participants reported that they shared childcare with their partners, who often worked similar hours like themselves. For a number of days per week they outsourced childcare to daycare centers or host families. If grandparents were involved, they usually took one day of childcare per week upon themselves. Some participants were adamant about accepting outsourcing childcare only to the family members and not to the daycare facilities. Outsourcing care for five days a week was frowned upon and not acceptable. Participants tried to share with their partners the care for children at home, but often women were the main organizers of care activities. The recent financial crisis and the decrease in childcare support from the government were perceived as a potential threat to women's labour participation:

'Now that the daycare has become so expensive, a woman's whole salary is spent on it, so I expect that there will be more women sitting at home, or work at home...so that the children do not go to daycare.' (Dutch participant 4, woman, nurse, aged 25-35)

By identifying woman's salary as paying for childcare, it indicated that despite a pursuit of gender equality, some aspects such as childcare seem to be deeply rooted in traditional gender role ideology. It appears that in situations of constraints, men and women may resort back to a more traditional role division, exposing the fragility of gender equality. In line with this, it appeared that the varieties of options for choosing the childcare and employment options in the Netherlands may be a restricted privilege to the professionals whose financial means make it possible for them to pay for childcare.

The persons in this group were embedded in the societal framework that reinforced their work and childcare preferences in the form of providing flexible childcare options and possibility as well as financial feasibility of part-time work. However, gender equality in this group may be fragile and highly dependent on facilitating contextual circumstances. Equality appeared attainable given that there were opportunities for it, but it did not seem to be an aim in itself. 


\section{Work domain equality with financial constraints (Group 2)}

Full-time employment for both men and women was financially necessary, but also widely accepted as the norm in this group. Outsourcing of child care duties to day care centers was also common. Members of this group experienced financial constraints concerning the possibility of living on less than two full time salaries. Part-time employment was institutionally not supported. This situation applied mostly to Serbian male and female participants of all ages. Participants in this group felt high pressure to earn an income. Having no job or working part-time was not desirable, given the low salaries and the high cost of living. Participants reported that responsibility for finding work to secure the family income was shared between them and their partners and little prerequisites were attached to accepting a job. One participant explained how he and his wife lived apart because they could not find work in the same city:

'Simple calculation is: salary is 450 euros, wherever we would live, iffor example, the worst appartment to rent costs 250 euros, what is left, 150 Euros. Impossible to live (on one salary).' (Serbian participant 7, man, doctor, aged 25-35)

The financial necessity of work was emphasized; paid work was important to survive and material realities constrained people's lives. Besides, work and parenthood were not perceived as conflicting with each other. Most participants sent their children to daycare centers. They perceived this option as being in the best interest of the child, since at daycare opportunities for socializing with other peers were ample.

I even think that it is healthier for children (to go to the daycare); I see children who do not go to the daycare, who stay with nannies or grandparents, that they lose a lot, they are insecure, find socialising more difficult.' (Serbian participant 19, woman, doctor, aged 36-45)

This is how in Serbia, working was compatible with parenting and outsourcing childcare was a norm which was financially feasible. In the home domain, men's gender roles seem to begin to shift from traditional to more egalitarian, by including childcare responsibilities into their role. However, women were still main carers and in charge of the household. Men's contribution was seen in the role of a helper.

Men and women in this group experience themselves as egalitarian concerning work and were in the process of a shift from traditional to more egalitarian childcare values and norms. Participants did not question this state of affairs, and gender arrangements in the home were not reported as unequal or unjust.

\section{Transitional roles with family values constraints (Group 3)}

This group experienced a lot of conflicting expectations put on them. Persons in this group (women only) felt that they were living in times of changing values regarding the role of men and women 
in the work and home domains. Old and new values were both strong, and sometimes conflicting. Women's main role was perceived to be that of the homemaker and childcarer. Legitimacy of paid labour participation was on the increase, but was contingent on many factors. Avoiding feelings of guilt of conflict was possible, but took a lot of emotion work, and negotiation. This group mainly concerned Maltese women of all ages and older Dutch women. Participation in paid labour was seen as an active choice, and often as a privilege. Work was enjoyed, and often contrasted to the experience of being a homemaker.

'...Spending so much time at home and with children... it's tedious. I go to work, at least I can have an adult conversation... staying at home was not good for my psychological wellbeing.' (Maltese participant 8, woman, nurse, aged 25-35)

The number of hours of work varied. Dutch women with children worked part-time more often, while Maltese women worked full-time, or reduced hours when the children were small. Paid work varied from being a financial necessity to being a personal choice for these women. In the latter case, labour conditions had to be compatible with childcare in order to justify paid work. For women in this group, besides providing financial benefits, work meant personal fulfilment and social contacts.

Return to paid labour after having children was often an exception to the societal norm and did not raise eyebrows (of family, friends, neighbours, colleagues) under the condition that their family life 'would not suffer'. This meant that they made sure that their partner and children would actually not notice that they were working. In practice then, working hours had to be compatible with school hours and be flexible. For these women, the notion of mothers being always available for their children was strongly valued.

'And I had this little job so I was home for tea. So I took them to school, and I worked, and then by three o'clock I was home again.' (Dutch participant 1, woman, nurse, aged 46-55)

'If I had to do it over again, yes, I would remain with the children...I cannot see why there is this stress for very young parents to go working both of them... one consistent important other needs to remain at home with the children.' (Maltese participant 5, woman, teacher, aged 46-55)

Many Dutch women in this group, and some Maltese women, joined the labour market only when children were old enough to be able to stay at home independently for some periods of time. Others, who joined earlier, were able and willing to do so because they had parents who were available to take care of the children. Only a few times nannies were reported.

When maternity leave was over, older women in this group generally stayed at home to take care of children. The process of this decision making was often reported by our participants as spontaneous and not a result of negotiation with their partner. In rare cases, participants reported 
negotiating with their partners, in which case finances were decisive. Women's lower incomes resulted in women staying at home. However, some women had negative experiences with societal norms when they were perceived to be 'career women', and not willing to put work on hold. Going against the norm was met with resistance from society.

'Initially they [men] are attracted to the fact that you work. But then, when they see that you are not ready to stop at some point it's like they, they're a bit put off... and they...try to keep you, you know, keep you back from what you want to do.' (Maltese participant 13, woman, teacher, aged 25-35)

For women in this group, both traditional gender norms that put them in the position of the homemaker, and the gender norms that accept female labour participation, coexisted. Based on these two different values, and norms, women in this group in effect experienced a constrained normative choice for joining the labour market.

\section{Traditional roles with work values constraints (Group 4)}

Members of this group were all males who experienced work as central to their lives, and lived in line with traditional (i.e. non-egalitarian) gender roles. Due to a strong breadwinner role, they were largely exempt from childcare responsibilities. This concerned mainly Maltese men and older Dutch men.

Maltese men in this study reported that as they grew older, the work domain gained in importance due to increased expectations of the standard of living one should have, creating greater pressure to work hard and long. They also saw their role as that of a provider for the family. Social comparison exacerbated the need for a high standard of living and they succumbed to it.

'There's also this, this thinking as well that men are almost expected to have an overtime job as well, that's what I think... The expectations on our lifestyle are very high expectations.' (Maltese participant 25 , male, teacher, aged 36-45)

Among persons in this group, their own salary was perceived as essential for the financial survival of the family. Work was an integral part of men's identity and was non-negotiable. When persons' individual preferences matched this scenario, they were satisfied. However, some persons voiced feeling the conflict as they preferred more childcare involvement.

'The things that I do with the kids or related to the kids, that is, that is something that I miss not doing enough.' (Maltese participant 25, man, teacher, aged 36-45)

Men in this group reported that their partners/wives did not object to unequal division of home duties, since their gender norms were in line with such a division of roles.

Participants in this group followed a traditional model of involvement in work and home domain. 
They had little options for changing this, but it was fine, since it was in line with their own values. However, men claimed that they experienced tension and wished to move away from this traditional model, while at the same time the societal values and norms made such a move difficult.

\section{Discussion}

In this study the role of the cultural context and gender roles were explored in relation to work-home interface among professionals in Malta, Serbia and the Netherlands. Special attention was paid to negotiations surrounding employment and childcare on work-home interface. By examining the complex interplay of cultural context and gender roles in relation to work and home domains four groups of people were identified who lived, experienced and negotiated their work-home interface differently: (1) Striving for gender equality; (2) Work domain equality with financial constraints (Work domain equality); (3) Transitional roles with family values constraints (Transitional roles) and (4) Traditional roles with work values constraints (Traditional roles). The groups were not culture, nor gender-specific. Groups were based on intersections of cultural context, gender, as well as age and socioeconomic position.

In each group there were both some privileges concerning negotiations of work and home domains, and also disadvantages. For persons in the striving for equality (group 1), it was both financially and institutionally feasible to work part-time. Furthermore, societal values were also in line with their own values, unlike for the people who were in the transitional roles (group 3). Persons in the transitional roles group were sometimes torn between their own values, and the more traditional societal values. However, persons were not necessarily locked in their positions, and considered going against the norms both possible and acceptable. In spite of this they were sometimes faced with resistance which was the 'price' for making unconventional choices. In line with the proposition of the cultural domain of the pyramid that experiences and possibilities can change over time, it is theorised by the authors that the identified groups reflect a snapshot of the process of change. The pendulum of change shifts to and from striving for gender equality (group 1) to traditional roles group (group 4), with work domain equality (group 2) and transitional roles (group 3) representing in between scenarios (Fig 2). Changing one's position in the group does not need to be linear (i.e. moving to the group 'next' to the one where he or she is at the moment). We saw that men and women of different ages grouped differently across countries. Thus, shifts in values do not necessarily take place at the same speed for all groups.

An important note to make about the four groups is that some participants observed that their partners were not necessarily being in the same process of change, i.e. not belonging to the same group, which in some instances was identified as a point of tension between partners. We found different intersections of culture, gender and age in relation to the work-home interface. For example, in the work domain equality group, age aspects did not come into play in the work-home interface. 


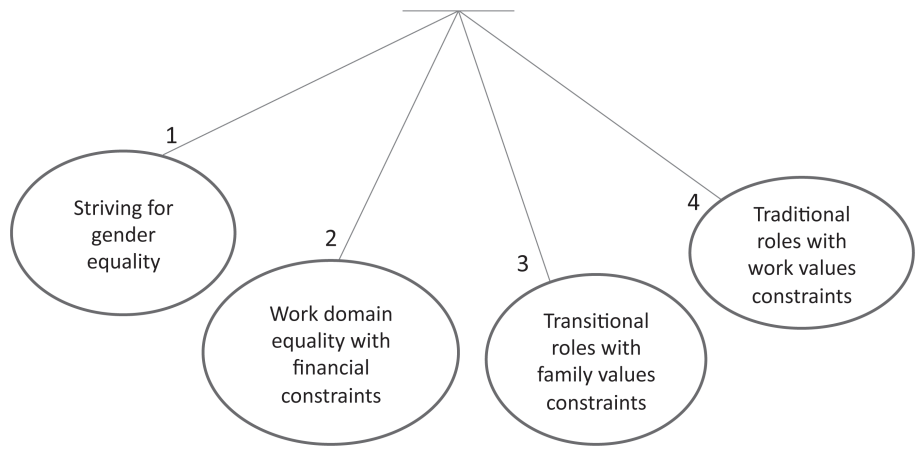

Figure 2 Pendulum of change: Groups showing shifts over time

The findings have shown that it is important to acknowledge the intersections of the cultural and gender domains in relation to the work and home domain. Furthermore the findings indicate a need to take a lifespan approach, since different age groups, as well as generational aspects play an important role for work-home interface. The intersectionality framework (Crenshaw, 1989), was useful in interpreting the results, as it allowed us to examine the cultural aspect and gender as intersecting, rather than as additive, and left opportunities open for identification of other relevant aspects for work-home interface. Work/family border theory (Clark, 2000) was useful for discussing the perspective of border keeper for the border crossers. For example, the opinion of the partner has an influence on the interpretation of the division of chores at home, as well as on appropriateness of centrality of each domain. If the partner disagrees with the centrality of work then a person may experience more difficulties in combining work and home domains. Furthermore, if one partner is to change the centrality of the domain and change the group in which he or she is situated, this may create conflict. We saw that the structural aspects of the cultural domain also play an important role. This is in line with the intersectionality theory and the pyramid of intersecting domains of work-home interface. For example, financial aspects played a role in labour participation. As has already been stated previously a certain level of affluence is needed for a male breadwinner earning model to prevail (Pfau-Effinger, 1998). In this study we saw that with a certain level of affluence breadwinner model was possible, but also that it was not necessarily the preferred way of organizing work and home domains for both men and women. Persons who were in the striving for gender equality group adjusted their working hours to best fit with the family needs. They reported that their partner also adjusted the working hours. Thus instead of only one partner adjusting and another working fulltime, they chose both to make changes. Surely, affluence affected this choice, as they could afford to live on adjusted working hours. Furthermore, persons in the transitional roles group are an example of how the economic situation is changing the values and expectations of persons towards female labour participation becoming more accepted. 
Previous literature has indicated that with arrival of children, women are more likely than men to adjust their paid work arrangements (Aveling, 2002; Verdonk, 2006; Visser, 2002). This finding holds particularly for the members of the transitional roles group (group 3 ) and traditional roles group (group 4). In these groups, it was the women who exited the labour market or adjusted working hours, arranged for flexible work to ensure that family and childcare needs are met. In striving for gender equality (group 1), it appears that work adjustments were done also by interviewees' partners and in work domain equality (group 2), it was a norm to work full-time for both men and women, prior and after, having children. So in the latter group, working less or exiting labour market was not common and was in line with family values. However with the arrival of children women's household tasks increased, since men's role was in the form of a 'helper'. As many researchers have already pointed out, women's work and/or home duties change with the arrival of children more pronounced as compared to men.

At the same time, men were also experiencing change. Men in striving for gender equality group managed to implement the wish for more family time by successfully adjusting the working time arrangements. On the other hand, men in traditional roles group were not able to do it yet, although they felt sorry for not participating enough in the lives of their children, and reported being trapped into providing for a luxurious lifestyle. The work values were too strong. If over time internal conflict between being a breadwinner and a more present and engaged father increases, one can expect a stronger push towards change being implemented. This process can also be facilitated by policies together with changes in cultural values and norms.

\section{Methodological reflections}

Phenomenology concerns the subjective experience of the participants and this was the starting point of our analyses (Table 3). Given that our theoretical approach was based on the pyramid of intersecting domains of work-home interface where the examination of intersections of social categories is particularly important, the qualitative data analysis approach needed to allow for such exploration. The interpretative phenomenological analysis approach therefore deemed suitable. It gave the freedom to explore the intersections, based on the subjective experience of the participants and coupled with the interpretation on the part of the authors. Table 3 reflects the experiences of the participants, while creation of the groups (Figure 2 ) is the product of the interpretation of the experiences of the participants by the authors of this study.

This study was based on 58 interviews, which for a qualitative study, is a relatively large number of participants. Given that intersections of culture, gender and age were salient, the study would have benefitted from more participants in certain age groups, such as very young participants $(<25$ years) or older participants $(55+)$. The Dutch sample would have benefitted from having more participants as well, especially male and those in the younger age groups $(<25-35)$. The latter could have benefitted the richness of the findings. Having more of these participants could have indicated the existence of yet more intersections. However, the sample we had seemed sufficient to answer the research question of this study, which was about the role of the cultural context and gender in 
relation to work-home interface in Malta, Serbia and the Netherlands. The sample was insufficient to generalize findings to entire populations, but it was enough to highlight the complexities of intersections that play a role in relation to work-home interface. Besides the ages of the sample that could be broadened, we also wish to stress that participants from different family constellations were not represented sufficiently or at all (e.g. single parents, same sex couples, stepfamilies, migrant families) and that it is not clear whether, and to what extent the findings of this study apply to members of these groups. All in all, transferability of the findings to other groups, like in most other qualitative studies is rather limited.

The focus in this article was on a rather specific professional group: healthcare and teaching employees. It may be that they represent a more advantaged group, given that with higher education, generally one's opportunities grow. Conducting a study among different sectors, with different level of education, may therefore produce additional insights. However, it is also important to note that the socioeconomic position of a profession may be dependent on the cultural context: as we have seen in our study, even when all interviewees were highly educated, there was a strong class dimension between the countries, and also within the countries. Future research should pay more attention to this and include more variety of participants in terms of age, family situation, sexual orientation and profession.

\section{Implications for practice and research}

The findings of this study are relevant to policymakers on different levels (national, international and organisational) and occupational health researchers. The main contribution to the policy and research field lies in raising awareness concerning the complexity of the way in which work and home domains are negotiated, which goes beyond the single level explanations. Our findings show a further need to examine the intersections of the culture and gender with age and socioeconomic position, rather than considering them as the additive effects on work-home interface. One of the main messages of this article is to be wary of the 'one size fits all approach', since policies that focus on a single social category (cultural context, gender, age), without taking into account other intersecting social categories are not likely to benefit all the relevant stakeholders. Thus, the European Union's approach towards policy convergence (Eurofound, 2014a) does not seem appropriate to tackle issues related to work-home interface. There is a need for divergence in policies and approaches in order to deal with work-home interface, which is reflected in the findings of this study. Different people experience work-home interface differently and thus need different strategies and support systems to deal with it.

What also became clear is that sometimes the societal values and expectations are not in line with the individual values and this has implications for policies. Here we see a potential for institutions that can aid individuals who are in transition, via adjusted policies to fit the local context and needs of individuals. For the sample of our study, it appears relevant that policymakers re-evaluate the appropriateness of policies after a certain period of time, as values and norms and broader societal frameworks change over time. For example, the financial crisis which has now been going on for 
quite some years impacts people's lives (like what we saw in the striving for gender equality group), and may call for a different set of policy recommendations than those that were installed during the more prosperous economic times. Thus, our findings indicate that locally adjusted policies should be implemented and evaluated after a certain period of time to check their effectiveness.

Another point of attention relates to traditional manhood as being a breadwinner-not-ahomecarer/caretaker and its relation to work and health, which was still a prevailing model in certain groups. Some men however (particularly those in the traditional roles group) wished to move away from this definition of the masculine gender role, since they experienced care work as emotionally fulfilling. Such a move towards less centrality of work in men's lives may also be important in order to protect men's health, since a strong emphasis on work may have negative health consequences. For instance, a strong identification with the professional identity is related to burnout (Putnik, de Jong, \& Verdonk, 2011). One option for a way forward would be a recommendation to change the 'ideal worker', also called 'male worker norm', which is based on the culture of availability and long working hours (Kreimer, 2004; Özbilgin, Beauregard, Tatli, \& Bell, 2010) into a worker norm that would decrease number of working hours, offer flexibility and create space and facilities to support family care work. Such a redefinition of a working norm, besides helping men reconcile work and home domains, would also benefit women, since greater men's involvement in the household would decrease women's total amount of care and household maintenance chores and make it easier to combine work and home domains.

This article indicates that if we wish to understand work and home interface better, we need to examine the cultural context and gender roles and norms and take the lifespan approach perspective. This implies that before evaluating whether work and home interface is positive or not, we need to consider the cultural aspects (financial options, structural as well as temporal aspects) and gender values and norms of people in relation to negotiating this interface. Future research should explore in more detail how these differences in options concerning work and home interface translate to different health outcomes. Such knowledge would be valuable in improving the public health of men and women, as well as aiding in developing guidelines for sustainable labour participation, an important issue on the agenda in the coming years. Including different countries in research and providing more representative samples could lead to better understanding of the complexity of this issue.

\section{Conclusion}

An extension of intersectionality and work/family border theory to the pyramid of intersecting domains of work-home interface appears to be a useful theoretical framework for examining the complex nature of work-home interface across cultural contexts. Cultural context, gender roles, age and socioeconomic position intertwine to impact work-home interface. Examining work-home interface without examining these aspects leads to incomplete understanding of observed work- 
home interface. For policies at the EU level to be effective, a more complex, locally tailor-made approach is called for, the one that besides tackling the work characteristics, also takes into account intersecting cultural and gender roles domains.

\section{Acknowledgments}

The authors would like to thank all the participants of this study for their time and openness in sharing their life stories about their work and private situation with us. We also thank Tessa de Bruin, bachelor student of Public Health at Maastricht University at the time, for conducting and transcribing seven Dutch interviews. We would also like to thank Yvonne Leenders for transcribing 2 other Dutch interviews and Estefania Velilla Perdomo and Jelena Arsenijević for transcribing the Maltese and Serbian interviews respectively. 


\section{References}

Acker, J. (2005). Class questions: Feminist answers. Oxford: Rowman \& Littlefield Publishers.

APA (2009). Publication manual of the Americal Psychological Association (6 ${ }^{\text {th }}$ ed.).Washington: APA.

Aveling, N. (2002). 'Having it all' and the discourse of equal opportunity: Reflections on choices and changing perceptions. Gender and Education, 14(3), 265-280.

Byron, K. (2005). A meta-analytic review of work-family conflict and its antecedents. Journal of Vocational Behavior, 67(2), 169-198.

Camilleri-Cassar, F. (2005). Gender equality in Maltese social policy? Graduate women and the male breadwinner model. Luqa, Malta: Agenda.

Casper, W. J., Eby, L. T., Bordeaux, C., Lockwood, A., \& Lambert, D. (2007). A review of research methods in IO/OB work-family research. Journal of Applied Psychology, 92(1), 28-43. doi: 10.1037/0021-9010.92.1.28

Centrale Commissie Mensgebonden Onderzoek (CCMO). (2014). Wet medisch-wetenschappelijk onderzoek met mensen (Law about medical research involving human subjects act). Retrieved 14-3-2014, from http:// wetten.overheid.nl/BWBR0009408/geldigheidsdatum_14-03-2014

CIA (2011). The world factbook. Retrieved 10032015 from https://www.cia.gov/library/publications/the-worldfactbook/geos/mt.html

CIA (2013). The world factbook. Retrieved 29032015 from https://www.cia.gov/library/publications/the-worldfactbook/rankorder/2054rank.html

Clark, S. C. (2000). Work/family border theory: A new theory of work/family balance. Human Relations, 53(6), 747-770.

Cloin, M., \& Souren, M. (2011). Onbetaalde arbeid en de combinatie van arbeid en zorg [Unpaid work and the combination of work and care]. In A. Merens, M. van den Brakel, M. Hartgers \& B. Hermans (Eds.), Emancipatiemonitor 2010 (pp. 108-147). Den Haag: Sociaal en Cultureel Planbureau, Centraal Bureau voor de Statistiek.

Crenshaw, K. (1989). Demarginalizing the intersection of race and sex: A Black feminist critique of antidiscrimination doctrine, feminist theory and antiracist politics. University of Chicago Legal Forum, 139, 139-167.

Drago, R. (2001). Time on the job and time with their kids: Cultures of teaching and parenthood in the US. Feminist Economics, 7(3), 1-31.

Eby, L., Casper, W., Lockwood, A., Bordeaux, C., \& Brinley, A. (2005). Work and family research in IO/OB: Content analysis and review of the literature (1980-2002). Journal of Vocational Behavior, 66, 124-197.

Engel, N., Van Hoyweghen, I., \& Krumeich, A. (2014). Making global health care innovation work: Standardization and localization. New York: Palgrave Macmillan.

Eurofound. (2014a). Policy lessons from the fifth EWCS: The pursuit of more and better jobs. Luxembourg: Publications Office of the European Union.

Eurofound. (2014b). Third European Quality of Life Survey-Quality of life in Europe: Trends 2003-2012. Luxembourg: Publications Office of the European Union.

Galovan, A. M., Fackrell, T., Buswell, L., Jones, B. L., Hill, E. J., \& Carroll, S. J. (2010). The work-family interface in the United States and Singapore: Conflict across cultures. Journal of family psychology, 24(5), 646-656. 
Gligorijevic, J. (2012, 25th October 2012). Socijalne razlike počinju u vrtiću [Social differences begin at daycare]. Vreme.

Green, J., \& Thorogood, N. (2014). Qualitative methods for health research (3rd ed.). London: Sage.

Grzywacz, J. G., \& Marks, N. F. (2000). Reconceptualizing the work-family interface: An ecological perspective on the correlates of positive and negative spillover between work and family. Journal of occupational health psychology, 5(1), 111-126.

Hankivsky, O. (2012). Women's health, men's health, and gender and health: implications of intersectionality. Social Science \& Medicine, 74(11), 1712-1720.

Hofstede, G. (1980). Culture's consequences: International differences in work-related values. Beverly-Hills, Ca: Sage. Hofstede, G. (1991). Cultures and organisations: Software of the mind. London: McGraw-Hill.

Hoppe, M. H. (1990). A comparative study of country elites: International differences in work-related values and learning and their implications for management training and development. (Unpublished doctoral dissertation), University of North Carolina at Chapel Hill.

Knippenberg, H. (2005). The changing religious landscape of Europe. Amsterdam: Het Spinhuis

Kreimer, M. (2004). Labour market segregation and the gender-based division of labour. European Journal of Women's Studies, 11(2), 223-246.

Lewis, S. (2003). The integration of paid work and the rest of life. Is post-industrial work the new leisure? Leisure studies, 22(4), 343-345.

Lu, L., Gilmour, R., Kao, S. F., \& Huang, M. T. (2006). A cross-cultural study of work/family demands, work/family conflict and wellbeing: the Taiwanese vs British. Career Development International, 11(1), 9-27.

Lu, L., Kao, S. F., Cooper, C. L., Allen, T. D., Lapierre, L. M., O’Driscoll, M., . . Spector, P. E. (2009). Work resources, work-to-family conflict, and its consequences: A Taiwanese-British cross-cultural comparison. International Journal of Stress Management, 16(1), 25-44.

Masuda, A. D., Poelmans, S. A. Y., Allen, T. D., Spector, P. E., Lapierre, L. M., Cooper, C. L., . . Woo, J. M. (2012). Flexible work arrangements availability and their relationship with work-to-family conflict, job satisfaction, and turnover intentions: A comparison of three country clusters. Applied Psychology: An International Review, 61(1), 1-29.

Michel, J. S., Kotrba, L. M., Mitchelson, J. K., Clark, M. A., \& Baltes, B. B. (2011). Antecedents of work-family conflict: A meta-analytic review. Journal of Organizational Behavior, 32(5), 689-725.

National Statistics Office Malta (NSOM) (2012). Malta in figures 2012. Valletta, Malta: National Statistics Office Malta.

Numbeo. (2011, 3004 2014). Cost of living index by country. Retrieved 3004 2014, 2014, from http://www. numbeo.com/cost-of-living/rankings_by_country.jsp?title=2011

Özbilgin, M. F., Beauregard, T. A., Tatli, A., \& Bell, M. P. (2010). Work-life, diversity and intersectionality: A critical review and research agenda. International Journal of Management Reviews, 177-198. doi: 10.1111/j.14682370.2010.00291.x

Pfau-Effinger, B. (1998). Gender cultures and the gender arrangement-a theoretical framework for crossnational gender research. Innovation: The European Journal of Social Science Research, 11(2), 147-166.

Plantenga, J., \& Remery, C. (2010). Flexible working time arrangements and gender equality: A comparative 
review of 30 European countries. Luxembourg: Publications Office of the European Union.

Polit, D. F., \& Beck, C. T. (2012). Nursing research: Principles and methods (9th ed.). Philadelphia: Lippincott Williams \& Wilkins.

Putnik, K., de Jong, A., \& Verdonk, P. (2011). Road to help-seeking among (dedicated) human service professionals with burnout. Patient education and counseling, 83(1), 49-54.

Putnik, K., Houkes, I., Jansen, N., Nijhuis, F., \& Kant, IJ. (2015). Work-home interface in a cross-cultural context: A framework for future research and practice. Manuscript submitted for publication.

Shaffer, M. A., Joplin, J. R. W., \& Hsu, Y. S. (2011). Special review article: Expanding the boundaries of work-family research: A review and agenda for future research. International Journal of Cross Cultural Management, 11(2), 221-268.

Smith, J. A., \& Osborn, M. (2003). Interpretative phenomenological analysis. In J. A. Smith (Ed.), Qualitative psychology: A practical guide to research methods (pp. 51-80). London: Sage.

Sollars, V. (2014). Early childhood education and care in Malta: The way forward. Malta: Ministry for education and employment Retrieved 10022014 from https://education.gov.mt/en/Documents/Public\%20Consultations/ White\%20Paper.pdf.

Statistical Office of the Republic of Serbia (SORS) (2012). Statistical yearbook of the Republic of Serbia. Belgrade Satistical Office of the Republic of Serbia, Belgrade.

Spector, P. E., Allen, T. D., Poelmans, S. A. Y., Lapierre, L. M., Cooper, C. L., O’Driscoll, M., . . Beham, B. (2007). Cross national differences in relationships of work demands, job satisfaction, and turnover intentions with work-family conflict. Personnel Psychology, 60(4), 805-835.

Spector, P. E., Cooper, C. L., Poelmans, S. A. Y., Allen, T. D., O’Driscoll, M., Sanchez, J. I., . . Lu, L. (2004). A crossnational comparative study of work-family stressors, working hours, and well-being: China and Latin America versus the Anglo world. Personnel Psychology, 57(1), 119-142.

United States Department of State (USDP). (2011). Serbia (Vol. July-December 2010): Bureau of democracy, human rights, and labor.

Strandh, M., \& Nordenmark, M. (2006). The interference of paid work with household demands in different social policy contexts: perceived work-household conflict in Sweden, the UK, the Netherlands, Hungary, and the Czech Republic. The British Journal of Sociology, 57(4), 597-617.

Teichgraber, M. (2013). EUROSTAT European Union Labour force survey-Annual results 2012. Retrieved 16072014 from http://www.google.nl/url?sa=t\&rct=j\&q=\&esrc=s\&frm=1\&source=web\&cd=2\&ved=0CDgQFjAB\&url= http\%3A\%2F\%2Fbookshop.europa.eu\%2Fen\%2Feuropean-union-labour-force-survey-pbKSSF13014 \%2Fdownloads\%2FKS-SF-13-014-EN-N\%2FKSSF13014ENN_002.pdf\%3FFileName\%3DKSSF13014ENN_002. pdf\%26SKU\%3DKSSF13014ENN_PDF\%26CatalogueNumber\%3DKS-SF-13-014-EN-N\&ei=NMZsU537CoG9OcSd gKgL\&usg=AFQjCNGRTHhKAWUFFC-wMNgmQdiAKGMQQg\&sig2=u2m9KijaGqFs4YPISussEA

van der Lippe, T., Jager, A., \& Kops, Y. (2006). Combination pressure: The paid work-family balance of men and women in European countries. Acta Sociologica, 49(3), 303-319. doi: 10.1177/0001699306067711

Verdonk, P. (2006). 'Ik wil er gewoon voor ze zijn' ['I just want to be there for them']. Lover, 1, 4-6.

Visser, J. (2002). The first part-time economy in the world: A model to be followed? Journal of European Social Policy, 12(1), 23-42. 


\section{Work related characteristics, work-home and home-work interference and burnout among primary healthcare physicians A gender perspective in a Serbian context}




\section{Abstract}

Background: Little information exists on work and stress related health of medical doctors in nonEU countries. Filling this knowledge gap is needed to uncover the needs of this target population and to provide information on comparability of health related phenomena such as burnout across countries. This study examined work related characteristics, work-home and home-work interference and burnout among Serbian primary healthcare physicians (PHPs) and compared burnout levels with other medical doctors in EU countries. Methods: Data were collected via surveys which contained Maslach Burnout Inventory and other validated instruments measuring work and home related characteristics. The sample consisted of 373 PHPs working in 12 primary healthcare centres. Data were analysed using $t$-tests and Chi square tests. Results: No gender differences were detected on mean scores of variables among Serbian physicians, who experience high levels of personal accomplishment, workload, job control and social support, medium to high levels of emotional exhaustion, medium levels of depersonalisation and work-home interference, and low levels of home-work interference. There were more women than men who experienced low job control and high depersonalisation. Serbian physicians experienced significantly higher emotional exhaustion and lower depersonalisation than physicians in some other European countries. Conclusions: To diminish excessive workload, the number of physicians working in Primary Healthcare Centres in Serbia should be increased. Considering that differences between countries were detected on all burnout subcomponents, work-related interventions for employees should be country specific. The role of gender needs to be closely examined in future studies as well.

Keywords: burnout; medical doctors; gender differences; work-home and home work interference; job characteristics 


\section{Background}

\section{Work characteristics and burnout}

Work characteristics and health problems such as burnout have been extensively researched in the Western countries, including the United Kingdom, the United States of America, Scandinavian countries and the Netherlands, to mention a few. Work characteristics are defined as job demands and resources at work (Bakker, Demerouti \& Verbeke, 2004 ), while burnout is a syndrome characterised by emotional exhaustion (feelings of having depleted one's emotional resources), depersonalisation (distant attitude towards the work and persons at work) and decreased personal accomplishment (perceived personal ineffectiveness at work) (Maslach \& Leiter, 1997). The job demands-resources model, strongly supported by research, offers an explanation for the relationship between work characteristics and burnout (Demerout, Bakker, Nachreiner \& Schaufeli, 2001). Job demands, referring to aspects of work that require physical and/or psychological effort, are strongly associated with emotional exhaustion. Job resources, aspects of work that facilitate achievement of work goals and stimulate personal growth and development, are more related to depersonalization and personal accomplishment (Bakker \& Geurts, 2004; Schaufeli \& Enzmann, 1998). Job resources can buffer the negative impact of high job demands. In this study, demands are examined through workload, childcare and household duties, work-home and home-work interference, while resources are explored through variables of job control, social support and favourable work content.

Scarce knowledge exists with regards to expression of these variables in different cultural settings. One such underexplored case example is physician burnout in Serbia. We know very little about health and work characteristics of medical doctors in Serbia and the extent to which they manage to combine work and family related duties. In fact, Lešić and colleagues (Lešić, Petrović-Stefanović, Peruničić, Milenković, Lečić-Toševski \& Bumbaširević, 2009) acknowledge this lack of research and call for studies in the Serbian cultural context that would look into the work-family balance. In light of this knowledge gap and taking into consideration that burnout is one very prominent example of stress related problems of which physicians are particularly at risk (Twellaar, Winants, \& Houkes, 2008), the present study set out to explore work characteristics, work family interference and burnout among Serbian primary healthcare physicians (PHPs), paying attention to gender and cross cultural differences.

\section{Serbian context}

In Serbia, full-time employment and dual income families are the norm (Krstić \& Corbanese, 2008). Only $1 \%$ of waged employment is part-time (ILO, 2007). Home chores and childcare are still largely in women's hands, regardless of labour participation, education level or occupation (Massey, Hahn, \& Sekulić, 1995). Instead of obtaining help from the partner, Serbian women can be expected to receive help from a mother or a paid helper (Gudac-Dodić, 2011). Thus, despite greater female labour emancipation, traditional values still prevail in the home sphere. 
Regarding the health sector, there are 116 primary healthcare centres (PHC), where $31 \%$ of all doctors work (IPHS, 2008). Unlike in many other countries, there are more female (64\%) than male physicians (36\%). Among general practitioners (GPs), the gender disparity is even more pronounced, with 95\% female representation (Lapčević, Gvozdenović, \& Stanković, 2008). To our knowledge, only two small-scale studies on Serbian medical doctors working in primary care have been conducted. One study was conducted on 39 GPs (Lečić-Toševski, Pejović-Milovančević, Pejušković, PopovićDeušić, Tanović-Mikulec \& Hofvedt, 2006) and the second study (Lešić et al., 2009) among 38 GPs. These studies are a valuable contribution to the initial assessment of physicians' health in Serbia. However, studies with larger samples and more variables under examination are needed for a more comprehensive overview of prevalence of burnout. Furthermore, a comparison of burnout levels in Serbia with other international research is needed in order to position the findings of this specific cultural setting in relation to other European countries.

\section{Perspective on gender, work characteristics, work-home interference and burnout}

When examining work and health conditions of employees, including gender in the analysis is of paramount importance in order to provide a better understanding of men's and women's conditions of work and illness aetiology.

Numerous evidence points to the connection between work circumstances and employees' health. For example, speed of work has increased in most countries since the last decade of the previous century (EFILC, 2002), and this work intensity is related to negative health outcomes, such as increased stress (Paoli \& Merllié, 2001). Amount and quality of social contacts, along with the job autonomy are also relevant variables to examine. Adequate social support and high levels of work autonomy are related to more positive health outcomes (Demerouti et al., 2001). Besides work characteristics, the interplay between the work and home sphere is also important to consider as this is related to stress and burnout (Allen, Herst, Bruck \& Sutton, 2000). In this study work-home interference (WHI) is defined as the extent to which work related tasks impede on fulfilment of home duties (Kopelman, Greenhaus, \& Connolly, 1983), while home-work interference (HWI) refers to interference of home roles with performance of work duties (Greenhaus \& Beutell, 1985). Gender differences regarding the role of WHI and HWI are still not clear. In Western populations, some studies found greater work-home and home-work interference for females (Burke \& Greenglass, 1987; Hochschild, 1989), while others found similar effects for both genders (Frone, Russell, \& Cooper, 1992; Geurts, Rutte, \& Peeters, 1999).

Both men and women can go on to develop stress, and subsequently burnout, in situations where work characteristics and WHI are unfavourable (Allen et al., 2000). The relationship between gender and burnout is not yet clear (Maslach, Schaufeli, \& Leiter, 2001). In some studies gender differences on the overall level of burnout were not detected (Twellaar et al., 2008), while some gender differences in burnout subcomponents were found (Ádàm, Gyorffy, \& Susànszky, 2008; Grassi \& Magnani, 2000; Twellaar et al., 2008).

In this study, we focus on gender differences in the prevalence of work characteristics, work- 
home and home-work interference and burnout among Serbian physicians working in PHCs, and compare burnout findings with other international results. Given that this is an early explorative study of the situation in Serbia, more complex gender analyses and interrelationships with health outcomes will not be addressed here.

To achieve the aim of the study, we will answer the following research questions:

1) What is the level and prevalence of work characteristics among Serbian PHPs and are there any gender differences?

2) What is the level and prevalence of home and childcare responsibilities, work-home and homework interference among Serbian PHPs and are there any gender differences?

3) What is the level and prevalence of burnout among Serbian PHPs and are there any gender differences?

4) What is the level of physicians' burnout in comparison to other European countries, that is, the Netherlands, Hungary and Italy?

\section{Methods}

\section{Sample}

A cross-sectional study based on a survey was conducted during the months of July and August 2008. Self-reported anonymous questionnaires were distributed by directors or head nurses to 850 doctors. To increase interest in participation in the study, personal contact was established with the directors and/or head nurses of the PHCs. The study was explained, and they were offered to receive a report with the findings and recommendations for practice, upon the end of the data collection. In this study, 12 PHCs (8 from Belgrade and 4 from other cities) took part. The mix of small and large PHCs was equally represented in Belgrade and other cities. All doctors working in the PHC were eligible to take part in the study. Excluded from participation were doctors who were on sick leave or holidays during the data collection period (approximately three weeks per institution). The response rate was $44 \%$, that is, 373 respondents answered the questionnaire. All the participants were informed in writing that their participation was voluntary and that data provided were treated confidentially. By completing the survey, the physicians gave their consent to participate in the study. According to the Dutch law (CCMO, 2010) our type of study based on paper and pencil survey does not require ethical committee approval.

Sample reflected gender differences in PHCs in Serbia: $84 \%$ were female and $16 \%$ were male. Mean age for both men and women was $47(S D$ (men)=10.15; SD (women)=8.48). Of the total sample, $31 \%$ of physicians were aged $20-44$ and the rest were in the age group $45-64$, reflecting a greater proportion of older participants in this study. Most respondents (77\%) had children; $61 \%$ of them lived with children and spouse or partner, $8 \%$ lived alone, $10 \%$ with the partner, $7 \%$ with children and $14 \%$ in some other form of family constitution. On average, participants had between 1 and 2 children ( $=1.4$ children), the average age of children was 19 years. Proportion of the sample with 
younger children, defined in this study as younger than 12 years of age, was $23 \%$. Years of working experience were similar between men (19.8 years) and women (19.6 years). The working hours and structure of work did not vary among the participants.

\section{Measurements}

The scales for workload, job control, work content, social support and work-home and home-work interference were translated from Dutch to Serbian using the back translation method. Following this, refinements were made using more iterative processes to check that the meaning stayed the same in both languages, a procedure suggested by American Educational Research Association, American Psychological Association and National Council on Measurement in Education (AERA, APAE, 1999).

i. Workload was measured by an eight item scale $(\alpha=.87)$ based on the Job Autonomy Questionnaire (Jonge, Landeweerd, \& Nijhuis, 1993). The participants indicated their agreement with each item on a four-point scale (1=never, 4=very often).

ii. Job control was measured by four items $(\alpha=.72)$ of the Inventory of feelings of motivation and demotivation (Dierendonck, Groenenweg \& Sixma, 1992). Responses ranged from 1=not at all to 4=very much.

iii. Work content was assessed via five items based on the Job Diagnostic Survey (Hackman \& Oldham, 1980) and developed by Janssen and colleagues (Janssen, Jonge, \& Bakker, 1999), which examines creativity, independence and chances for feedback on person's work. The scale $(\alpha=.82)$ offered four answering options (1=never, 4=very often).

iv. Social support was measured by three five item scales deducted from the Questionnaire on Organizational Stress-Doetinchem (VOS-D), each assessing the social support received from supervisor/colleague, partner and family/friends (Berger, Marcelissen \& Wolff, 1986). The scores on three subscales were averaged to yield a sum score. Reliability of the scale was good $(\alpha=.82)$. Items were rated on four point scales (1=never, $4=$ =always).

v. Home and childcare responsibilities were each measured by a one item measure created for the purpose of this study: "What is the percentage of the household duties carried out by yourself?" and "What is the percentage of the childcare duties carried out by yourself?"

vi. Work-home and home-work interference were assessed via two scales consisting of 13 items (Kopelman et al., 1983; Netemeyer, Boles \& McMurrian, 1996). Work-home interference scale assesses the amount of interference from work to home domain, such as work clashing with home and family plans. It consists of seven items $(\alpha=.90)$. Home-work interference examines the extent of interference from home to work domain, for example having difficulties concentrating at work because of being preoccupied with domestic matters. The scale contains six items $(\alpha=.84)$. The respondents answered via five point scale ( $1=$ =never, $5=$ always).

vii. Burnout was measured using the Serbian translated version of the Maslach Burnout InventoryGeneral Survey (Lečić-Toševski et al., 2006), which contained 22 items and three scales. Emotional exhaustion was measured by ten items $(\alpha=.89)$, depersonalisation by five items $(\alpha=.68)$ and reduced 
personal accomplishment by seven items $(\alpha=.75)$. Previous research shows that the reliability of depersonalisation score is usually low (Lee \& Ashforth, 1996; Schaufeli \& Enzmann, 1998). Responses were made on a six-point scale $(0=$ never, $6=$ every day).

\section{Data analyses}

We started with the preliminary analyses (Means, SD and Pearson correlations for the subgroups of males and females). Since no Serbian national cut-off points exist for different levels of burnout, we used the cut-off points from the Utrechtse Burnout Schaal (UBOS) manual (Schaufeli \& van Dierendonk, 2000). No standardised cut-off points for work characteristics were found, so we used general rules of thumb, which indicate when high levels of certain variable are experienced. According to Houkes (2002), for scales ranging from 1-4, the cut-off point according to the rule of thumb is 2.5 , and for scales $1-5$, the cut-off point is 3.5 . For example, workload scale ranges between 1 (never) and 4 (very often), and individuals who score above 2.5, experience 'often' or 'very often' high workload. In order to examine gender differences in mean values of variables and determine whether the prevalence differs among men and women independent samples $t$-tests and chi-square tests were performed, respectively. To examine burnout differences between Serbian physicians and their colleagues in European countries, findings were compared to the studies of physician burnout in Hungary, the Netherlands and Italy. All studies used MBI as a measure of burnout. Studies in the Netherlands (Twellaar et al., 2008) and Italy (Grassi \& Magnani, 2000) were conducted on samples of general practitioners (GPs), while the Hungarian study (Ádàm et al., 2008) included physicians from various specialties and GPs. To examine differences between Serbian physicians and their colleagues in other countries, one sample $t$-tests were carried out. All the analyses were performed using SPSS 15.01 version.

\section{Results}

\section{Research question 1: Work characteristics among Serbian PHPs}

Mean levels of work characteristics, as well as gender differences and Pearson correlations are reported in Table 1.

We found that Serbian physicians had mostly favourable working conditions. No gender differences on mean levels of work characteristics were detected (Table 1). Physicians reported overall high levels of job control $\left(_{(\text {men) }}=2.89\right.$ and $\left.{ }_{(\text {women) }}=2.74\right)$, work content $\left(_{(\text {men) }}=2.89\right.$ and $_{(\text {women) }}=2.92$ ) and low levels of lack of social support $\left.{ }_{(\text {men) }}=1.66^{\text {and }}{ }_{(\text {women) }}=1.74\right)^{\text {). }}$

We also looked at the prevalence of these variables and examined gender differences. These results are reported in Table 2 . We found that significantly more women suffered from low control at work (42.4\%) compared to men, where prevalence was $24.1 \%$. Both genders experienced high workload: $73.6 \%$ of women and $65.5 \%$ of men complained of high amount of work. The prevalence of unfavourable work content and lack of social support was small. This was reflected by the finding 
that more than $70 \%$ of the sample experienced high possibility for creativity in their work and felt they had a lot of chances to learn new things and develop as measured by work content. Physicians experienced high levels of support from their colleagues and supervisors, which was reflected in the finding that only $2 \%$ of physicians experienced low social support.

\section{Research question 2: Home and childcare responsibilities and work-home and home-work interference}

Levels of home and childcare responsibilities, work-home and home-work interference and gender differences are reported in Table 1 . The prevalence of these variables, and any associated gender differences in prevalence are reported in Table 2.

Analyses revealed that home and childcare responsibilities differed between men and women. Women in our sample carried out disproportionally more childcare than men $(63.84 \%$ versus 43.37\%), and more home chores than men (69.99\% versus $51.71 \%$ ).

Regarding the balance of work and home duties, we found that WHI was higher than HWI for men and women (Table 1). However, no significant gender differences were identified between mean levels of WHI and HWI.

Concerning the prevalence of WHI, we saw that only $13.3 \%$ of female physicians and $10.3 \%$ of male physicians experienced high WHI (Table 2). Prevalence of high HWI was $1 \%$ among women, and $1.7 \%$ among men.

Since the presence of young children involves more childcare duties, and can thus be associated with higher WHI and HWI, we carried out further analyses to examine this (results not reported in tables). Contrary to previous findings, the presence of younger children aged less than 12 years was not found to be related to WHI. In fact, having children older than age 12 produced slightly higher levels of WHI for both women and men. Women with older children experienced mean level of WHI of 2.71, while women with younger children experienced mean level of WHI of 2.61, $t(239)=.85$, $p \geq .05$. Men with older children had a mean level of $\mathrm{WHI}$ of 2.55 , while men with younger children experienced the level of WHI of $2.24, t(40)=.99, p \geq .05$. We also found the same pattern of higher HWI for physicians with children older than 12 , and again the difference between the two groups was non significant.zz Women with older children had a mean score of 1.83 of HWI, while women with younger children had a mean score of 1.67 of $\mathrm{HWI}, t(238)=1.71, p \geq .05$. Men with older children had a mean score of 1.73 of HWI, while men with younger children had a mean score of $1.44, t(30.44)=-$ $1.95, p \geq .05$. 


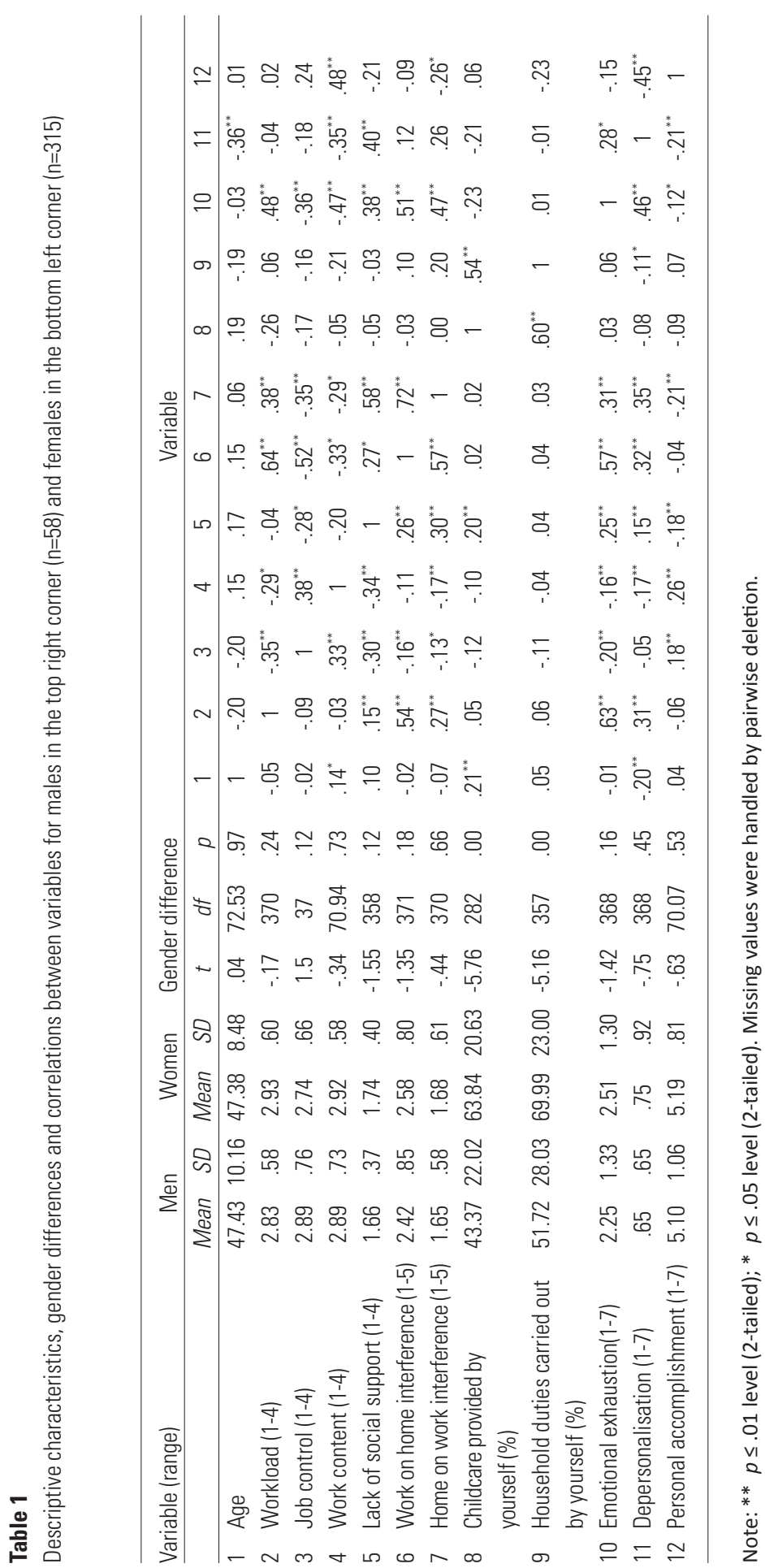


Table 2 Gender differences in work characteristics, work-home interference, home-work interference and burnout prevalence

\begin{tabular}{|c|c|c|c|c|c|}
\hline \multirow[t]{2}{*}{ Variable } & \multirow{2}{*}{$\begin{array}{l}\text { Men } \\
\text { Percent (\%) }\end{array}$} & \multirow{2}{*}{$\begin{array}{l}\text { Women } \\
\text { Percent (\%) }\end{array}$} & \multicolumn{3}{|c|}{ Gender differences between levels of variables } \\
\hline & & & $x^{2}$ & $d f$ & $p$ \\
\hline \multicolumn{6}{|l|}{ Workload a $^{a}$} \\
\hline $\operatorname{Low}^{b}(\leq 2.5)$ & 34.5 & 26.4 & 1.58 & 1 & .21 \\
\hline High (>2.5) & 65.5 & 73.6 & & & \\
\hline \multicolumn{6}{|l|}{ Job control ${ }^{\text {a }}$} \\
\hline Low $(\leq 2.5)$ & 24.1 & 42.4 & 6.80 & 1 & .01 \\
\hline High (>2.5) & 75.9 & 57.6 & & & \\
\hline \multicolumn{6}{|l|}{ Work content ${ }^{\mathrm{a}}$} \\
\hline Low $(\leq 2.5)$ & 27.6 & 23.2 & .51 & 1 & .48 \\
\hline High (>2.5) & 72.4 & 76.8 & & & \\
\hline \multicolumn{6}{|l|}{ Lack of social support ${ }^{\text {a }}$} \\
\hline Low $(\leq 2.5)$ & 93.1 & 97.7 & .31 & 1 & .58 \\
\hline High (>3.5) & 3.4 & 2.3 & & & \\
\hline \multicolumn{6}{|l|}{ Work-home interference ${ }^{a}$} \\
\hline Low $(\leq 3.5)$ & 89.7 & 86.7 & .39 & 1 & .53 \\
\hline High (>3.5) & 10.3 & 13.3 & & & \\
\hline \multicolumn{6}{|c|}{ Home-work interference ${ }^{a}$} \\
\hline Low $(\leq 3.5)$ & 98.3 & 99 & .27 & 1 & .60 \\
\hline High (>3.5) & 1.7 & 1 & & & \\
\hline \multicolumn{6}{|l|}{ Emotional exhaustion ${ }^{b}$} \\
\hline $\operatorname{Low}(0-1.12)$ & 22.4 & 17.0 & 1.55 & 2 & .46 \\
\hline Medium (1.13-2.49) & 36.2 & 33.7 & & & \\
\hline High $\quad(>2.50)$ & 41.4 & 49.4 & & & \\
\hline \multicolumn{6}{|l|}{ Depersonalisation ${ }^{b}$} \\
\hline Low (0-.59) & 48.3 & 55.4 & 7.72 & 2 & .02 \\
\hline Medium (.60-1.59) & 46.6 & 30.1 & & & \\
\hline High $\quad(>1.60)$ & 5.2 & 14.4 & & & \\
\hline \multicolumn{6}{|c|}{ Personal accomplishment ${ }^{\mathrm{b}}$} \\
\hline $\operatorname{Low}(0-3.70)$ & 10.3 & 4.2 & 3.85 & 2 & .15 \\
\hline Medium (3.71-4.70) & 15.5 & 17.3 & & & \\
\hline High $\quad(>4.71)$ & 74.1 & 78.5 & & & \\
\hline
\end{tabular}

Note: Bold font indicates significant results; ${ }^{a}$ Cut off points based on Houkes (2002); ${ }^{b}$ Cut off points based on Schaufeli \& van Dierendonk (2000) 


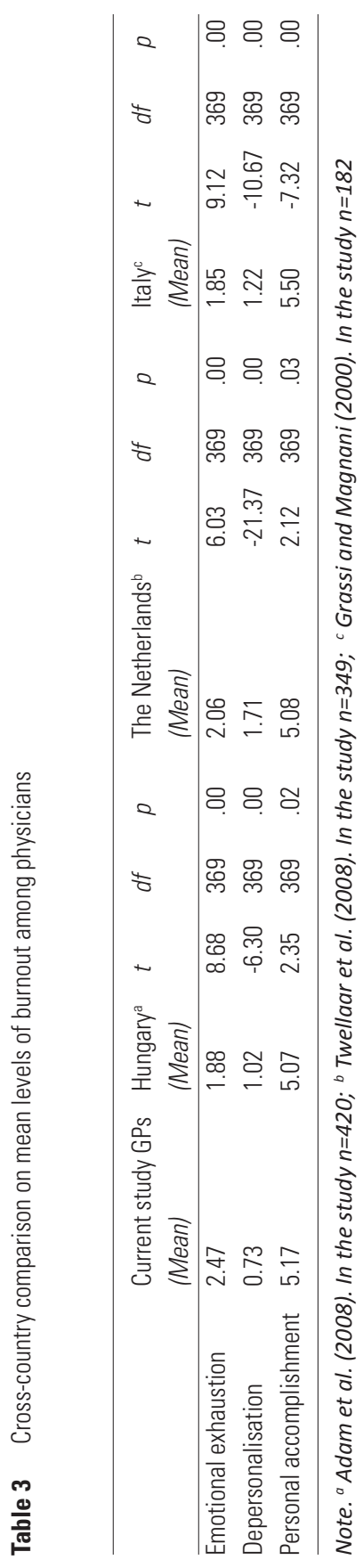




\section{Research question 3: Burnout prevalence}

Levels of burnout are reported in Table 1, and its prevalence in Table 2. Based on the cut-off points (Schaufeli \& van Dierendonk, 2000), emotional exhaustion among Serbian PHPs was medium to high, depersonalisation was medium and personal accomplishment was high. We also examined the prevalence of emotional exhaustion, depersonalisation and personal accomplishment. $49 \%$ of women and $41 \%$ of men experienced high levels of emotional exhaustion. Medium level of depersonalisation was experienced by both men and women. Unlike in other studies, in our sample, significantly more women experienced high levels of depersonalisation than men. $14.4 \%$ of women compared to $5,2 \%$ of men experienced high depersonalisation, $\chi^{2}(2)=7.72, p=.02$. Feelings of personal accomplishment at work were high for both men and women, with $78.5 \%$ of women, and $74.1 \%$ of men reporting high levels of personal accomplishment. No statistically significant gender differences were detected, but there was a tendency for greater proportion of women to experience low personal accomplishment than men ( $10 \%$ vs. $4 \%)$.

\section{Research question 4: European comparison of burnout levels among physicians}

The findings on mean levels of physicians' burnout in the current study, Hungary, the Netherlands and Italy are reported in Table 3.

When comparing the current study with other European research carried out on similar samples in Hungary (Ádàm et al., 2008), the Netherlands (Twellaar et al., 2008) and Italy (Grassi \& Magnani, 2000), it appears that Serbian physicians experience the highest levels of emotional exhaustion. Depersonalisation levels among Serbian physicians are significantly lower than in other countries $(p=.000)$. Personal accomplishment is high among physicians in all countries, but differences between Serbian physicians and physicians in other countries have been detected. Level of personal accomplishment is significantly higher among Italian than Serbian physicians, $(t(369)=-7.32, p=.00)$, but lower among Hungarian $(t(369)=2.35, p=.02)$ and Dutch physicians $(t(369)=2.12, p=.03)$.

To summarise, the cross-country results indicate that the current sample of Serbian physicians experienced the highest level of emotional exhaustion and lowest level of distancing from patients (depersonalisation) when compared to other samples.

\section{Discussion}

Our results show that physicians in Serbia have favourable work characteristics in terms of high job control, favourable work content and social support, but face adversely high work demands. The indication of high job demands may not be surprising, considering that in Serbia, there are 281 primary healthcare physicians per 100,000 people (IPHS 2008). As a comparison, countries, such as Hungary, Italy and the Netherlands, have much higher numbers of physicians per 100,000 inhabitants: 316, 606 and 329 respectively (UNDP, 2005).

Women physicians in our sample carry out more childcare and household duties than their male 
colleagues, confirming previous findings that female emancipation in Serbia has not yet translated fully into the home sphere (Massey et al., 1995; Prodanović, 2010).

In our study, levels of WHI were higher than levels of HWI. However, currently, WHI does not seem to be problematic; perhaps, a buffering factor against high $\mathrm{WHI} / \mathrm{HWI}$ is the organization of the working time schedule. In Serbia, employees of PHCs do not have night duties and work either mornings or afternoons. Since offices are shared between physicians of different shifts, this prevents structural overtime. Unlike in some other countries, like the Netherlands, on-call duties are also not part of PHPs' work. Predictability is associated with lower stress levels (Lazarus, 1999), and such stable working hours can be one potential explanatory factor for the finding that physicians with younger children do not experience more WHI than their colleagues with older children.

Lack of gender differences with respect to the levels of WHI/HWI is in line with the findings of Winants and colleagues (Winants, Twellaar, Janssen, Houkes, \& Kester). In our sample such a lack of difference may be surprising, since women carry out higher proportion of home and childcare duties than the males in this study. One possible explanation might lie in the extensive web of social network that women can rely on, which ensures that the childrearing duties do not spill over to work. It may also be due to a traditional gender ideology that prevails in Serbia. According to Greenstein, women with traditional gender ideology do not perceive unequal division of household labour as unfair, and it does not lead to increased tension between work and family sphere since the unequal division of chores is consistent with their gender ideology (Greenstein, 1995).

We found job demands to be high among our sample of participants. Based on job demandsresources model (Greenstein, 1995), high workload can explain high exhaustion. The more workload physicians experience, the higher the pace of their work and the more effort they exert, leading to higher exhaustion. Considering that they work directly with patients, this can be an emotionally demanding encounter, creating emotional exhaustion. However, high levels of exhaustion experienced among Serbian physicians may also be a reflection of demands stemming from wider economic and political situation. For many years, economic instability has created financial worries about having enough to provide for the family's needs. As an illustration, average salary of the medical doctor in 1999 in Serbia was €85 per month (Milovanović, Vasović-Mekina, Tagirov, Udovičić, Topić, \& Filkov, 2000). There was also a lot of political instability and changes in governments. The international community imposed sanctions in the 1990s as well as travel restrictions until 2010. These political events, together with the cultural norm of caring for the elderly family members, may have created increased strain on persons. This strain can manifest itself in the form of higher emotional exhaustion. Cross-cultural comparison lends support to this argument. Physicians in Serbia had the highest level of emotional exhaustion: higher than their Hungarian, Dutch or Italian colleagues.

Depersonalisation levels among Serbian physicians were lower than those of their colleagues in other countries. This indicates that Serbian physicians show less emotional distance (depersonalisation) from patients than Hungarian, Dutch or Italian physicians. Such a finding may be a reflection of the specific cultural context. In Serbia, unlike in the Netherlands for example, it is less socially acceptable to have an emotional distance from the patients. However, whether in reality 
physicians are truly that involved with the clients is worth exploring further, since social desirability might have played a role in the findings.

Unlike in other studies (Maslach, Jackson, \& Leiter, 1996; Prins et al., 2007), women in our sample reported higher levels of distancing to patients (depersonalisation) than men. An explanation for such finding may be related to different coping and communication styles between men and women. Men's greater employment of avoidance coping style (Houkes et al., 2008), may mean that it protects them from being overly involved with the patients. Such over-involvement with the patients is seen as a stage preceding development of depersonalisation (Schaufeli \& Enzmann, 1998). Thus, men's avoidance coping style may act as a buffer against distancing to patients (depersonalisation). Feminine communication style characterized by greater involvement with the clients, may at a certain point become too strenuous, resulting in depersonalisation, which acts as a form of coping mechanism (Houkes, Winants, Twellaar, \& Verdonk, 2011).

Prevalence of personal accomplishment is generally high in international studies, indicating that physicians feel efficient in their work (Ádàm et al., 2008; Lečić-Toševski et al., 2006; Twellaar et al., 2008). High level of professional accomplishment might be inherent in the profession of general physicians, since they often see clients who generally recover fast following the therapy prescribed. In cases where more serious diagnoses are found, physicians refer these patients to secondary and tertiary levels of care.

Our findings show no gender differences on mean scores of work characteristics. However, gender differences were noted regarding higher percentage of women than men having low control, high levels of depersonalisation, and greater tendency for being represented in the low personal accomplishment group. This finding indicates that women may be a particularly vulnerable group. Future research could explore in more depth the underlying mechanisms and variables associated with such poorer work and health characteristics of women.

The main drawback of our study is that no available data exist for burnout cut-off points in Serbia. As we utilized cut-off points standardized on a Dutch sample, the interpretation regarding the level of burnout should be done with caution because a different threshold for burnout might exist in the Serbian population. Scholars suggest using only nation-specific cut-off points (Schaufeli, Bakker, Hoogduin, Schaap, \& Kladler, 2001). Considering that these were unavailable, we believe it is better to have some cut-off points as a potential indicator of severity of the problem, rather than none at all. Another limitation of the study is that it was based on cross-sectional data, so no conclusion about causality can be drawn.

\section{Recommendations for future research}

Our study shows that mean values for studying gender differences may not be sensitive enough to uncover complexities of gender expressions in relation to issues of work and health, which were detectable when examining levels of work characteristics, work-home duties or burnout components. It is being recommended that in future studies, it might be worth exploring the similarity or difference in mechanisms that operate in producing particular outcomes for men and women. This 
might provide a better understanding of gendered expressions of health (Hammarström, 2003). Furthermore, we suggest a more fine tuned approach to gender research in the future.

Our final remark concerns the need for research on the topic of work and health in different cultural settings. Considering that national differences were found on all burnout subcomponents, we call for further and more in-dept examination of work and health related issues across countries.

\section{Recommendations for policy and practice}

We also formulate several main recommendations for policy and practice. First, given high workload, the number of physicians working in Serbian PHCs should be increased to help the physicians deal with the excessive work demands. Second, the position of female physicians in the workplace should be considered, given the finding that more women than men feel low control and high depersonalisation at work. More empowerment, trust and positive feedback may need to be communicated to these female employees. Finally, we make a call for culturally sensitive interventions, given the finding that all burnout subcomponents differ between Serbia and other countries. For example, targeting emotional exhaustion among Serbian physicians should be a priority, while among Dutch and Italian GPs depersonalisation is a more important symptom of burnout to be addressed. Furthermore, specific cultural norms and values may produce variant health outcomes across countries and insights on such differences/similarities can provide useful directions for proper implementation of work and health recommendations in different settings.

\section{Conclusion}

We conclude that Serbian PHPs in this study experienced unfavourable conditions in terms of high workload and medium to high emotional exhaustion. They had a medium level of depersonalisation (which was lower than in other international findings), but unlike many other studies, women tended to be more represented in the high depersonalisation group than men. Level of personal accomplishment was high among men and women, and across the countries. We saw however, inter-country differences on all burnout subcomponents, indicating that the role of nation-specific, cultural aspects might be important to consider in the future research. 


\section{References}

Ádàm, S., Gyorffy, Z., \& Susànszky, É. (2008). Physician burnout in Hungary: A potential role for work-family conflict. Journal of Health Psychology, 13(7), 847-856.

Allen, T. D., Herst, D. E. L., Bruck, C. S., \& Sutton, M. (2000). Consequences associated with work-to-family conflict: A review and agenda for future research. Journal of occupational health psychology, 5(2), 278308.

American Educational Research Association, American Psychological Association, \& Education. (AERA, APAE,). (1999). Testing Individuals of diverse linguistic backgrounds Standards for educational and psychological testing. (Vol. Rev ed., pp. 91-100). Washington, DC American Educational Research Association.

Bakker, A. B., Demerouti, E., \& Verbeke, W. (2004). Using the job demands resources model to predict burnout and performance. Human Resource Management, 43(1), 83-104.

Bakker, A. B., \& Geurts, S. A. E. (2004). Toward a dual-process model of work-home interference. Work and Occupations, 31(3), 345-366.

Bergers, G. P. A., Marcelissen, F. H. G., \& Wolff, C. J. d. (1986). VOS-D. Vragenlijst Organisatie stress-Doetinchem: Handleiding [VOS-D. Work Stress Questionnaire Doetinchem: Manual]. Nijmegen: University of Nijmegen.

Burke, R. J., \& Greenglass, E. R. (Eds.). (1987). Work and family. New York: Wiley.

Centrale Commissie Mensgebonden Onderzoek (CCMO). (2010). Wet Medisch-Wetenschappelijk Onderzoek met Mensen (Law about Medical Research Involving Human Subjects Act). Retrieved 01-2-2010, from http://wetten.overheid.nl/BWBR0009408/geldigheidsdatum_01-02-2014

Demerouti, E., Bakker, A. B., Nachreiner, F., \& Schaufeli, W. B. (2001). The job demands-resources model of burnout. Journal of Applied Psychology, 86(3), 499-512.

Dierendonck, D. v., Groenenweg, P. P., \& Sixma, H. (1992). Opgebrand. Een inventariserend onderzoek naar gevoelens van motivatie en demotivatie bij huisartsen/[Burnout. A study into feelings of motivation and demotivation among General Practitioners]. Utrecht: NIVEL.

European Foundation for the Improvement of Living Conditions (EFILC). (2002). Quality of work employment in Europe: Issues and challenges. Luxembourg: Office for Official Publications of the European Communities.

Frone, M. R., Russell, M., \& Cooper, M. L. (1992). Prevalence of work-family conflict: Are work and family boundaries assymetrically permeable? Journal of Organizational Behavior, 13(7), 723-729.

Geurts, S., Rutte, C., \& Peeters, M. (1999). Antecedents and consequences of work-home interference among medical residents. Social Science \& Medicine, 48(9), 1135.

Grassi, L., \& Magnani, K. (2000). Psychiatric morbidity and burnout in the medical profession: An Italian study of general practitioners and hospital physicians. Psychotherapy\& Psychosomatics, 69, 329-334.

Greenhaus, J., \& Beutell, N. (1985). Sources of conflict between work and family roles. Academy of Management Review, 10(1), 76-88.

Greenstein, T. N. (1995). Gender ideology, marital disruption and the employment of married women. Journal of Marriage and Family, 57(1), 31-42.

Gudac-Dodić, V. (2011). Work of women at home: Serbian practice. Currents of History, 2/2010, 152-168.

Hackman, J. R., \& Oldham, G. R. (1980). Work redesign. Reading: Addison-Wesley. 
Hammarström, A. (2003). The integration of gender in medical research and education-Obstacles and possibilities from a Nordic perspective. Women Health, 37(4), 121-133.

Hochschild, A. R. (1989). The second shift. New York: Avon.

Houkes, I. (2002). Work and individual determinants of intrinsic work motivation, emotional exhaustion and turnover intention: A study among bank employees and teachers. (Doctoral dissertation), Maastricht University, Maastricht

Houkes, I., Winants, Y., Twellaar, M., \& Verdonk, P. (2011). Development of burnout over time and the casual order of the three dimensions of burnout among male and female GPs: A three-wave studyBMC Public Health, 11:240, 13.

Houkes, I., Winants, Y. H. W. M., \& Twellaar, M. (2008). Specific determinants of burnout among male and female general practitioners. A cross-lagged panel analysis. Journal of Occupational and Organisational Psychology, 81, 249-276.

Institute of Public Health of Serbia (IPHS). (2008). Zdravstveno statisticki godisnjak Republike Srbije [Health statistical yearbook of Serbia]. Beograd: Institut za javno zdravljeSrbije 'Dr Milan Jovanovic-Batut'

Janssen, P. P. M., Jonge, J. d., \& Bakker, A. B. (1999). Specific determinants of intrinsic work motivation, burnout and turnover intentions: A study among nurses. Journal of Advanced Nursing, 29, 1360-1369.

Jonge, J. d., Landeweerd, J. A., \& Nijhuis, F. J. N. (1993). Constructie en validering van de vragenlijst ten behoeve van het project 'autonomie in het werk'[Construction and validation of the questionnaire for the 'job autonomy project'] Studies bedrijfsgezondheidszorg nummer 9. Maastricht: University of Limburg.

Kopelman, R. E., Greenhaus, J. H., \& Connolly, T. F. (1983). A model of work, family, and interrole conflict: A construct validation study. Organizational Behavior and Human Performance, 32(2), 198-215.

Krstić, G., \& Corbanese, V. (2008). Situation analysis of youth employment in the Republic of Serbia ILO Employment Papers. Budapest: International Labour Office.

Lapčević, M., Gvozdenović, B. S., \& Stanković, S. (2008). Health-related quality of life of general practitioners: Family physicians in South-Eastern Europe. Srpski arhiv za celokupno lekarstvo, 136(7-8), 397-405.

Lazarus, R. S. (1999). Stress and emotion: A new synthesis. London: Free Association Books.

Lečić-Toševski, D., Pejović-Milovančević, M., Pejušković, B., Popović-Deušić, S., Tanović-Mikulec, E., \& Hofvedt, B. O. ( 2006). Burnout syndrome of general practitioners in post-war period. [Letter to the editor]. Epidemiol Psichiatr Soc, 15(4), 319-322.

Lee, R. T., \& Ashforth, B. E. (1996). A meta-analytic examination of the correlates of the three dimensions of job burnout. Journal of Applied Psychology, 81(2), 123-133.

Lešić, A. R., Petrović-Stefanović, N., Peruničić, I., Milenković, P., Lečić-Toševski, D., \& Bumbaširević, M. Z. (2009). Burnout in Belgrade orthopedic surgeons and general practitioners, a preliminary report. Acta Chir lugosl 56(2), 53-59.

Maslach, C., Jackson, S. E., \& Leiter, M. P. (1996). Maslach Burnout Inventory manual (3 ${ }^{\text {rd }}$ ed.). Palo Alto: Consulting Psychologists Press.

Maslach, C., \& Leiter, M. P. (1997). The truth about burnout: How organizations cause personal stress and what to do about it. San Francisco, CA: Jossey-Bass.

Maslach, C., Schaufeli, W. B., \& Leiter, M. P. (2001). Job burnout. Annu Rev Psychol, 52, 392-442. 
Massey, G., Hahn, K., \& Sekulić, D. (1995). Women, men, and the 'second shift' in socialist Yugoslavia. Gender \& Society, 9(3), 359-379.

Milovanović, V., Vasović-Mekina, S., Tagirov, T., Udovičić, R., Topić, T., \& Filkov, G. (January 15 2000). Od Slovenije do Makedonije/[From Slovenia to Macedonia]. Retrieved September 13, 2010 http://www.vreme.com/ arhiva_html/471/02.html

Netemeyer, R., Boles, J., \& McMurrian, R. (1996). Development and Validation of Work-Family Conflict and Family-Work Conflict Scales* 1. Journal of Applied Psychology, 81(4), 400-410.

Paoli, P., \& Merllié, D. (2001). Third European survey on working conditions 2000. Luxembourg: Office for Official Publications of the European Communities.

Prins, J. T., Hoekstra-Weebers, J. E. H. M., Wiel, H. B. M. v. d., Gazendam-Donofrio, S. M., Sprangers, F., Jaspers, C. A., \& Heijden, F. M. M. A. v. d. (2007). Burnout among Dutch medical residents. International Journal of Behavior Medicine, 14(3), 119-125.

Prodanović, K. (2010). Double duty: Time stands still for Serbian women. Retrieved August 15, 2010

Schaufeli, W. B., Bakker, A. B., Hoogduin, K., Schaap, C., \& Kladler, A. (2001). On the clinical validity of the Maslach Burnout Inventory and the Burnout Measure. Psychology \& Health, 16, 565-582.

Schaufeli, W. B., \& Enzmann, D. (1998). The burnout companion to study and practice: A critical analysis. Philadelphia: Taylor \& Francis.

Schaufeli, W. B., \& Van Dierendonk, D. (2000). UBOS: Utrechtse Burnout Schaal, Handleiding. Lisse: Sweets Test Publishers.

Twellaar, M., Winants, Y., \& Houkes, I. (2008). How healthy are Dutch general practitioners? Self-reported (mental) health among Dutch general practitioners. European Journal of General Practice, 14(1), 4-9.

UNDP (2005). Human development report 2005: International cooperation at a crossroads. New York: UNDP.

Winants, Y. H. W. M., Twellaar, M., Janssen, P. P. M., Houkes, I., \& Kester, A. Work-family conflict in general practitioners: A gender specific analysis. Manuscript submitted for publication. 
General discussion 


\section{Introduction}

The main aim of this thesis was to explore the influence of the cultural context on work-home interface (WHI) through the lenses of workers in Malta, Serbia and the Netherlands. The cultural context was operationalised as the country of residence. Malta, Serbia and the Netherlands appeared to be an appropriate choice for examining the role of the cultural context: these three countries are characterised by different values and norms and different institutional frameworks, as represented through different types of welfare regimes and different stages of convergence towards the EU and its policies. Furthermore, the three countries also differ concerning cultural values of power distance and masculinity/femininity (Hofstede, 2008). Malta and Serbia are countries with high power distance, while the Netherlands have a low power distance. Malta scores high on masculinity, while Serbia and the Netherlands score low (as demonstrated in Appendix A).

Work-home interface is an umbrella term for both positive and negative influences between work and home domains. The focus of this thesis was on difficulties in combining work with the home domain, the so called negative work-home interface (-WHI), which is also known as work-home conflict or work-home interference. Given that $-\mathrm{WHI}$ is associated with numerous unfavourable individual, organizational and societal outcomes (Allen, Herst, Bruck, \& Sutton, 2000; Amstad, Meier, Fasel, Elfering, \& Semmer, 2011), we wished to contribute to its better understanding and create knowledge that can be put into future practice for prevention purposes.

This thesis is based on both quantitative data (chapter 2 and 5) and qualitative data (chapter 4) that were collected for the purpose of this study, and is partially relying on data from the Maastricht Cohort Study, a large prospective study conducted in the working population in the Netherlands (Kant, Bültmann, Schröer, Beurskens, van Amelsvoort, \& Swaen, 2003). Data for chapters 2 and 4 were collected between 2010 and 2013, while data for chapter 5 were collected in 2008. The participants belonged to the group of professionals that had care as a common denominator. They were all human service professionals, meaning that they worked as healthcare employees or teachers. In this way, the effect of profession on the outcome was minimized and allowed us to focus more on differences that were due to cultural context. An additional strength of the thesis is that it relies on both quantitative and qualitative approaches, which allowed us to examine work-home interface from different angles, each providing its own insight to the topic. Quantitative data was collected using the same, or highly comparable instruments. Qualitative data was collected based on the topic list that was the same for the three cultural contexts. Differences in findings that could originate from differences in data collection methods were in this way diminished.

This chapter will outline and discuss the main findings regarding the work-home interface in relation to different cultural contexts, provide methodological reflections and suggestions for future research. After that, recommendations for policy and practice will be presented. 


\section{Summary of the main findings}

The findings of this thesis show that the cultural context plays a role in relation to the negative work-home interface. Being measured with the same instrument, the prevalence of negative workhome interface differed between the cultural contexts. In Malta, every fourth, and in Serbia every fifth participant suffered from -WHI, while in the Netherlands only every $20^{\text {th }}$ participant reported problems with it. There were also different associations between work characteristics and negative work-home interface in different cultural contexts. For example, full-time work was related to -WHI in Malta and the Netherlands but not in Serbia, and colleague support was related to -WHI in the Netherlands only. Even when work and home characteristics and individual factors were controlled for, the cultural context still made a distinct contribution to -WHI, explaining around $20 \%$ of the variance, appearing to be at least as important as work and home characteristics for -WHI. These findings made us examine the conceptualization of work-home interface by current theoretical frameworks to see whether they took into account, and were sensitive to these cultural aspects.

Most literature on work-home interface focuses on the micro, individual, level of work and home characteristics. The meso and macro levels are often not included into the theoretical frameworks. Some exceptions are the models by Powell and colleagues, that make a model of specific cultural aspects in relation to $-\mathrm{WHI}$, and Shaffer and colleagues that make a more universal model of culture in relation to -WHI (Powell, Francesco, \& Ling, 2009; Shaffer, Joplin, \& Hsu, 2011). However, the former does not account for positive work-home interface and the latter does not include gender roles in the model. Thus, after examining the existing literature on work-home interface in relation to the cultural context, we developed our own framework termed the pyramid of intersecting domains of work-home interface. The pyramid has foundations in the intersectionality (Crenshaw, 1989) and work/family border theories (Clark, 2000), which we found very useful for understanding work-home interface. Intersectionality posits that social categories are context and time dependent. This implies that no social category should be presumed to be more dominant than another. It also asserts that intersections between social categories need to be examined simultaneously and that the time and cultural aspect need to be acknowledged (Hankivsky, 2012). Work/family border theory sets work and home as two separate domains, each with its own level of permeability, flexibility, degree of blending and strength. It sees people as border crossers, who are influenced by border keepers, that is, important people in each domain, such as spouses or colleagues and supervisors. We have further built on these theories in the pyramid of intersecting domains of work-home interface. The pyramid describes work-home interface as consisting of four intersecting domains: the individual work and home characteristics domain, the roles domain and the cultural domain, which all together explain the fourth domain, the observed work-home interface. All domains consist of intersecting subdomains, which can further be divided into other subdomains. The added value of the pyramid is that it takes different levels of the analysis into account (micro, meso, macro) and that it provides signposts for conducting research on work-home interface across 
cultural contexts. Furthermore, it can be used as a framework to guide policy makers in developing guidelines tailored to different cultural contexts and to people with different roles and work and home characteristics.

The Pyramid

(3-dimensional)

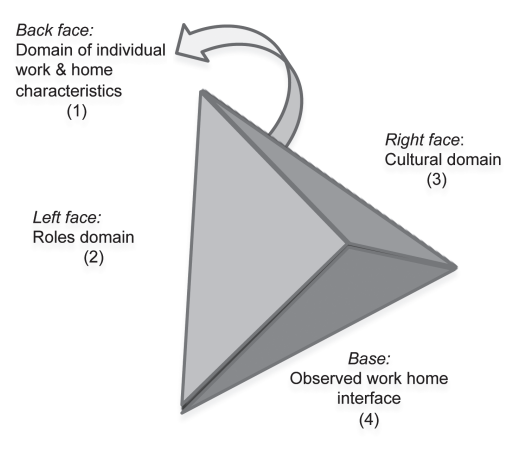

The Pyramid expanded

(2-Dimensional)

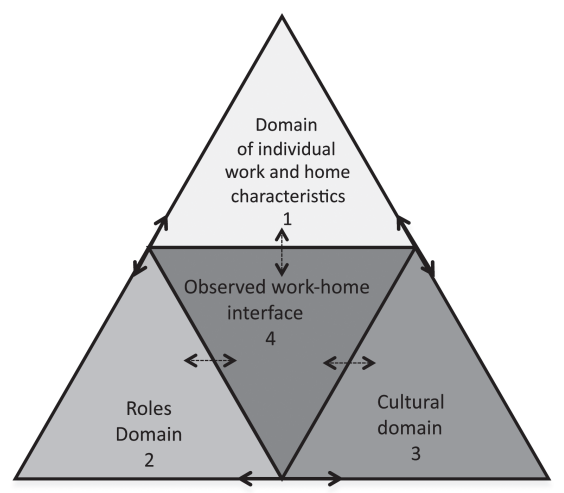

Figure 1 The pyramid of intersecting domains of work-home interface

In order to explore in more detail the way work-home interface was experienced by people in different cultural contexts, we conducted a qualitative study. The focus was on the experience with work-home interface, particularly concerning combining parenthood with employment, for both men and women. We identified four types of experience of combining work and home duties that differed from each other with regards to work centrality and family values: (1) striving for gender equality group; (2) work domain equality with financial constraints group; (3) transitional roles with family values constraints group and (4) traditional roles with work values constraints group. These four groups represent different intersections of cultural context, gender as well as age and socioeconomic positions in relation to work-home interface: Furthermore, it appeared that the cultural and gender values and norms change over time, and that these changes are often not in line with the institutional frameworks.

Lastly, we wished to explore whether these differences between cultural contexts that could be seen in work-home interface, were also related to differences in health outcomes. Thus in our final empirical study we examined work characteristics, work-home interface and health outcomes among primary healthcare physicians in Serbia and the differences across European cultural contexts in relation to health outcomes (burnout), paying close attention to the role of sex and gender. In Serbia, women carried more household and childcare tasks than men and experienced significantly 
less job control than men. Female primary healthcare physicians also experienced higher levels of depersonalization than men. When comparing the burnout levels, it appeared that the Serbian sample experienced higher levels of emotional exhaustion than other similar samples in the Netherlands, Hungary or Italy. This may be due to the lower number of healthcare physicians per inhabitant, but may also be related to the wider socio-political situation. On the other hand, Serbian physicians reported lower depersonalization than Hungarian, Dutch or Italian physicians. Cultural values and norms appeared to have played a role in the findings.

\section{Reflections on the main findings}

\section{Discussing the results of work-home interface between and within cultural contexts}

Work-home interface was measured by the same instrument in three countries. The differences in work-home interface that were detected thus cannot be due to differences in instruments. The findings of this thesis indicate that negative work-home interface is more common in Malta and Serbia, than in the Netherlands. Thus, countries that are based on more traditional gender ideology appear have higher -WHI than a country that is based more on gender equality principles. This is contrary to the gender culture hypothesis (Strandh \& Nordenmark, 2006; van der Lippe, Jager, \& Kops, 2006), that found higher -WHI in more gender equal countries. It is also contrary to the expectations based on the family economic gender model (Pfau-Effinger, 1998), whereby when both men and women contribute to the financial survival of the family unit, they are less concerned with the work-home interface and less likely to report -WHI. The findings for the Dutch sample are in line with findings that more chance for part-time work is associated with less -WHI (Jansen, Mohren, van Amelsvoort, Janssen, \& Kant, 2010; Peters, den Dulk, \& van der Lippe, 2009).

We can deduce that the single-level explanations cannot fully account for the observed results. An extension of intersectionality and work/family border theory to the pyramid of intersecting domains of work-home interface appears to be a useful theoretical framework for examining the complex nature of work-home interface across cultural contexts. Thus, besides interpreting the results through the first domain of work and home characteristics only, or the second, gender roles domain only, it appears necessary to examine the culture domain in more depth and its interplay with gender role domain and work and home characteristics domain, in order to understand the observed level of work-home interface better.

Besides comparing the findings between cultures, the results of this thesis also allow us to compare the similarities and differences in findings within a country. Namely, in Serbia, two data collection points were used and the samples consisted of human service professionals. However, the samples slightly differed: one data collection point consisted of healthcare and teaching professionals and the other of primary healthcare physicians only (i.e. no nursing and teaching professionals). The findings concerning work characteristics and work-home interface between the two data collection points in Serbia varied in some aspects. The findings were rather similar concerning the prevalence 
of unfavourable work characteristics of mental demands and low job control. Thus, it may be that the work of human service professionals (doctors, nurses and teachers) in general may be subjected to high mental demands and low job control as part of the nature of the job. However, one of the results that differed concerns negative work-home interface, which was more prevalent among healthcare and teaching professionals than among primary healthcare physicians in Serbia. One of the reasons may lie in the organisation of work: primary healthcare physicians have no shift work and have clearly structured working hours with no overtime. On the other hand, teachers in Serbia, due to limitation in number of schools available, work in weekly shifts (one week morning, one week afternoon). In this way the school is occupied by two 'shifts' of students, one in the morning and one afternoon, every day. Healthcare workers in Serbia are on irregular shift work depending on the particular organisation and the department they work in.

To conclude, the findings of this thesis indicate that the cultural context is an important aspect to be taken into account when discussing work-home interface. Furthermore, aspects such as gender and age are also important variables to be examined. Implications of such findings are that nonuniform approaches to work-home interface are most likely to yield to positive results.

\section{Shifts over time that impact work-home interface}

The qualitative paper of this thesis (chapter 4) has shown that Malta, Serbia and the Netherlands are going through changes, and that these changes are in many ways context-specific, affecting workhome interface in different ways. We reflect on some changes over time.

Financial pressure as a driver of change The financial and economic situation, situated in the cultural domain of the pyramid of intersecting domains of work-home interface, influences to the shifts that are taking place. According to Pfau-Effinger, a certain level of affluence is a pre-condition for having the male breadwinner (single earner) model as a norm (Pfau-Effinger, 1998). However, affluence does not necessarily always coincide with the male breadwinner models as the norm. In our study some of the findings could partly be explained by affluence or a lack thereof. In Malta, for example, financial pressure has often been identified as a reason for families to move from a male breadwinner model to a one-and-a half/dual earner model. In Serbia, the dual earner model is preferred, given that the earnings are relatively low, and thus negotiations for part-time work are not feasible (and also not institutionally supported). In the Netherlands, a shift appears to be taking place among the younger generations towards both men and women working part-time. This has been facilitated by a certain level of affluence i.e. two part-time incomes are sufficient to sustain a living. However, increasing financial costs of the daycare are threatening the sustainability of this model. Thus, the Netherlands is facing a pressure for the potential shift back towards a male breadwinner model or another combination of work and childcare that is more affordable, such as for example more frequent involvement of grandparents in childcare. Thus, when discussing workhome interface one cannot disregard the 'pull' factor of the financial aspect for men and women's labor participation. Furthermore, examining labour participation, without taking into account the level of affluence in the country is not giving a full picture. For example, in poorer countries, dual 
earner families are a necessity, while in the richer countries the individuals actually experience a choice between the male breadwinner and dual earner model. To conclude, although affluence is a pre-requisite for male breadwinner model, it does not imply that all affluent countries are based on it. Social values and norms are also important in influencing the labour participation of men and women.

Rate of change of societal values and norms and institutions The three cultural contexts show a time lag between changes in values and norms on the one hand and institutional frameworks on the other. In Malta a shift has been reported towards more women taking part in the labour force. However, at the time of the interviews, the shift was not accompanied by changes in institutions, such as the provision of childcare facilities. Furthermore, values and norms were also not shifting uniformly to accompany this actual shift: women who were working were not liberated from the caretaking roles. Thus, 'the male breadwinner model is still a cultural artifact, even of the dualworker family' (p. 17, Rizzo, 2009). Men on the other hand had often more than one full-time job, and although they were happy that they contributed to their family obligation by being the main financial provider, they also reported dissatisfaction with missing out on many family moments. Social norms exert pressure to remain with the current pattern and not make changes in the working commitments.

In Serbia on the other hand, the institutional support for dual earner workers was already there since the 1950s. Childcare facilities are widely available and there was no societal disapproval of women who have children and work full-time. However, values and norms concerning the mother's role at home such as raising the children has been more resistant to change. There is a process of shift described by the participants towards more equal sharing of the household and childcare between men and women.

In the Netherlands, at the time of the interview the societal values and norms were largely in line with each other. Having two full-time working parents was not a norm, but neither did the institutions support this kind of scenario. It was believed that children under the age of four should stay at home at least a few days a week, and this was supported institutionally: childcare costs were rather high, making it financially unfeasible for parents to make use of it for more days in a week.

\section{Reflection on methodological aspects}

This study was based on a relatively large quantitative and qualitative data sets and can as such be considered a mixed method study. These two types of methods allowed us to gain insight into the topic of work-home interface across cultural contexts from different perspectives. The data in each country were collected in a rather short period of time, thus minimizing intra-country differences due to differences in time selection windows. The qualitative data collection in three cultural contexts was based on the same interview guide and the same topic list (points of emphasis varied depending on the relevance for a particular cultural context). The survey examined the same variables across 
the three countries. This section explains how the results of the quantitative and qualitative parts can reinforce each other and can also yield different insights. The findings associated with these two different types of data sources were reflected on.

\section{Operationalisation of variables}

One of the main challenges in this dissertation was to operationalise gender and cultural context, as these two concepts are broad and multidimensional. In this thesis, the quantitative operationalisations of sex, gender and cultural context contributed to gaining insight into the extent of importance of these variables in relation to work-home interface. Furthermore, it allowed us to correct for differences between samples and between cultural contexts. In the qualitative study, independent impact of sex, gender and cultural context was difficult to disentangle. At the same time, the qualitative study allowed us to appreciate the complexity and interrelatedness, and intersectional nature of these issues. It is important to reflect on the operationalisation of the main variables in the study.

Sex Operationalising sex in the quantitative and qualitative study at a first glance appeared rather simple, one was a man or a woman. However, upon further investigation, it appeared to be a more complex issue, both in the quantitative and qualitative approaches. The extent to which scales are affected by sex and gender was hard to grasp and in the qualitative approach it was also not clear to what extent certain situations or views were due to the person's sex or gender. It appears that the values behind sex, that are associated with gender are difficult to grasp. Moreover, there is also a question whether other issues came to play a role as well. For example, was one acting in a certain way because of his or her sex, gender, or even maybe because of a certain socio-economic status/ class issue? These questions remain unanswered.

Gender We managed to examine only the masculinity aspect of one's gender in the quantitative study, since the femininity subscale did not have adequate reliability, limiting the gender operationalization only to one aspect of it. In the quantitative study, neither sex, nor masculinity, appeared to be associated with work-home interface. However, taking the insights from the qualitative approach, it appears that sex and gender aspects play an important role. Qualitative data brought into the light societal expectations concerning men and women, and exposed the differences in expectations concerning work and home domains.

Cultural context We detected the importance of the cultural context in relation to WHI, but did not gain insight into exactly which aspects of the cultural context are the most relevant for workhome interface: whether it is due to the institutional aspects, financial and economic reasons or societal and organizational norms. We also did not examine cultural differences in the threshold for reporting negative work-home interface, or burnout. A study by Madan and colleagues has shown that the threshold for reporting certain health issues may be influenced by cultural beliefs (Madan, Reading, Palmer, \& Coggon, 2008). The fact that the Dutch sample reported lower -WHI may be due to differences in sample compositions, but could also possibly be explained by cultural aspects concerning the threshold for -WHI. Furthermore, cultural contexts are not uniform, and 'although 
there is a set of dominant cultural values and ideals, it cannot be assumed that there is cultural 'coherence' in society. Alternative and competing cultural value systems may exist' (p150, PfauEffinger, 1998). Thus, one may wonder whether we have captured only the dominant culture, or by chance captured a part of subculture, and to what extent. Given that in the qualitative data we did not have many single parents and did not have persons belonging to sexual minorities, it is highly likely that our sample represents a dominant culture. Thus, we have probably failed to capture the subcultures and the existing diversities within each culture.

Work and home characteristics In the quantitative approach, generally already existing, validated measures were used to examine work and home characteristics. A lot of the instruments used were identical in the three cultural contexts. However, some differed between the Netherlands and Malta/Serbia, given that the Dutch data was largely based on an already existing dataset. Having said that, the scales were largely comparable, and most of the time provided the same number of answering options. In a few rare cases when answering options differed, recoding of scales was done to make them comparable between the countries. The reliability of measures was good in all three cultural contexts. Qualitative data collection provided additional insights into variables that could be explored in further detail in the future. For example, expectations concerning childcare and costs as well as availability of childcare options appear to be relevant for labour participation and could be explored in more detail in the future. Furthermore, meso level characteristics concerning work culture should also be incorporated in the future studies, as they may play an important role in workhome interface and health of employees.

Work-home interface A reflection on the operationalization of work-home interface is also needed. We used a validated measure, the SWING questionnaire (Geurts, Taris, Kompier, Dikkers, van Hooff, \& Kinnunen, 2005), which showed a high reliability in our sample (Cronbach's alpha was around .80 in all three samples) and Work-Family Conflict/Family-Work Conflict scale in the Serbian primary healthcare physician study (Kopelman, Greenhaus, \& Connolly, 1983; Netemeyer, Boles, \& McMurrian, 1996) which also showed high reliability (Cronbach's alpha was above .80). The advantage of both scales was that they examined the direction of conflict from work to home and home to work. The strength of the SWING questionnaire was that it inquired about work and home aspects. The Work-Family Conflict/Family-Work Conflict scale inquired about work and family and only in a few items inquired about work and home. Thus, this scale may be less applicable to the participants who live alone. Furthermore, the weak point of both scales was that they inquired mostly about the time and energy conflicts, leaving the behavior subcomponent of work-home interface less explored. Furthermore, some aspects of the work-home interface such as expectations and norms were not capture by the surveys, although they do shape the way work and home domains are combined, and experienced (Greenstein, 1995). These aspects of work-home interface were difficult to capture in a survey, but were captured by the qualitative approach. 


\section{Added value of using both quantitative and qualitative approaches}

Findings between quantitative and qualitative approaches yielded distinct insights into work-home interface, allowing us to examine the topic more thoroughly. Via the quantitative approach we examined in depth the questions related to how much certain variables were important for workhome interface and to quantify the differences. On the other hand, via the qualitative approach we could stay open to emergence of variables that were important to the participants, of which we could not think of ourselves (Creswell, 2003). Thus, each of the two approaches had the added value for understanding work-home interface.

Through surveys, we assessed the current situation of the participants and through interviews we also gained insight into the changes in work-home interface over time. Thus, although one of the limitations for examining the time aspect and changes over time in this thesis could be pinned down to the lack of longitudinal quantitative data, by employing qualitative techniques this pitfall was partially overcome. Interviews were a rich source of information concerning the changes in societal values and norms, as well as institutional frameworks that do (not) change to reflect these societal changes.

Findings between the two approaches explained different aspects of work-home interface. Quantitative approach appeared to capture work characteristics particularly well. It showed the extent of work characteristics' contribution to work-home interface. The qualitative study on the other hand gave more detailed insight into what type of macro level characteristics associated with cultural context could be responsible for making a contribution to differences in WHI. The qualitative study did not go into detail concerning work characteristics and WHI. Thus, the two approaches appeared to be complementary, each giving its own valuable contribution to better understanding of WHI.

The two approaches led to some different findings. The quantitative approach found no association between age, sex (except for the Maltese sample) and gender and work-home interface, nor found the interaction effect of age, sex, gender and culture on work-home interface. On the other hand, the qualitative approach indicated that expectations concerning work and home domains, as well as constraints and facilitators of work-home interface often differed between men and women of different ages and between countries. Thus, unlike the quantitative approach, that found no interaction effects of age, sex, gender and country, the qualitative approach indicated that they were intertwined and intersecting. The qualitative approach was able to capture nuances and complexities that were not detected by the instruments used in a survey, which may explain the differences in findings concerning interactions between social categories. It may also be that the time aspect is crucial in detecting the intersections of sex, gender, age and country in relation to WHI, something that the qualitative approach allowed us insight into, but cross-sectional quantitative data did not.

\section{Sampling issue and time window}

Given that the quantitative and qualitative data were collected concurrently most of the time, it did not allow us to match the characteristics and variety of interviewees with the majority of the characteristics exhibited by the quantitative sample. This may have created differences in findings 
between the quantitative and qualitative data, particularly concerning the Dutch sample, as there was most deviation between the quantitative and qualitative sample. The majority of the Dutch quantitative sample was above the age of 50 . The qualitative data on the other hand were based on a much greater variety of younger and older participants, being able to catch also the generational differences. Thus, potential differences between quantitative and qualitative findings may partly also reflect differences in samples as seen in differences in age and family constellation. Furthermore, in order to avoid that the significance of results differs between countries due to differences in sample sizes, rather than actual differences in associations, we have used the smallest common denominator to calculate the sample size. In our study, the Dutch sample was the smallest ( $n=288$ ), and then for the Serbian and Maltese samples 288 participants were randomly selected per country from the larger sample we collected (for Serbia, $n=595$ and for Malta $n=720$ ). Another point relevant to be pointed out is that the sample consisted of employees working in education and healthcare, meaning that they were all (highly) educated. The working conditions and work-home interface need to be explored in other professions, with different working conditions and among people with different educational backgrounds than our sample. Thus, caution needs to be exercised in using the findings from this thesis for other occupational groups. Given the rather narrowly defined professional group and their educational level, as well as the non-representative sampling technique, the findings should not be generalised to other professional groups or countries.

The majority of data for this study were collected in 2010 in Malta and Serbia, and in 2012 and 2013 in the Netherlands. This time window encompasses that period of time that was after the first wave of financial crisis that occurred in $\mathbf{2 0 0 8}$ worldwide. However, the crisis has continued and in many ways even deepened from the moment we collected data to the present moment. In countries like Serbia, there has been a decrease in salaries and pensions and in the Netherlands a tighter financial scenario followed as well, where citizens are asked to pay higher contributions to childcare, healthcare and take more caring tasks than in previous years. Thus it is plausible that the work-home interface and its unfavorable health and organisational effects are more unfavourable today than what our study indicates.

\section{Cultural sensitivity during data collection}

Conducting research across cultural contexts requires cultural sensitivity, both for the process of data collection and for the content of the data to be collected. Concerning the process of data collection, we would like to highlight the need for flexibility and adaptability to the local context. Cultural contexts differ concerning the degree of structure and hierarchy as well as planning. For example, while conducting the study in Malta and the Netherlands, a relatively long study preparation time was needed for contacting potential participants and agreeing on the meetings. This meant that once the data collection began, the pre-planned road was to a large extent followed. Good preparation appeared to be essential. On the other hand, in Serbia, a very different approach appeared to work. Initially, we approached the study setting in the same way: trying to prepare the research ground in advance, obtain contacts, set up meetings well in advance. However, this approach yielded no 
results. Presence of the researcher in the country was of essential importance, and meetings were planned at relatively short periods of time. Long-term planning appeared not to be the appropriate strategy for the Serbian context. Rather, spontaneity and adaptability to the circumstances appeared to be crucial for data collection. Thus, in the process of data collection, sensitivity and adaptability to the local cultural context are of essence for successful data collection.

Similarly, the content of the data collected may vary between the cultural contexts, something that was apparent during the qualitative data collection (interviews). The topic list was prepared that would take into account different aspects of all three cultural contexts, and it appeared that some questions were not relevant for certain settings, while in others they yielded rich information. For example, asking women whether they returned to work after they had a first child was quite strange in the Serbian context, as for many women there was no doubt that they would return to work, it was a 'normal' thing to do. On the other hand, such a question in Maltese and Dutch cultural settings was very appropriate and yielded a lot of information about the work and home domains of new mothers. Similarly, the role of the wider socio-economic changes, yielded a lot of response from the Serbian and Maltese participants. Serbian participants reflected on the recent war history, a rather unstable political situation and economic hardships, while Maltese participants reflected on the changes that have happened as the country joined the EU and economic changes. Role of religion also played an important role in shaping work and family values in Malta, while in Serbia and the Netherlands it was rarely reflected on.

\section{Implications for future research}

We call on researchers to be culturally sensitive and adapt to local circumstances when collecting data in different cultural contexts. Furthermore, data collection procedure should also reflect this sensitivity and leave space for participants to elaborate on aspects that are culturally relevant for them. This is relatively easy to implement in qualitative data collection processes and harder via quantitative data collection means. A suggestion would be to pilot both quantitative and qualitative data collection methods in each cultural setting and add culturally relevant aspects per country.

In order to understand the relation between institutions, values and norms and their association with work and home characteristics and work-home interface, we suggest that future research takes a closer look at the temporal aspect. Examining the aspects of culture and roles will take time, as changes that deal with values, norms and complex systems need time to take effect and are complex to implement. Thus, evaluating the impact of such changes on work-home interface calls for a longitudinal data collection method with a long follow-up period.

Furthermore, we advise that samples be matched closely concerning individual characteristics, such as age, family constellation and profession. A mixed method approach seems the most appropriate for this kind of data collection.

It would also be important to quantify gender and cultural aspects more elaborately, and include 
for example gender roles and expectations, societal norms and values as some of the variables in the studies. Related to this more attention should be paid to intergenerational differences and socioeconomic/class differences. Also more single parent, same sex families and less educated samples should be added to capture the diversity of the general population better.

\section{Implications for policy and practice}

The findings of this thesis clearly point towards the importance of the cultural context: there are differences in factors that are associated with work-home interface, there are different problem areas to be tackled as shown by different prevalence of unfavourable variables and above all, the cultural context has its own, independent and substantial contribution to work-home interface. Achieving convergence on a socioeconomic level is of high priority in the EU agenda. It may be best to achieve the convergence on the results (average socioeconomic level in each EU country) by the divergence in the approaches, i.e. policies and ways of achieving socio-economic targets need to fit with the cultural context. Thus, applying a 'one size fits all' approach will clearly not be useful for policy makers and practitioners. This thesis indicates that divergence on a policy level should be the future of the EU in order to ensure efficient and appropriate approach to work-home interface issues. By employing a culturally sensitive approach, we can use the resources more efficiently and achieve better results on a country level, which eventually leads to better overall EU health levels. Our findings also signal the added benefit of using mixed method approaches for understanding the issue of work-home interface. Policy makers benefit from consulting both quantitative and qualitative sources of information, and taking into account sex, gender and ages of the target group population when writing country-specific policies.

The findings of this thesis indicate that there is a need to explore the work-home interface beyond emic and etic approaches. Although the thesis lends support to the mental demands being a uniform stressor among human service professionals working in Malta, Serbia and the Netherlands, other aspects are much more complex. It appears that it is a mix of individual, meso and macro levels that impact work-home interface, and the way these levels intertwine is unique. As the qualitative findings have indicated, it is a mix of age, gender as well as cultural context that impacts work-home interface. Thus, a culturally specific approach needs to include also other social categories in order to create efficient, tailor-made policies. A specific, tailor made approach is called for, that includes, and goes beyond, culture-specific aspects.

\section{Sustainable employment}

The findings of this thesis also have implications for sustainable employment practices across cultural contexts, which is high on the EU agenda. Sustainable employment is dependent on health and well-being of employees, as well as their attitudes and motivation for work (van der Klink, Brouwer, Bültmann, Burdorf, Schaufeli, van der Wilt, \& Zijlstra, 2010). Sustainable employment underpins the 
importance of combining productivity with psychological and economic well-being of individuals over time (Michigan State University, 2013). In view of the greying of the population there is a need for an increase in labour participation that would contribute enough to financially sustain the growing elderly population through taxpayers' contributions. Furthermore there is also a need to decrease negative work-home interface, since it is associated with negative health outcomes, leading to sickness absence rates and its long duration, which are large financial burden for the organisations and society.

High mental and emotional demands appear to be a threat to human service professionals' and primary healthcare physicians' well-being, as they were reported by over $60 \%$ of the participants. Relatively high level of emotional exhaustion is also a potential threat to sustainable employment, as with poor psychological health or exhaustion one is more likely to experience long-term sickness absence (Peterson, Bergström, Demerouti, Gustavsson, Åsberg, \& Nygren, 2011) or even completely exit the labour market (prematurely). Thus, working conditions that impact mental and emotional well-being need to be addressed. Given that the cultural context is important in this regard, one should employ a culturally-sensitive approach, meaning that policies used to tackle mental and emotional well-being need to fit to the needs of the different groups of people. For example, high mental and emotional demands in one cultural context may be due to limited amount of professionals per number of patients or students, while in another they may be related to the organisation of work and yet in another due to overall difficult living conditions that drain people's resources. These different scenarios would need different policies to decrease high mental and emotional demands.

Another way of supporting sustainable employment would be that the organisations invest time and effort in primary prevention measures. Some concrete examples could be to include family friendly policies that deal with work and life balance, paid parental leave, flexible working hours or possibility to telework. However, different aspects of primary prevention may be relevant in different cultural contexts and may differ for men and women, so cultural and gender sensitivity needs to be exercised also in the realm of prevention. For example, countries that are low in power distance are more likely to accept teleworking, and thus this could be an approach to tackle $-\mathrm{WHI}$ in countries like the Netherlands. Flexible working hours may be more very useful in countries such as Malta and the Netherlands where the presence of a parent at home when children come back from school is highly valued.

Besides offering the policies in the written form, management should actively encourage their use, as otherwise the provisions offered by policies may not be used by employees (Hochschild, 1997). Furthermore, health and well-being of the employees should regularly be monitored, and secondary prevention measures be put in place for employees being detected at risk of $-\mathrm{WHI}$ or poor health.

Sustainable employment is also related to the attitude and motivation of the employee (van der Klink et al., 2010). Our findings suggest that the attitudes and motivation for employment may vary between cultural contexts and genders. For example, in certain cultural contexts it is the financial necessity that is the main motivator for employment (such as Serbia and for certain subgroups Malta), while in other cultural contexts work is primarily seen as contributing to personal development (such 
as some Maltese subgroups, and some Dutch participants). This implies that should one work on motivation for longer participation in paid employment of persons, different approaches need to be taken, depending on the cultural context, gender as well as age of employees. For example, ensuring that there is space for personal growth would be an important aspect to focus on for some Maltese and Dutch groups, while financial incentive would play an important role in Serbia and for some participants in Malta.

\section{Final conclusion}

Cultural context and gender roles matter for work-home interface. Associations between variables and work-home interface as well as their prevalence vary between the cultural contexts. Given that the commonly studied work and home characteristics explain roughly as much variance as the cultural context, we call for a more detailed exploration of its contribution to work-home interface. For example, the role of the policies concerning work and home interface along with the gender roles and values should be included in future studies on this topic. Also, various intersections of culture, gender, age and other social categories in relation to work-home interface should be explored.

Work-home interface, as described by the pyramid of intersecting domains of work-home interface, is a multifaceted phenomenon. The findings in this thesis lend the support to this framework. We believe that this thesis can be of use to occupational health researchers, as well as policy makers at the organizational, governmental and EU levels. The findings emphasise the need for sensitivity that needs to be exercised in carrying out research and policy writing on work-home interface across cultural contexts, age groups and genders. The approach 'one size fits all' does not appear useful, and a call is made for flexible and tailor made policies instead. 


\section{References}

Allen, T. D., Herst, D. E. L., Bruck, C. S., \& Sutton, M. (2000). Consequences associated with work-to-family conflict: A review and agenda for future research. Journal of occupational health psychology, 5(2), 278-308.

Amstad, F. T., Meier, L. L., Fasel, U., Elfering, A., \& Semmer, N. K. (2011). A meta-analysis of work-family conflict and various outcomes with a special emphasis on cross-domain versus matching-domain relations. Journal of occupational health psychology, 16(2), 121-169.

Clark, S. C. (2000). Work/family border theory: A new theory of work/family balance. Human Relations, 53(6), 747-770.

Crenshaw, K. (1989). Demarginalizing the intersection of race and sex: A Black feminist critique of antidiscrimination doctrine, feminist theory and antiracist politics. University of Chicago Legal Forum, 139, 139-167.

Creswell, J. W. (2003). Research design: Qualitative, quantitative, and mixed methods approaches (2nd ed.). London: Sage publications.

Geurts, S. A., Taris, T. W., Kompier, M. A., Dikkers, J. S., Van Hooff, M. L., \& Kinnunen, U. M. (2005). Work-home interaction from a work psychological perspective: Development and validation of a new questionnaire, the SWING. Work \& Stress, 19(4), 319-339.

Greenstein, T. N. (1995). Gender ideology, marital disruption and the employment of married women. Journal of Marriage and Family, 57(1), 31-42.

Hankivsky, O. (2012). Women's health, men's health, and gender and health: implications of intersectionality. Social Science \& Medicine, 74(11), 1712-1720.

Hochschild, A. R. (1997). The time bind: When work becomes home and home becomes work. New York: Metropolitan/Holt.

Hofstede, G. (2008). Values Survey Module 2008 manual. Retrieved 1909 2009, from http://www.geerthofstede. eu/vsm-08

Jansen, N. W., Mohren, D. C., van Amelsvoort, L. G., Janssen, N., \& Kant, I. (2010). Changes in working time arrangements over time as a consequence of work-family conflict. Chronobiology international, 27(5), 10451061.

Kant, I., Bültmann, U., Schröer, K., Beurskens, A., Van Amelsvoort, L., \& Swaen, G. (2003). An epidemiological approach to study fatigue in the working population: the Maastricht Cohort Study. Occupational and Environmental Medicine, 60(suppl 1), 32-39.

Kopelman, R. E., Greenhaus, J. H., \& Connolly, T. F. (1983). A model of work, family, and interrole conflict: A construct validation study. Organizational Behavior and Human Performance, 32(2), 198-215.

Madan, I., Reading, I., Palmer, K. T., \& Coggon, D. (2008). Cultural differences in musculoskeletal symptoms and disability. International journal of epidemiology, 37(5), 1181-1189.

Netemeyer, R., Boles, J., \& McMurrian, R. (1996). Development and validation of Work-Family Conflict and Family-Work Conflict Scales. Journal of Applied Psychology, 81(4), 400-410.

Peters, P., den Dulk, L., \& van der Lippe, T. (2009). The effects of time-spatial flexibility and new working conditions on employees' work-life balance: The Dutch case. Community, Work \& Family, 12(3), 279.

Peterson, U., Bergström, G., Demerouti, E., Gustavsson, P., Åsberg, M., \& Nygren, Å. (2011). Burnout levels and 
self-rated health prospectively predict future long-term sickness absence: A study among female health professionals. Journal of Occupational and Environmental Medicine, 53(7), 788-793.

Pfau-Effinger, B. (1998). Gender cultures and the gender arrangement-a theoretical framework for crossnational gender research. Innovation: The European Journal of Social Science Research, 11(2), 147-166.

Powell, G. N., Francesco, A. M., \& Ling, Y. (2009). Toward culture-sensitive theories of the work-family interface. Journal of Organizational Behavior, 30(5), 597-616.

Rizzo, S. (2009). The dual-worker family: Combining working life with social life. Bank of Valletta Review(39), 1-19.

Shaffer, M. A., Joplin, J. R. W., \& Hsu, Y. S. (2011). Special review article: Expanding the boundaries of work-family research: A review and agenda for future research. International Journal of Cross Cultural Management, 11(2), 221-268.

Strandh, M., \& Nordenmark, M. (2006). The interference of paid work with household demands in different social policy contexts: perceived work-household conflict in Sweden, the UK, the Netherlands, Hungary, and the Czech Republic. The British Journal of Sociology, 57(4), 597-617.

van der Klink, J. J. L., Brouwer, S., Bültmann, U., Burdorf, A., Schaufeli, W. B., van der Wilt, G. J., \& Zijlstra, F. R. H. (2010). Duurzaam inzetbaar: Werk als waarde [Sustainable employability: Work as value]. Den Haag: ZonMw.

van der Lippe, T., Jager, A., \& Kops, Y. (2006). Combination pressure: The paid work-family balance of men and women in European countries. Acta Sociologica, 49(3), 303-319. doi: 10.1177/0001699306067711 


\section{Appendix A}




\section{Differences in cultural values between Malta, Serbia and the Netherlands}

In this thesis, country was used as a proxy for cultural context. To check whether this assumption is correct, we examined the differences in Hofstede's cultural values of power distance and masculinity/ femininity between Malta, Serbia and the Netherlands

Power distance and masculinity/femininity items were obtained from the Values Survey Module questionnaire (Hofstede, 2008). Power distance and masculinity/femininity were measured by four items each. Answering categories ranged from of utmost importance (1) to of very little importance (5). An example of the item for power distance was: "In choosing an ideal job, how important would it be to you to be consulted by your boss in decisions involving your work?". An example of the item for the masculinity/femininity subscale was: "In choosing an ideal job, how important would it be to you to get recognition for good performance?". The subscales of power distance and masculinity/ femininity were calculated using the index provided by Hofstede and colleagues (Hofstede, Hofstede, Minkov, \& Vinken, 2008). In table 1 are findings from our study presented alongside findings of Hofstede (Hofstede, 1980) and his citing of Hoppe's findings (Hoppe, 1990). It is important to keep in mind when comparing the findings between studies that it is the relative standing of countries in relation to each other that matters, rather than their absolute numbers. Table 1 highlights that our findings are similar to findings of Hofstede and Hoppe concerning dimensions of power distance and masculinity/femininity for the three countries.

Table 1 Comparison of Malta, Serbia and the Netherlands on value dimensions of power distance and masculinity/ femininity

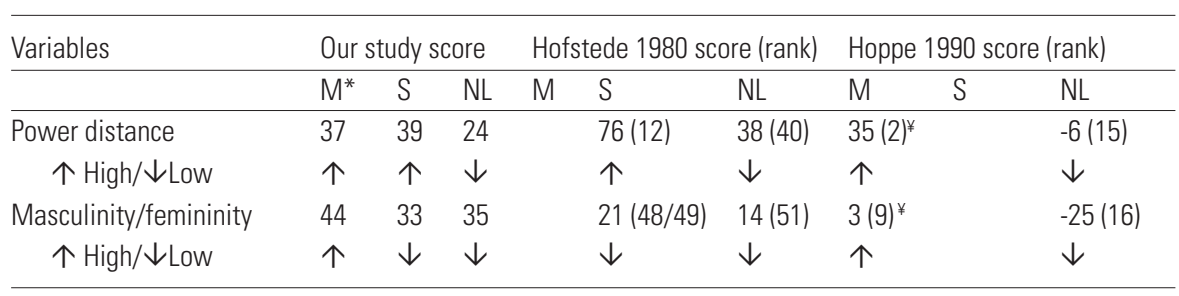

Note: *M=Malta, $\mathrm{S}=\mathrm{Serbia}, \mathrm{NL}=$ The Netherlands; ${ }^{*}$ rank position inferred based on other countries' scores

When examining findings from our study we saw that Malta, Serbia and the Netherlands had different cultural values, as shown by statistically significant differences between countries on the cultural dimension of power distance, $F(2,528.92)=9.29, \mathrm{p}<.001$, and masculinity/femininity, $F(2$, $524.79)=3.05, p<.05$. Dunett's post-hoc test revealed a statistically significant difference on power distance between the Netherlands and Serbia $(p<.001)$ and the Netherlands and Malta $(p<.01)$ and on masculinity/femininity dimension between Malta and Serbia $(p<.05)$. Thus, it is plausible to conclude that the three countries of Malta, Serbia and the Netherlands represent three different cultural contexts. 


\section{References}

Hofstede, G. (1980). Culture's consequences: International differences in work-related values. Beverly-Hills, Ca: Sage.

Hofstede, G. (2008). Values Survey Module 2008 questionnaire. Retrieved 1909 2009, from http://www. geerthofstede.eu/vsm-08

Hofstede, G., Hofstede, G.J., Minkov, M., \& Vinken, H. (2008). Values Survey Module 2008 manual. Retrieved 19 09 2009, from http://www.geerthofstede.nl/vsm-08

Hoppe, M. H. (1990). A comparative study of country elites: International differences in work-related values and learning and their implications for management training and development. (Unpublished doctoral dissertation), University of North Carolina at Chapel Hill. 
Summary 
Work-home interface concerns the relationship between work and home domains. The two domains can be enriching, or conflicting, with each other. Negative work-home interface (-WHI) represents the difficulties in combining work with the home domain, which can be due to time, role or behaviour conflict. Previous research shows that negative work-home interface is associated with poor health and burnout, decreased productivity, increased sickness absence rates and higher turnover rates. Gender roles and values vary between cultural contexts, and impact the work-home interface. Furthermore, through differences in societal values and institutional frameworks, workhome interface is also affected. Thus, factors that are important for the work-home interface are likely to vary between different cultural contexts. In order to further the understanding of the workhome interface, there is a need for more studies that explore the work-home interface between two or more cultural contexts and also a need for more qualitative studies. Developing a theoretical framework that takes into account cultural aspects would also be beneficial for research as well as practice.

The main aim of this study was to gain insight into the role of the cultural context in relation to the work-home interface in order to serve future research and policy makers at various levels in optimising work-home interface and improving health and well-being. The cultural contexts examined in this study were Malta, Serbia and The Netherlands. The study population included healthcare and teaching professionals.

Chapter one introduces the topic of work-home interface and the relevance of paying attention to the role of the cultural context. It gives an insight into the current state of knowledge in the field concerning the role of the cultural context, sex and gender. It also introduces the importance of work-home interface from the policy and science perspective. The chapter ends with giving an overview of the research setting, and provides background information about Malta, Serbia and the Netherlands.

Chapter two examines in a quantitative manner the prevalence of -WHI in Serbia, Malta and the Netherlands as well as the similarities and differences in associations between work and home characteristics among healthcare, nursing and teaching professionals in these different cultural contexts. Healthcare professionals were all working in the secondary healthcare centers and teachers worked in primary, secondary or tertiary level of education. The sample size consisted of 288 participants per cultural context, of which $39 \%$ were men and $61 \%$ were women. Findings indicate that cultural context plays an important role in relation to negative work-home interface. Being measured with the same instrument, the prevalence of negative work-home interface differed between the cultural contexts. In our sample in Malta, every fourth, and in Serbia every fifth participant suffered from -WHI, while in the Netherlands only every $20^{\text {th }}$ participant reported problems with it. These differences in prevalence could be due to differences in work and home characteristics. However, when work and home characteristics and individual factors were controlled for, the cultural context still made a distinct contribution to $-\mathrm{WHI}$, explaining around $20 \%$ of the variance, appearing to be at least as important as work and home characteristics for -WHI. There were also different associations between work characteristics and -WHI in different cultural contexts. 
For example, full time work was related to -WHI in Malta and the Netherlands but not in Serbia, and colleague support was related to -WHI in the Netherlands only. Being a planner of the household duties and having poor health were associated with -WHI in Malta only, while having a child younger than 12 years of age was associated with -WHI in the Netherlands only. We conclude that cultural context appears to play an important role in experiences with $-\mathrm{WHI}$. Thus, these findings made it relevant to examine the conceptualization of work-home interface by current theoretical frameworks to see whether they took into account these cultural aspects.

In chapter three we propose a new framework for the work-home interface. Currently, most literature on work-home interface focuses on the micro, individual, level of work and home characteristics. The meso and macro levels are often not included in the theoretical frameworks. A few models are exceptions, as they do take into account specific, or more universal, cultural aspects in relation to - WHI. However, what they do lack is that they for example do not account for positive work-home interface or do not include gender roles in the models. Thus, after examining the existing literature on work-home interface in relation to the cultural context, we developed a new framework termed the pyramid of intersecting domains of work-home interface. The pyramid has foundations in the intersectionality and work/family border theories, which we found very useful for understanding work-home interface. Intersectionality posits that social categories are context and time dependent. This implies that no social category should be presumed to be more dominant than another. It also asserts that intersections between social categories need to be examined simultaneously and that the time and cultural aspect need to be acknowledged. Work/family border theory sets work and home as two separate domains, each with its own level of permeability, flexibility, degree of blending and strength. It sees people as border crossers, who are influenced by border keepers, that is, important people in each domain, such as spouses or colleagues and supervisors. We have further built on these theories in the pyramid of intersecting domains of work-home interface. The pyramid describes work-home interface as consisting of four intersecting domains: the individual work and home characteristics domain, the roles domain and the cultural domain, which all together explain the fourth domain, the observed work-home interface. All domains consist of intersecting subdomains, which can further be divided into other subdomains. The added value of the pyramid is that it takes different levels of the analysis into account (micro, meso, macro) and that it provides signposts for conducting research on work-home interface across cultural contexts. Furthermore, it can be used as a framework to guide policy makers in developing guidelines tailored to different cultural contexts and to people with different roles and work and home characteristics. 
The Pyramid

(3-dimensional)

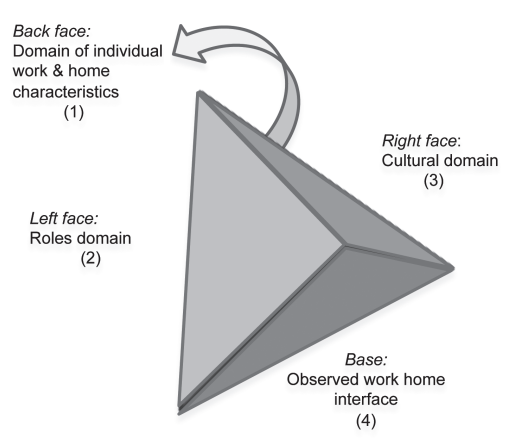

The Pyramid expanded

(2-Dimensional)

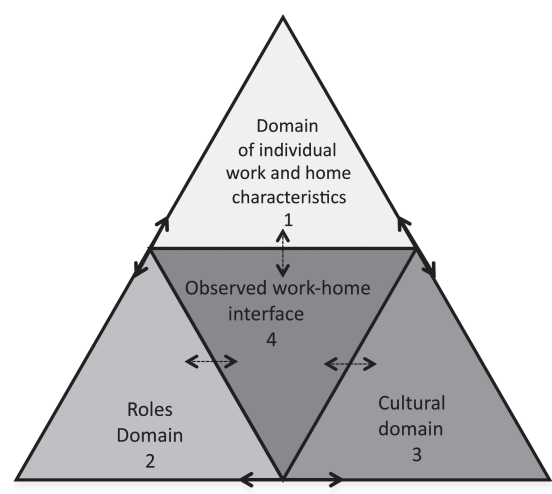

Figure 1 The pyramid of intersecting domains of work-home interface

In order to explore in more detail the way work-home interface was experienced by people in different cultural contexts, we conducted a qualitative study, reported in chapter four. The aim was to explore how cultural context and gender are related to combining paid labour participation (work domain) and childcare (home domain) in Malta, Serbia and the Netherlands, and to provide recommendations for future research and policy. Based on 25 semi-structured interviews with men and 33 with women, and using the interpretative phenomenological approach, we identified four groups of people who lived, experienced and negotiated their work-home interface differently: (1) Striving for gender equality; (2) Work domain equality with financial constraints (Work domain equality); (3) Transitional roles with family values constraints (Transitional roles) and (4) Traditional roles with work values constraints (Traditional roles). Groups were based on intersections of cultural context, gender, as well as age and socioeconomic position. We theorize that the identified groups reflect a snapshot of the process of change. The pendulum of change shifts to and from striving for gender equality (group 1) to traditional roles group (group 4), with work domain equality (group 2) and transitional roles (group 3) representing in between scenarios (Fig 2). Changing one's position in the group does not need to be linear (i.e. moving to the group 'next' to the one where he or she is at the moment). We saw that men and women of different ages grouped differently across countries. We also saw that institutional framework did not always align well with the values and norms of the participants. Thus, shifts in values do not necessarily take place at the same speed for all groups and are not necessarily matched with institutional changes. 


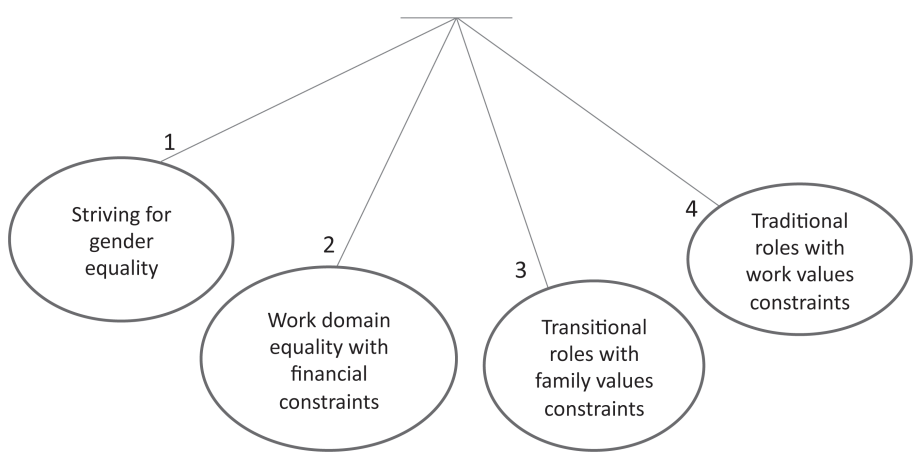

Figure 2 Pendulum of change: Groups showing shifts over time

In chapter 5, we explored whether the differences between cultural contexts that could be seen in work-home interface were also related to differences in health outcomes. Thus in our final, quantitative empirical study, we examined work characteristics, work-home interface and health outcomes among primary healthcare physicians in Serbia and the differences across European cultural contexts in relation to health outcomes (burnout), paying close attention to the role of sex and gender. The sample consisted of 373 Serbian primary healthcare physicians, of whom 58 were men and 315 women. In Serbia, women carried out more household and childcare tasks than men and experienced significantly less job control than men. Female primary healthcare physicians also experienced higher levels of depersonalization than men. When comparing the burnout levels, it appeared that the Serbian sample experienced higher levels of emotional exhaustion than other similar samples in the Netherlands, Hungary or Italy. This may be due to the lower number of healthcare physicians per inhabitant, but may also be related to the wider socio-political situation. On the other hand, Serbian physicians reported lower depersonalization than Hungarian, Dutch or Italian physicians. Cultural values and norms appeared to have played a role in the findings.

In the final chapter, chapter six of this thesis, we reflect on the main findings as well as on methodological issues. The chapter also provides suggestions for future research and recommendations for policy and practice. The main findings are that the cultural context is an important aspect to be taken into account when discussing the optimisation of work-home interface. Furthermore, aspects such as gender and age are also important. This thesis also indicates that shifts in work-home interface take place over time. For example, the three cultural contexts show a time lag between changes in values and norms on the one hand and institutional frameworks on the other. Changes in financial aspects also appear to influence the trends of change. Thus, in future studies, temporal aspects should closely be examined, and policy makers should also evaluate the applicability and effectiveness of policies periodically. A strength of this study was that it relied on both quantitative and qualitative approaches. Via the quantitative approach we could examine the extent of contribution of different 
variables to work-home interface. On the other hand, via the qualitative approach we could stay open to emergence of aspects that were important to the participants, and also gain insight into the changes in work-home interface over time. One of the limitations for examining the time aspect and changes over time in this thesis could be pinned down to the lack of longitudinal data. However, by employing qualitative techniques this pitfall was partially overcome, since the participants reflected on the changes that have occurred over time. In this final chapter we also highlight the importance of cultural sensitivity in designing, as well as carrying out, data collection. One of the implications for future research is that cultural aspects should be acknowledged, and taken into account in the studies. Concerning policy implications, the main conclusion is that the 'one size fits all' approach does not appear useful. Instead, we call for flexible and tailor made policies. For example, fostering colleague support is likely to benefit Dutch employees with decreasing -WHI, while it is not likely to have an impact among Maltese and Serbian employees. Furthermore, having affordable and accessible childcare centers appears very relevant for combining work and home duties in Serbia and The Netherlands (but only on a part-time basis in the latter context), but not very much so in Malta. The needs and preferences with respect to work-home balance also appear to vary across generations, so the example of the daycare centers would be very relevant for new generations of mothers, while for older generations of women it would not be necessary, as it didn't fit their mothering role. Thus, in order to create useful policies, the needs and preferences of different social categories and their intersections need to be taken into account. 
Samenvatting 
De werk-thuis balans betreft de relatie tussen werk en het privéleven. Beide domeinen kunnen elkaar positief maar ook negatief beïnvloeden. Een negatieve werk-thuis balans betreft de problemen die ontstaan door het combineren van werk met het privéleven. Deze problemen kunnen voortkomen uittijdgebrek, rolverdeling of gedrag. Onderzoek wijst uit dat een negatieve werk-thuis balans samenhangt met een slechtere gezondheid en burnout, verminderde productiviteit, toenemend ziekteverzuim en een hoger verloop. Genderpatronen en overige waarden verschillen tussen culturele contexten en kunnen de werk-thuis relatie beïnvloeden. Ook verschillen in maatschappelijke waarden en institutionele kaders hebben een invloed op deze relatie. Het is dus aannemelijk dat factoren die belangrijk zijn voor de werk-thuis balans verschillen al naar gelang de culturele achtergrond. Om de werk-thuis relatie beter te kunnen doorgronden dient deze onderzocht te worden binnen twee of meer verschillende culturele contexten, en is er behoefte aan meer kwalitatief onderzoek. Verder moet er een theoretisch kader worden ontwikkeld dat deze culturele aspecten includeert.

Het voornaamste doel van deze studie was inzicht te verkrijgen in de rol van culturele context in de werk-thuis balans, ter ondersteuning van toekomstig onderzoek en beleid gericht op het optimaliseren van de werk-thuis balans, om zo uiteindelijk gezondheid en welzijn te bevorderen. De culturele context in deze studie is onderzocht in Malta, Servië en Nederland. De onderzoekspopulatie bestond uit leerkrachten en gezondheidszorgprofessionals.

In hoofdstuk 1 wordt de relatie tussen werk en privéleven en de relevantie van de culturele context voor deze relatie beschreven. De rol van culturele context, geslacht en gender wordt inzichtelijk gemaakt aan de hand van de huidige wetenschappelijke kennis op dit gebied. Ook het belang van deze relatie voor beleid en onderzoek komt aan bod. Het hoofdstuk eindigt met een overzicht van de onderzoekssetting en achtergrondinformatie over Malta, Servië en Nederland.

Hoofdstuk twee geeft de resultaten weer van een kwantitatieve beschrijvende studie. De prevalenties van een negatieve werk-thuis balans in Servië, Malta en Nederland worden weergegeven, alsook de verschillen en overeenkomsten in de associaties tussen de kenmerken van werk en privéleven onder leerkrachten, verplegend personeel en andere zorgprofessionals binnen deze drie culturele contexten. De zorgprofessionals waren allen werkzaam in tweedelijns zorginstellingen en de leerkrachten werkten op basisscholen, in het middelbaar onderwijs of in het hoger onderwijs. De steekproef bestond uit 288 deelnemers per land, 39\% was man en $61 \%$ was vrouw. De resultaten tonen aan dat de culturele context een belangrijke rol speelt in een negatieve werk-thuis balans. De prevalentie van een negatieve werk-thuis balans verschilde tussen de culturele contexten. De prevalentie in Malta was 25\%, in Servië 20\%, terwijl deze in Nederland slechts 5\% bedroeg. Deze verschillen zouden te maken kunnen hebben met verschillen in kenmerken van werk en privéleven. Echter zelfs na controle voor deze kenmerken en voor individuele factoren, verklaarde de culturele context nog steeds $20 \%$ van de variantie in negatieve thuis-werkbalans. Daarmee lijkt culturele context even belangrijk als de kenmerken van werk en privéleven. Er zijn ook verschillende associaties gevonden tussen werkkenmerken en negatieve werk-thuis balans in de verschillende landen. Voltijds werken bijvoorbeeld was gerelateerd aan een negatieve werk-thuis balans in Malta en Nederland maar niet in Servië, en gebrek aan sociale steun van collega's was alleen in Nederland 
geassocieerd met een negatieve werk-thuis balans. Het verantwoordelijk zijn voor het plannen van huishoudelijke taken en een slechte gezondheid waren alleen in Malta geassocieerd met een negatieve werk-thuis balans, terwijl het hebben van kinderen onder de 12 jaar alleen in Nederland geassocieerd was met een negatieve werk-thuis balans. We concluderen dat de culturele context van belang is bij een negatieve werk-thuis balans. Deze bevindingen tonen aan dat het relevant is om de conceptualisering van werk-thuis balans te toetsen aan de huidige theoretische kaders, en na te gaan in welke mate deze kaders culturele aspecten behelzen.

In hoofdstuk 3 introduceren we een nieuw theoretisch kader voor werk-thuis balans. De meeste literatuur over werk-thuis balans is gericht op het microniveau, de individuele kenmerken van werk en privéleven. Vaak wordt het meso- of macroniveau hier niet in betrokken. Enkele modellen vormen hierop een uitzondering en includeren specifieke, of meer algemene culturele aspecten in relatie tot werk-thuis balans. Wat hier echter ontbreekt zijn de positieve werk-thuis balans of genderpatronen. Op basis van de bestaande literatuur over werk-thuis balans in relatie tot culturele context, hebben we een nieuw kader ontwikkeld genaamd de 'pyramid of intersecting domains of work-home interface' (de piramide van elkaar overlappende en kruisende domeinen van werk-thuis balans, zie figuur 1). De piramide is gebaseerd op de 'intersectionality' theorie (theorie over intersecties tussen verschillende sociale categorieën, kruispuntdenken) en de 'work/family border' theorie (theorie over grenzen tussen werk en privé-leven). Beide theorieën achtten wij zeer bruikbaar voor een goed begrip van de werk-thuis balans. De intersectionality theorie stelt dat sociale categorieën afhangen van context en tijd. Dit impliceert dat geen enkele sociale categorie dominant is over een andere. Er wordt gesteld dat overlap tussen sociale categorieën simultaan dient te worden onderzocht en dat rekening gehouden moet worden met tijds- en culturele aspecten. De work/family border theorie stelt dat werk en privéleven twee aparte domeinen zijn, elk met hun eigen permeabiliteit, flexibiliteit, en mate van interactie. Volgens deze visie overschrijden mensen dagelijks de grenzen tussen beide domeinen, waarbij zij worden beïnvloed door grenswachten (belangrijke anderen) zoals echtgenoten, collegars of supervisoren. Beide theorieën zijn geïncorporeerd en verder uitgebreid in de 'pyramid of intersecting domains of work-home interface'. De piramide beschrijft werk-thuis balans als bestaande uit vier overlappende domeinen: het individuele werk- en privédomein, het rollendomein en het culturele domein, die tezamen het vierde domein, de geobserveerde werkthuis balans verklaren. Alle domeinen bestaan uit overlappende subdomeinen (intersecties), die ook weer verder gedifferentieerd kunnen worden in subdomeinen. De toegevoegde waarde van de piramide is dat deze verschillende analyseniveaus includeert, en handvatten biedt voor crosscultureel onderzoek naar werk-thuis balans. Verder kan de piramide gebruikt worden als een kader dat beleidsmakers helpt richtlijnen op maat te ontwikkelen al naar gelang de culturele context en voor mensen met verschillende rollen en verschillende werk- en privékenmerken. 
The Pyramid

(3-dimensional)

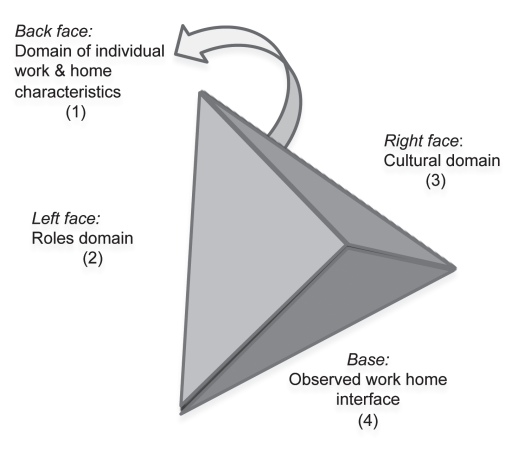

The Pyramid expanded

(2-Dimensional)

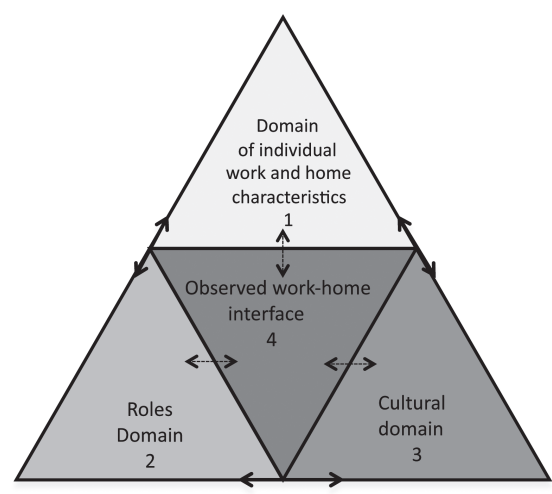

Figuur 1 De 'pyramid of intersecting domains of work-home interface'

In hoofdstuk 4 wordt het kwalitatieve onderzoek beschreven, waarin de ervaringen met werkthuis balans binnen verschillende culturele achtergronden in meer detail zijn verkend. Het doel was te exploreren op welke manier culturele context en gender samenhangen met het hebben van betaald werk (werkdomein) en de zorg voor kinderen (privédomein) in Malta, Servië en Nederland. Op basis van semi-gestructureerde interviews met 25 mannen en 33 vrouwen, en gebruik makend van de interpretatieve fenomenologische benadering, hebben we vier groepen gedefinieerd die hun werk-thuis balans op een verschillende manier ervoeren en beleefden: (1) 'Striving for gender equality' (Streven naar gender gelijkheid), (2) 'Work domain equality with financial constraints (Work domain equality)' (Gelijkheid in het werkdomein met financiële beperkingen), (3) 'Transitional roles with family values constraints (Transitional roles)' (Rolpatronen in transitie met beperkingen in het domein van gezinswaarden) en (4) 'Traditional roles with work values constraints (Traditional roles)' (Traditionele rolpatronen met beperkingen in het domein van de werkwaarden). Deze groepen zijn gedefinieerd op basis van de intersecties tussen culturele context, gender, leeftijd en sociaal-economische status. We veronderstellen dat deze groepen een weerspiegeling zijn van een bepaald moment in een veranderingsproces. Dit kan worden voorgesteld worden als een pendule die verandering weergeeft en waarvan de slinger heen en weer beweegt tussen het streven naar gender gelijkheid (groep 1), en de traditionele rolpatronen (groep 4), met groep 2 en groep 3 ertussenin gelegen (zie figuur 2). Mensen kunnen dus van groep veranderen, maar dit veranderen gebeurt niet per se lineair (dat wil zeggen naar een naastgelegen groep). We zagen dat mannen en vrouwen van verschillende leeftijden tot andere groepen behoorden in de drie landen. We bemerkten ook dat institutionele kaders niet altijd overeen 
kwamen met de normen en waarden van de deelnemers. Veranderingen in waarden vinden niet noodzakelijkerwijs plaats met gelijke snelheid voor alle groepen en kwamen niet per se overeen met institutionele veranderingen.

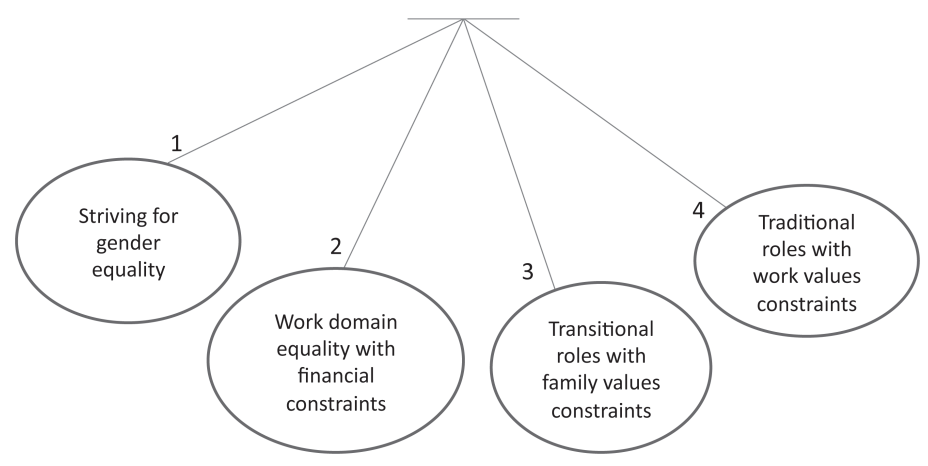

Figuur 2 Pendule van verandering

In hoofdstuk 5 werd onderzocht of de verschillen in culturele context van werk-thuis balans ook gerelateerd waren aan gezondheidsverschillen. In deze laatste, kwantitatieve empirische studie hebben we werkkenmerken, werk-thuis balans en gezondheid gemeten bij artsen in Servië, en hierbij ook gelet op gender en geslacht, alsmede de verschillen tussen Europese culturele contexten in relatie tot gezondheid (burnout). De steekproef bestond uit 373 Servische huisartsen, onder wie 58 mannen en 315 vrouwen. In Servië hadden vrouwen meer huishoudelijke taken dan mannen en zorgden zij vaker voor de kinderen, ze ervoeren ook significant minder controlemogelijkheden in het werk dan mannen. Vrouwelijke huisartsen ervoeren meer depersonalisatie dan hun mannelijke collega's. Vergelijking van de mate van burnout liet zien dat de groep uit Servië een hogere emotionele uitputting rapporteerde dan vergelijkbare groepen in Nederland, Hongarije of Italië. Dit wordt mogelijk veroorzaakt door het kleinere aantal artsen per inwoner, maar kan ook te maken hebben met de sociaal-politieke situatie. Aan de andere kant rapporteerden de Servische artsen minder depersonalisatie dan Hongaarse, Nederlandse of Italiaanse artsen. Culturele normen en waarden spelen waarschijnlijk een rol in deze bevindingen.

In het laatste hoofdstuk, hoofdstuk zes, reflecteren we op de belangrijkste bevindingen alsook op methodologische aspecten van deze studie. In dit hoofdstuk doen we ook praktische aanbevelingen, en aanbevelingen voor toekomstig onderzoek en beleid. De belangrijkste bevinding is dat culturele context een belangrijke factor is bij het optimaliseren van de werk-thuis balans. Verder zijn gender en leeftijd belangrijke factoren. Dit proefschrift toont ook aan dat werk-thuis balans niet statisch is, maar aan verandering onderhevig. Er is bijvoorbeeld een vertraging gevonden tussen veranderingen 
in normen en waarden aan de ene kant, en veranderingen in institutionele kaders aan de andere kant in de drie landen. Ook veranderingen in de financiële situatie van een land beïnvloeden deze trends. In toekomstig onderzoek moeten de tijdsaspecten nader worden onderzocht. Ook zouden beleidsmakers de toepasbaarheid en effectiviteit van beleid periodiek moeten evalueren. Een sterk punt van dit onderzoek is gelegen in de combinatie van een kwantitatieve en kwalitatieve benadering. Door middel van het kwantitatieve onderzoek konden we de unieke bijdrage van de verschillende variabelen aan werk-thuis balans vaststellen. Door middel van het kwalitatieve onderzoek hebben we meer inzicht gekregen in eventuele andere aspecten die meegenomen moeten worden omdat die belangrijk waren voor de deelnemers. Hiermee verkregen we ook een beter inzicht in veranderingen in werk-thuis balans. In dit licht bezien was het gebrek aan longitudinale data één van de beperking van dit onderzoek. In het kwalitatieve onderzoek echter werd dit hiaat gedeeltelijk ingevuld, omdat deelnemers reflecteerden op veranderingen die hadden plaatsgevonden. In dit laatste hoofdstuk benadrukken we ook het belang van culturele sensitiviteit in het ontwerp van onderzoek en het verzamelen van data. Eén van de implicaties voor toekomstig onderzoek is dat het belang van culturele aspecten onderkend moet worden en dat deze culturele aspecten geïncludeerd moeten worden in onderzoek. Voor wat betreft de implicaties voor beleid is de belangrijkste conclusie dat een generalistische benadering niet bruikbaar lijkt. In plaats daarvan raden we flexibiliteit en maatwerk in beleidsmaatregelen aan. Het stimuleren van collegiale steun bijvoorbeeld lijkt in Nederland de negatieve werk-thuis balans positief te beïnvloeden, terwijl dit niet waarschijnlijk is voor Maltese of Servische werknemers. Verder blijkt het bestaan van toegankelijke en betaalbare kinderopvang van groot belang in Servië en in Nederland (hier met name op part-time basis), maar niet in Malta. De behoeften en voorkeuren voor wat betreft werk-thuis balans lijken te variëren tussen generaties, dus het voorbeeld van de kinderopvang zal relevant zijn voor jongere generaties moeders, maar niet relevant voor de oudere generatie moeders, omdat dat niet past bij hun ideeën over de moederrol. Om bruikbaar beleid te creëren, dient er dus rekening te worden gehouden met de behoeften en voorkeuren van verschillende sociale categorieën en de intersecties daartussen. 


\section{Valorisation}


Let's go back again to our fictitious characters Tom and Ana. Tom is a professor at University, married and living with a small child in Malta. His work takes up most of his time and his home and childcare responsibilities are subservient to his profession. He cherishes his family and wishes for more time with them. Ana is a nurse, married and living with two young children in Serbia. She, like her husband, works full time. Most of the home duties are her responsibility while her husband offers a supportive role. What they have in common is that both Ana and Tom are busy with work and family life. They live in different contexts where working possibilities, expectations and family roles vary. One wonders what effect these intense days have for their health and wellbeing. It is also a question regarding which policies would best benefit each of their situations.

\section{Introduction}

To obtain a PhD degree, the candidate's work is judged by the scientific professionals in the field and its success is amongst others examined through the impact factor lens of the publications list. However, besides this scientific contribution, not less important is the contribution that the generated knowledge has for the society. Tom and Ana's work-home interface could be improved if the findings of this thesis were translated into policies: one example concerns change of policies in Malta so that men would be more encouraged to be involved in childcare from birth onwards, or in Serbia if there would be a chance to work part-time. Below I would like to highlight two types of contributions to society: one that concerns the valorisation of the findings already during the PhD trajectory, and the second that concerns possible future application of the generated knowledge for the benefit of the society.

\section{Valorisation of findings during the PhD trajectory}

Knowledge gained from this PhD thesis has been shared with the participants who took part in the study by filling out the survey. Furthermore, the national and international scientific and practitioners community has also been informed about the findings of this thesis. Below we explain the acts of valorisation of the findings so far.

When the organisations were approached for taking part in this study in Serbia and Malta, they were promised, and received, in return two reports: a general report and an individual report. In the general report we highlighted the main findings regarding burnout levels, work and home interface and work characteristics of doctors, nurses and teachers in Serbia and Malta, separately. We also drew attention to some characteristics that needed monitoring, and provided a more detailed explanation of possible solutions for unfavourable work and health characteristics. The most important aim of the individual reports was to give insight to the management about issues that may need attention regarding the employees' psychosocial work characteristics and health outcomes. In order to help interpret the meaning of results, we wrote this individual report in the form of a comparison of the 
particular organisation's employees' well-being to that of employees from other organisations that participated in this research. Thus, besides gaining insight about how well the employees of the organisation were doing with regards to psychosocial work characteristics and health outcomes and which areas may require particular attention, the management was also able to compare the findings relative to the findings of employees from other participating organisations (that were not named to preserve anonymity of participating organisations). In total, 19 individual reports were written for Malta and Serbia, and 2 general reports, one for each country. The agreement was that the management would spread the findings among the interested employees within the organisations.

Given that the Dutch participants were part of the larger Maastricht Cohort Study, samples were not large enough per organisation to write a report about it. Thus, for the Dutch participants, the information was given back to them in the form of the general newsletter reporting on the findings of the study.

Besides giving the information to the management and participants, the findings of the thesis were also disseminated during a number of national and international conferences and in this way reached a broader scientific and practitioners community. Findings based on the qualitative paper of this thesis (chapter 4) were disseminated in the form of a presentation during the Gender, Work and Organisation conference, which took place in Staffordshire, UK in 2014.

Results of the thesis that focused on gender, work-home interface and emotional exhaustion among Serbian and Maltese human service professionals were presented during the European Public Health Association (EUPHA) Public Health Conference in Copenhagen, Denmark in 2011. Findings concerning burnout and the role of work-home and home-work interference among female physicians in Serbia were presented during the same international conference that took place in Łodz, Poland, in 2009.

Similarities and differences in work-home interface across the countries were presented during the European Association of Work and Organizational Psychology (EAWOP) conference, that took place in Maastricht, the Netherlands in 2011.

Knowledge concerning work characteristics, work-home interface and burnout among physicians in Serbia that are described in chapter 5 of this thesis was spread in the form of a presentation during the International Commission on Occupational Health-Work Organization and Psychology (ICOHWOPS) conference in Amsterdam, the Netherlands in 2010.

\section{Future application of the generated knowledge for the benefit of society}

We identified three avenues where the findings of the thesis could be of particular benefit in the future. They concern the contributions to sustainable work, to people who are currently not employed but would wish to work (or are underemployed), and to the policy field. Since the study was conducted among health professionals and teachers the benefits are addressed with an emphasis on these professions. 
Contribution to sustainable work. Work-home interface is related to sustainable work. Sustainable employment is dependent on health and well-being of employees, as well as their attitudes and motivation for work (van der Klink, Brouwer, Bültmann, Burdorf, Schaufeli, van der Wilt, \& Zijlstra, 2010). Sustainable employment underpins the importance of combining productivity with psychological and economic well-being of individuals over time (Michigan State University, 2013). With positive work-home interface, employees are more likely to experience high job satisfaction and affective commitment as well as better physical and mental health (McNall, Nicklin \& Masuda, 2010). They are thus less likely exit the labour market prematurely and also less likely to experience absence due to sickness. Low sickness absence rates, low turnover and optimal productivity are some of the organisational benefits of appropriate work-home interface (Allen, Herst, Bruck, \& Sutton, 2000; Amstad, Meier, Fasel, Elfering, \& Semmer, 2011). Findings of this thesis, concerning different needs of people in different cultural contexts, different ages and genders, if applied in policies could stimulate better work-home interface and subsequently contribute to sustainable employment.

Contribution to people who would like to participate in labour (more). Labour non-participation, when involuntary, was found to be associated with poor well-being (Paul \& Moser, 2009). Furthermore, given that it is estimated that by 2020 , around one million healthcare professionals will be in short supply (Sermeus \& Bruyneel, 2010), it is important to create possibilities for all those who would like, but currently cannot join the labour market or who work less hours than desired due to poor possibilities of adequate work-home interface. If the tailor-made approach to work-home interface would be used in the future, it could help persons who would like to work, but because of the barriers in work-home interface are currently not participating in paid labour. Such an approach would also be relevant for persons who currently work less hours than preferred due to difficulties in balancing work-home interface. Thus better work-home interface could help them work more hours. Here we reflected on the groups of people who are intrinsically motivated to join the labour market but are due to various obstacles not able to.

Contribution to the policy field. This thesis has shown that individual values and norms change over time and that the institutional aspects do not necessarily support this change. This implies that at a societal level, funds might be spent in areas that are not in line with the societal changing values and norms and that it is important to evaluate policies after a number of years in order to ensure that they are still in line with current societal values and norms. For each of these aspects, we examine the impact on an individual, organisational and societal level.

The findings of this thesis indicate that it would be important for the participants that working hours are compatible with the childcare responsibilities in order to facilitate work-home interface. One of the ways in which this is currently done in the Netherlands is through the possibility of parttime work and reduced hours for Maltese women who have children. We would thus recommend that part-time work should also be available as an option in Serbia, and in general in Malta as well also for employees who have no children. Given the difficult socioeconomic situation in Serbia we can expect that part-time work would be less frequently used, however we believe that the possibility to work part-time should be offered. Concerning values and norms we see in the example of Tom 
and Ana that they limit their options for change. Tom is limited by work values that do not 'let' him work less and give more time to family, while for Ana it is the family values that do not 'let' her have more free time by having more equally shared chores at home. And in order to improve the workhome interface for Tom and Ana, values would need to change first. Having said that, institutions and policies could help and give a 'push' in that direction. For example, some men expressed a wish for greater involvement in childcare but due to work involvements did not manage. Perhaps greater involvement of fathers could be facilitated by following a Nordic model, which makes a part of the parental leave reserved for fathers that is nontransferable to mothers. This thesis indicated that women in Malta often exited the labour market for a number of years after having children due to inability to combine work and childcare. If working schedules would be more flexible and if more often part-time work would be available, it would help women return to paid labour sooner. In the Netherlands, we see that the cost of daycare may be a limiting factor for labour participation. If the childcare costs equal the paid wage of the parent, this thesis indicated that chances increase for the parent to stay at home with children. In the long run these parents (generally women) appear to be disadvantaged when it comes to finding paid work again, resulting in lower female labour participation and lower family income overall.

As mentioned above, the healthcare sector is expected to experience shortage of healthcare workers in the coming years (Sermeus \& Bruyneel, 2010). Thus, it would not only be important for the current labour force to be able to work in optimal conditions and thus not leave the workforce but also to find ways to allow inactive population to join labour force Previous research indicates that positive work-home interface is associated with increased commitment to work, job satisfaction as well as better health of employees (McNall, Nicklin \& Masuda, 2010). Thus, organisations would benefit from improved work-home interface of their employees. Our findings indicate that flexible working hours and schedule control are some of the aspects that appear to be beneficial for workhome interface. With more staffing, there would also be less stress on current workforce and working pace. One of the ways in which organisation could keep track of the (changing) preferences of their employees is through yearly surveys on work preferences. By providing policies and ways of organising work-life that suits their employees organisations are likely to have a sustainable workforce.

As already mentioned, the availability and affordability of childcare appear to be important issues in Serbia and the Netherlands for ensuring appropriate work-home interface. The findings of this thesis also indicated that the policies concerning childcare need to be compatible with the cultural values. Given that the childcare costs have been increasing in the Netherlands the last few years, this may pose a threat for labour participation of (female) persons who have children. Thus the recommendation for the Dutch context would be that childcare centers may need to be subsidised more if (female) labour participation is to remain high or even increase. In Serbia, it is important to maintain childcare centers affordable and accessible to young parents, as this is the way in which parents manage to combine childcare and paid employment. 


\section{Novelty in the topic of the PhD thesis and novelty in the findings}

One of the defining factors of every PhD thesis is its innovativeness: this thesis contributes something new to the scientific field and creates knowledge that can be used by the practitioners in field. Below we describe the two novelty aspects of this $\mathrm{PhD}$ thesis.

Concerning the scientific innovativeness, this thesis has addressed the knowledge gap that exists concerning the role of the cultural context in relation to work-home interface (Cohen \& Kirchmeyer, 2005). Firstly, this thesis examined the role of the cultural context through the lens of three distinct European countries of Malta, Serbia and the Netherlands. Malta and Serbia have scarcely been represented in the international research so far. Secondly, there is a scarcity of qualitative studies on this topic (Poelmans, 2005) and this thesis addressed this issue as well, by applying a mix of quantitative and qualitative approaches on the topic of work-home interface. Thirdly, there was a lack of an adequate theoretical framework that links the individual and cultural level of analysis (Parasuraman \& Greenhaus, 2002). This thesis contributed to the field by proposing a new framework for studying work-home interface in a cross cultural context, the pyramid of intersecting domains of work-home interface, which can be used in research and policy fields to better understand the experiences of work-home interface in different contexts.

Second, the results of this thesis generated knowledge that can be used in the future by the practitioners in the field, such as policy makers and human resource professionals. The findings revealed some important new insights. The thesis has shown that a tailor-made approach to workhome interface is needed. It is important to examine the role of the cultural context, gender as well as age and socioeconomic position and their interplay alongside the more traditionally studied work and home characteristics. We have seen that work and home characteristics, although important and relevant aspects to consider, are insufficient in accounting for differences in work-home interface across cultural contexts. Cultural context has been shown to be as relevant for work-home interface as work and home characteristics. Thus, there is a need to include also the meso and macro levels when discussing work-home interface and developing policies. Temporal aspects are also important, given that values, norms as well as institutional frameworks change over time. On the basis of our findings we cannot present one specific policy or intervention recommendation, as our main contribution lies in actually giving insight into the need to tailor-make policies and adapt them to specific cultural contexts and target groups every time. This is not an easy, nor a fast approach to setting policies, but we believe that it is promising because we think that tailor made polices will be more effective in the long run.

\section{Target groups}

As already mentioned, the findings of this thesis are relevant for the scientific community and practitioners in the field, such as policy makers and human resources professionals. The benefits 
for the scientific community are in showing the importance of taking into account the cultural context when discussing and studying work-home interface and in showing the importance of the intersections of different factors such as cultural context, gender, age and socioeconomic position on work-home interface. Policy makers' and human resources professionals' benefit from this thesis is in avoiding a 'one size fits all' approach. Our findings indicate a need for a tailor-made approach in order to facilitate the work-home interface appropriately. Overall, this research has a large potential for future valorisation, both nationally and internationally. Policy makers, organisational experts as well as researchers benefit from the findings concerning the role of culture in relation to workhome interface. For example, HR managers of organisations may examine the policies in light of preferences of different groups (age, gender, culture) to see how they are matching the needs of these employees concerning work-home interface. 


\section{References}

Allen, T. D., Herst, D. E. L., Bruck, C. S., \& Sutton, M. (2000). Consequences associated with work-to-family conflict: A review and agenda for future research. Journal of occupational health psychology, 5(2), 278-308.

Amstad, F. T., Meier, L. L., Fasel, U., Elfering, A., \& Semmer, N. K. (2011). A meta-analysis of work-family conflict and various outcomes with a special emphasis on cross-domain versus matching-domain relations. Journal of occupational health psychology, 16(2), 121-169.

Byron, K. (2005). A meta-analytic review of work-family conflict and its antecedents. Journal of Vocational Behavior, 67(2), 169-198.

Cohen, A., \& Kirchmeyer, C. (2005). A cross cultural study of the work/nonwork interface among Israeli nurses. Applied Psychology, 54(4), 537-567.

Eurofound. (2014). Policy lessons from the fifth EWCS: The pursuit of more and better jobs. Luxembourg: Publications Office of the European Union.

Grzywacz, J. G., \& Marks, N. F. (2000). Reconceptualizing the work-family interface: An ecological perspective on the correlates of positive and negative spillover between work and family. Journal of occupational health psychology, 5(1), 111-126.

McNall, L. A., Nicklin, J. M., \& Masuda, A. D. (2010). A meta-analytic review of the consequences associated with work-family enrichment. Journal of Business and Psychology, 25, 381-396.

Michigan State University (2013). Sustainable workforce. Retrieved $10^{\text {th }}$ February 2015. Available:http://www. thesustainableworkforce.org/index.php/sustainable-workforce

Parasuraman, S., \& Greenhaus, J. H. (2002). Toward reducing some critical gaps in work-family research. Human Resource Management Review, 12(3), 299-312. doi: 10.1016/s1053-4822(02)00062-1 Paul, K. I., \& Moser, K. (2009). Unemployment impairs mental health: Meta-analyses. Journal of Vocational Behavior, 74(3), 264282.

Poelmans, S. (2005). Organisational research on work and family: Recommendations for future research. In S. A. Y. Poelmans (Ed.), Work and family: An international research perspective (pp. 439-462). London: Lawrence Erlbaum Associates.

Sermeus, W., \& Bruyneel, S. (2010). Investing in Europe's health workforce of tomorrow: Scope for innovation and collaboration. Leuven: European Observatory on Health Systems and Policies.

van der Klink, J. J. L., Brouwer, S., Bültmann, U., Burdorf, A., Schaufeli, W. B., van der Wilt, G. J., \& Zijlstra, F. R. H. (2010). Duurzaam inzetbaar: Werk als waarde [Sustainable employability: Work as value]. Den Haag: ZonMw. 
Acknowledgments 
I am very grateful for all the support I have experienced throughout the years of my PhD 'marathon' and for the fact that it has given me an opportunity to meet and work with many wonderful people! I am also very thankful for all that I have experienced and learnt in the past years. There are many people who helped me to reach the 'finish line' and whom I would like to thank.

My PhD team was the best team that I could have wished for: full of support, enthusiasm, coupled with sharp comments and full of trust in my work. Inge, I admire you for staying calm and for making things simple and manageable when they seemed extremely complex and unclear. I am also very thankful that I had a feeling you were always there for me in case I needed you, a little bit like a safety net: you let me explore, fly, but in case of falling you were there to catch me and help me continue with the 'marathon' ${ }^{-}$. Thank you also for being sensitive and understanding not only of my work, but also my life aspects during this trajectory. I learnt a lot from you. Nicole, thank you for joining our team meetings, for your sharp comments and for being supportive throughout the trajectory of this thesis. I really enjoyed all the working process with you and the pleasant and warm atmosphere of it. IJmert, thank you for accepting to 'take me under your wing' and for all the brainstorming sessions, continuous encouragement and for always being available should there a need arise. I particularly appreciate how you stood available during my data collection moments in Serbia and Malta, it really meant a lot to me. It also meant a lot that I could openly discuss with you my wishes for the future and that you supported me in this process. Frans, you have been there from the beginning of my Maastricht time...I admire for how you are able to see 'the bigger picture', and for the ability to abstract the essence during the discussions. I have also a lot of respect and admiration for the way you approach life and the strength that you have.

Petra, certain things in life one never forgets. One of them is the way you supported me in standing up to my values and what I believe in, providing me with additional strength and energy so that I did not compromise on things that are non-negotiable. I have deep respect for you. Thank you also for the wonderful working atmosphere, for being a great motivator, encourager and for all the discussions on gender (in)equality and the society we live in today.

Guy, thank you for your guidance and involvement in the first stages of the trajectory and for your selfless offer to pass on the promotorship to IJmert.

I would like to thank the reading committee Dr. Agnes Meershoek, Prof. Dr. Kea Tijdens, Prof. Dr. Guy Widdershoven, Prof. Dr. Hans Bosma, and the chair Prof. Dr. Fred Zijlstra for taking the time and effort to read this thesis and provide me with valuable feedback.

A big thank you goes out to the participants for filling out a rather long survey and for sharing experiences of balancing work and home duties with me. I also thank wholeheartedly all the contact persons who helped me get in touch with the participants in Malta and Serbia. I truly value each and every one of the contributions. Here I mention just a few: Anne Tabone, Dr Bojana Milosevic, Catherine Tabone, Charmaine Attard, Geraldine Borg, Gospava Djuric, Dr Hugo Agius Muscat, Dr. Mary Anne Lauri, Nathalie Muscat, Dr Zarko Puzigaca, and Dr Zoran Krstic. 
I would also like to thank Angelique, Bram, Danielle, Elena, Hans, Isel, Marin, Miriam, Nicole H., Yvonne and other colleagues at the Social medicine department for good working years together and the chair Frans Feron for his support and cheerful attitude, and the best birthday message I ever received (on the topic of why having a child is different than doing a $\mathrm{PhD}$ ) $(-)$. I am also very grateful for having been part of the Occupational epidemiology team and for all the good working relations we had.

I would also like to thank my new TNO colleagues, for their support and understanding of the pressure and emotions that appear in the final ' 100 meters' of the PhD marathon. I am very much looking forward to new TNO 'sprints' and 'marathons' we will pursue.

I have beautiful memories of the years as a PhD representative. I met, and worked with very supportive, hard working and enthusiastic people. I would in particular like to thank Hannerieke and Marla for such a wonderful team spirit and amazing experience of working together. I am also thankful for the friendship that grew out of it.

I am very thankful for my paranymphs Gonnie and Lineke who quickly helped me get a feeling of home in the Netherlands far back in 2008. Gonnie, thank you for great wine nights and for listening and supporting me during the PhD years, especially the times when energy was low, you were there to help me see the finish line. I hope to share the carnival and nights out again with you, now that the marathon has come to an end! Lineke, I enjoy our talks on work and life very much and our friendship means a lot to me...I hope we have many shared moments with our 'little ones' in the future too.

Jelena, draaga moja, thank you for the Zondag and Café Zuid moments, for all the advice and reading of different first draft ideas of my work, for all the talks about life, dreams, hopes, wishes... and finally, thank you for being a friend that you are!

My dear Den Bosnians, thank you for providing excellent life counterweight to the busy work times. Thank you for the parties, travel times, camping adventures and sudden and unexpected visits (they are the best!!). Moments in Palm are very special to me.

Thank you also to my other friends in the Netherlands, who have supported me, especially in the final phases of this marathon, with empathy and good breaks from working weekends and evenings.

There are also very many of you, my dear family and friends, who are not in the Netherlands and with whom I am not able to share a daily reality, but who nonetheless mean a lot to me and who, despite the physical distance, supported me in this process. Sometimes I wish the world was a bit of a smaller place!

My dear parents, thank you for showing me what unconditional love and support mean. I also appreciate immensely all the sacrifices and hard choices you have made for me to be where I am today. I am also very grateful for all the life energy, love and care that you so enthusiastically share with Relja.

Thank you Tetka and Mare for being my 'second parents'. It is such a privilege to have another home with you. You are my role models in many ways.

Dear Alek, thank you for being the best uncle in the world. I enjoy the moments we spend 
together and it is from our differences that we learn more about the world.

Aca thank you for providing the calm harbour that soothes some of my over-enthusiastic-all-overthe-place-energy moments:-... for giving me lots of love, support and freedom in our togetherness, for the good laughs and carefree moments. Relja you are my incessant source of joy, my sunshine and a true little wonder. Aca and Relja, I look forward to our day-to-day and life adventures! 


\section{ABOUT THE AUTHOR}

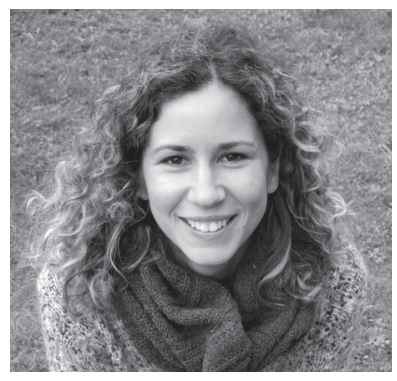

Katarina Putnik (1979) was born in Belgrade, Serbia. She read Psychology with a minor in Communications at the University of Malta, where she obtained a first class degree, finishing as the best student of the cohort in 2002. She obtained a partial scholarship to study for an M.A. degree in Peace studies and conflict transformation at the European Peace University, in Stadtschlaining, Austria where she graduated in 2005. She obtained a full Matra Training for European Cooperation (MTEC) scholarship of the Dutch Ministry of Foreign Affairs for the M.Sc. in Public Health with the specialisation in Work and Health at Maastricht University, the Netherlands, where she graduated in 2007.

In 2008, Katarina obtained a Kootstra Talent Fellowship from the Faculty of Health, Medicine and Life Sciences of Maastricht University given to young, talented researchers to develop a PhD proposal. From 2010 to 2014 Katarina worked at the departments of Social medicine and Epidemiology on the topic of work-home interface in relation to different cultural contexts, which resulted in the current thesis. Driven by a motivation to be engaged in the $\mathrm{PhD}$ issues that go beyond her own trajectory, Katarina has been chosen as the PhD representative for the CAPHRI research school from 20092011 and a PhD representative for the Netherlands School of Primary Care (CaRe) from 2012-2014. During the PhD trajectory Katarina took part in teaching activities at the Faculty of Health, Medicine and Life Sciences on a Bachelor and Master level by delivering lectures and trainings, tutoring and supervising students.

Currently, Katarina works as a research scientist on the topic of work innovations at TNO in Leiden.

Katarina lives with Aleksandar and their son Relja. 